\title{
The Experience of Transition as told by First-Year, First-Generation Appalachian College Students
}

Jeffrey T. Bush

Follow this and additional works at: https://researchrepository.wvu.edu/etd

\section{Recommended Citation}

Bush, Jeffrey T., "The Experience of Transition as told by First-Year, First-Generation Appalachian College Students" (2015). Graduate Theses, Dissertations, and Problem Reports. 5290.

https://researchrepository.wvu.edu/etd/5290

This Dissertation is protected by copyright and/or related rights. It has been brought to you by the The Research Repository @ WVU with permission from the rights-holder(s). You are free to use this Dissertation in any way that is permitted by the copyright and related rights legislation that applies to your use. For other uses you must obtain permission from the rights-holder(s) directly, unless additional rights are indicated by a Creative Commons license in the record and/ or on the work itself. This Dissertation has been accepted for inclusion in WVU Graduate Theses, Dissertations, and Problem Reports collection by an authorized administrator of The Research Repository @ WVU.

For more information, please contact researchrepository@mail.wvu.edu. 


\title{
The Experience of Transition as told by First-Year, First-Generation Appalachian College Students
}

\author{
Jeffrey T. Bush \\ Dissertation submitted to the \\ College of Education and Human Services, \\ at West Virginia University \\ in partial fulfillment of the requirements for the degree of \\ Doctor of Education \\ in \\ Curriculum and Instruction \\ Samuel F. Stack Jr., Ph.D., Chair \\ Patricia Obenauf, Ed.D. \\ Neal Shambaugh, Ph.D. \\ Charline Barnes Rowland, Ed.D. \\ Mary K. Devono, Ed.D. \\ Department of Curriculum and Instruction
}

Morgantown, West Virginia

2015

Keywords: First-Generation; College Transition; Appalachian

Copyright 2015 Jeffrey T. Bush 


\begin{abstract}
The Experience of Transition as told by First-Year, First-Generation Appalachian College Students
\end{abstract}

\title{
Jeffrey T. Bush
}

The study examines the transitional experiences of Appalachian first-generation students during their first year of college. Because first-generation status, alone, has a negative affect on student persistence (Ishitani, 2003; Paulsen \& Martin Lohfink, 2005), this phenomenological inquiry explores perceptions and experiences of separation and adjustment as expressed by students through semi-structured interviews with Tinto's Theory of Student Departure (1993) as a theoretical framework. Tinto's theory states that students arrive at college with personal attributes, as well as intentions and commitment, however it is their perception of their transition from home culture into the college that can affect persistence. This study examined students' journey through stages of separation and adjustment — social and academic — within the institution. Findings revealed their transition to be not unlike those of traditional students. Further analysis reveals themes of college scale and size, personal transformation, communication technology, and being first-generation. First hand student accounts provided a qualitative dimension to the large number of existing studies, giving voice to an underrepresented population, better informing policies for higher education and public high schools. 


\section{Dedication}

Dedicated to the memory of Kathleen Mathews.

To Nana, always the teacher, you instilled in me the value of education. You were with me as I began this endeavor, and remain with me as I continue on. With passing each day and with all that comes, I remember your words, "Over one hurdle, and on to the next." 


\section{Acknowledgements}

The writing of this dissertation has been one of the most significant academic challenges I have ever had to face. It has been an endurance race complete with joy and despair, sureness and self-doubt, too many sleepless nights, and one whose finish line brought an indescribable peace. Without the support, patience and guidance of the following people, this study would not have been completed. Their insight, careful reading, and critical questions provided me the necessary challenge to focus my energy and efforts to achieve more than I once thought possible. It is to them that I owe my deepest gratitude.

To Dr. Sam Stack, for agreeing to take over the helm as committee chair, despite your many other academic and professional commitments. Your knowledge, commitment to high standards, and yes, your tough questions inspired and motivated me with this study and throughout my academic career.

To Dr. Patricia Obenauf, for guiding me intellectually and spiritually, and for lifting and grounding me in ways that few would understand. You have been my mentor and will always be my friend. Namaste.

To Dr. Neal Shambaugh, for challenging and pushing this academic neophyte to "be bold!"

To Dr. Charline Barnes Rowland, for sharing your ideas, you enthusiasm, and your encouragement.

To Dr. Kay Devono, my friend and colleague, for pushing me along and providing much needed support.

I would also like to express my sincere gratitude to my family and friends. Thank you for your patience with my absence. Thank you for your support, for your encouragement, and for your dedication to all that we have made together. 


\section{Table of Contents}

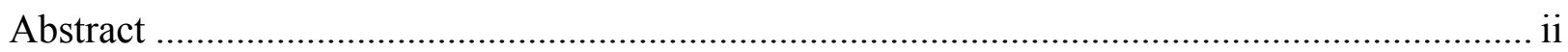

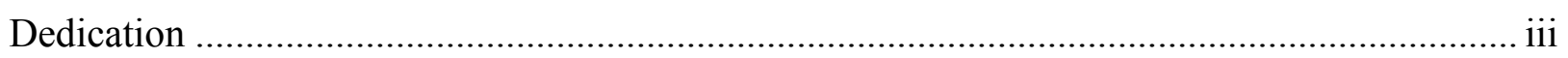

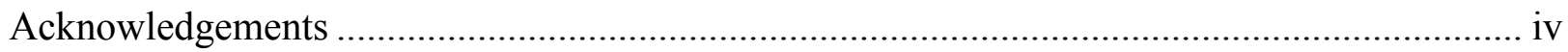

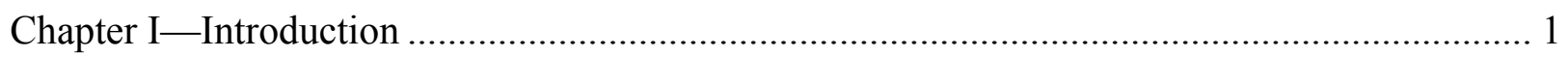

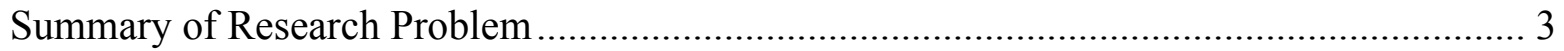

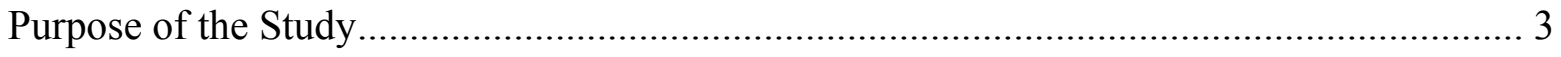

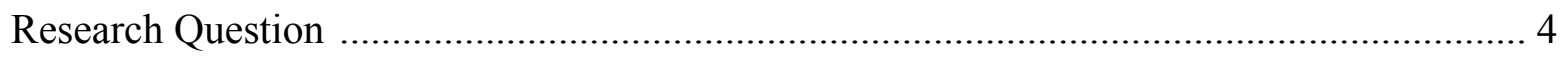

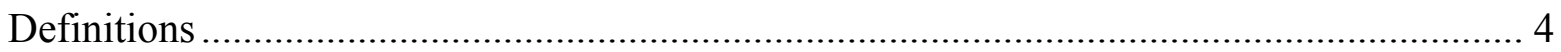

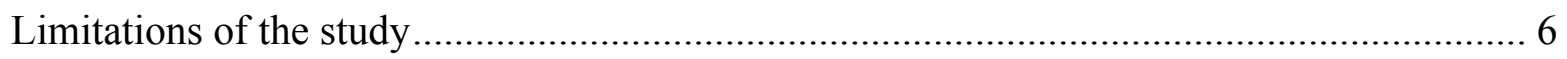

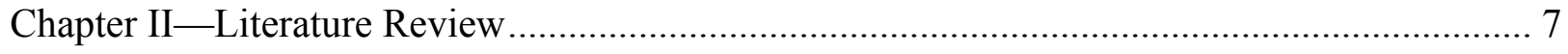

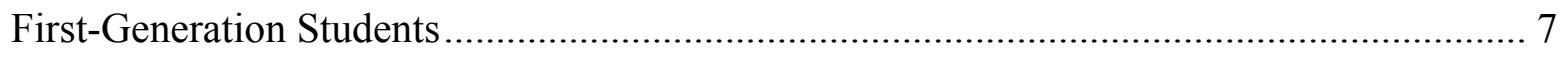

The Transitional Experience ................................................................................ 11

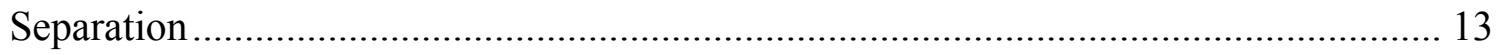

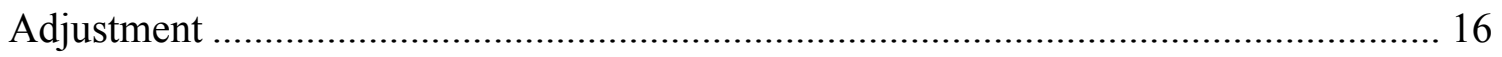

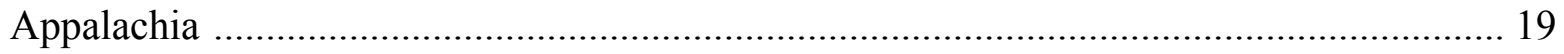

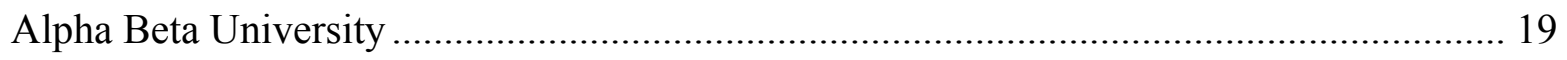

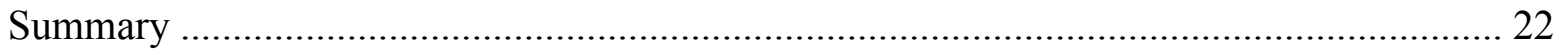

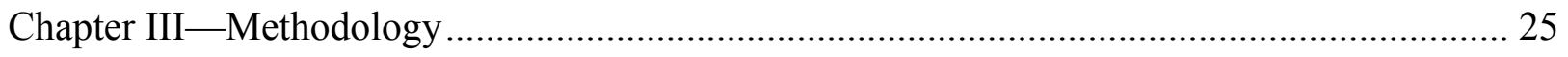

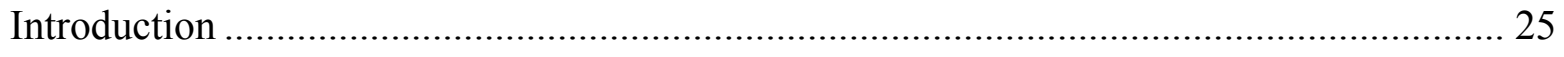

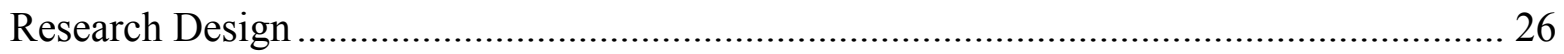

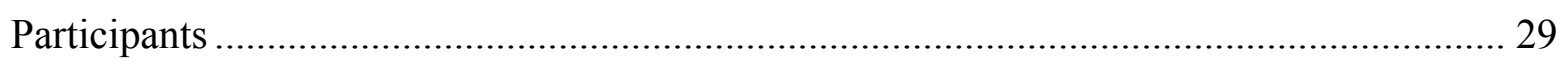

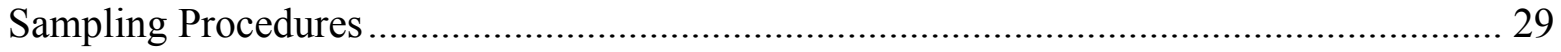




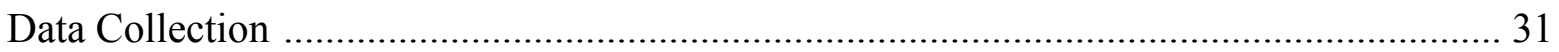

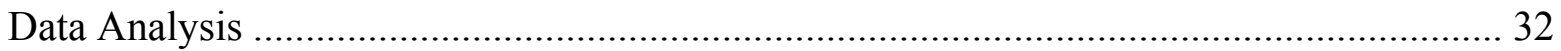

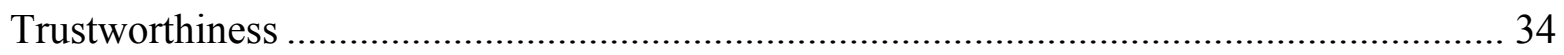

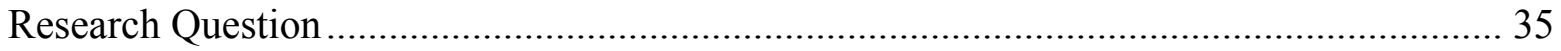

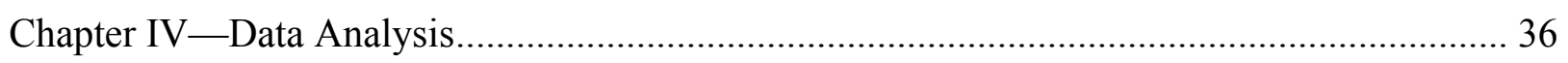

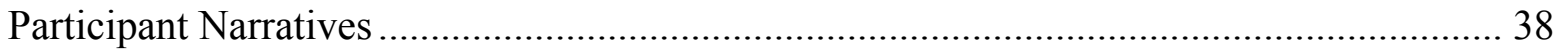

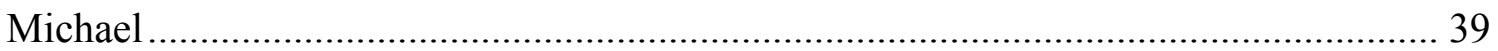

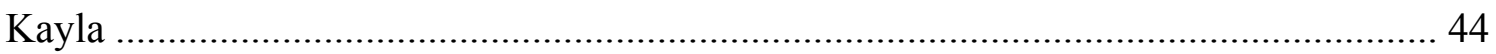

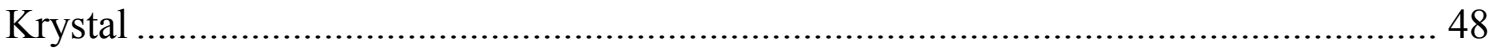

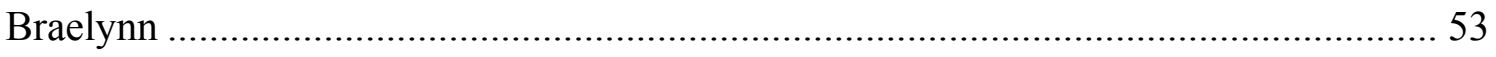

Jesse

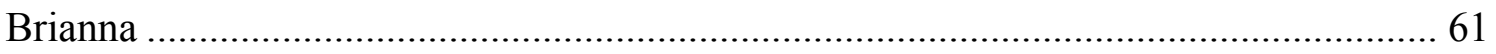

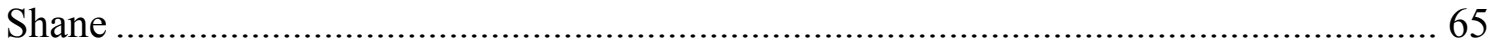

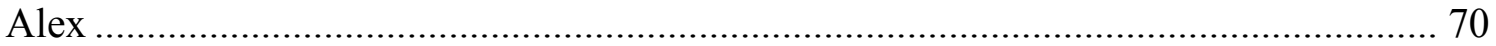

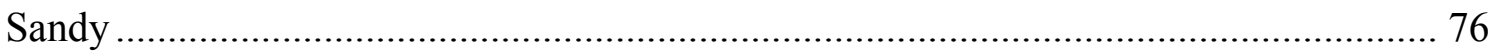

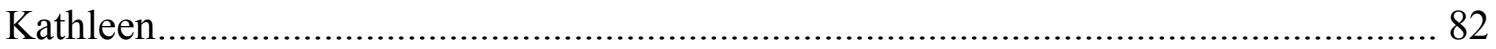

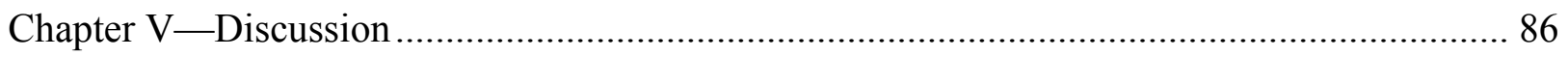

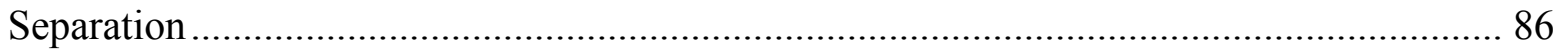

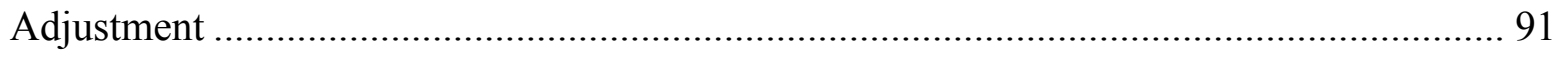

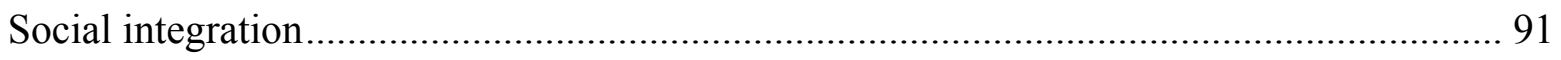

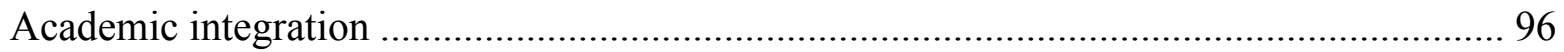

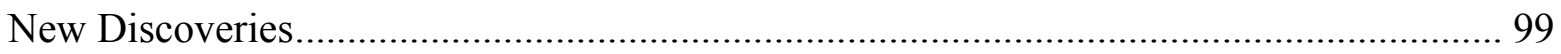

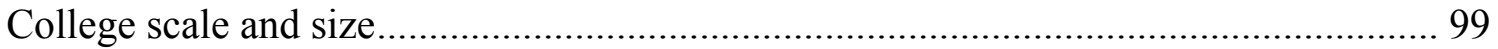




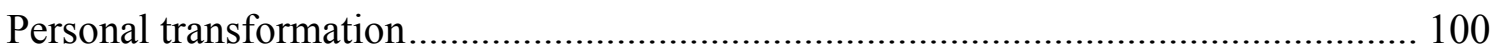

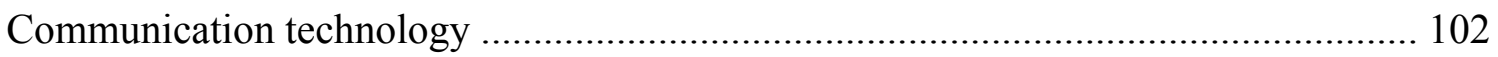

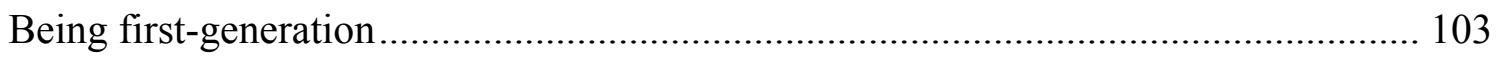

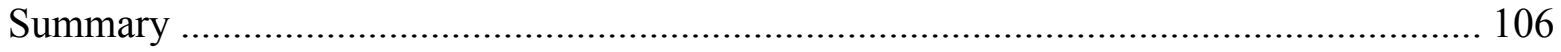

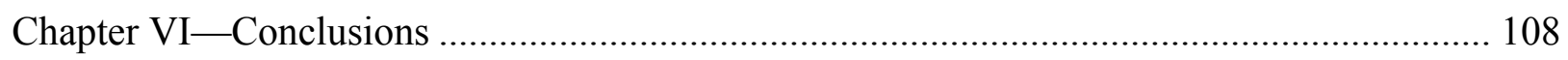

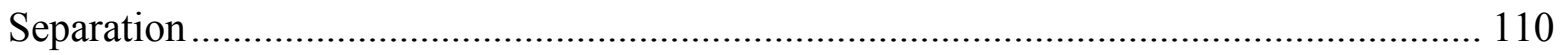

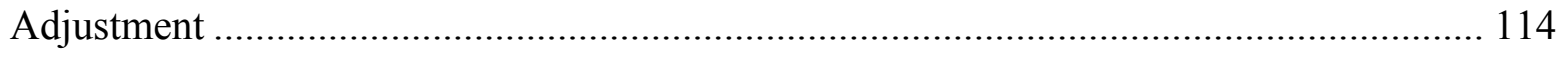

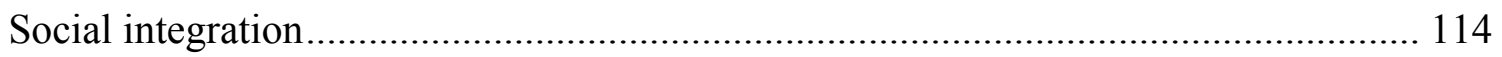

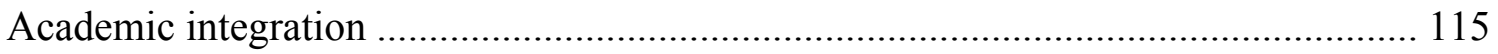

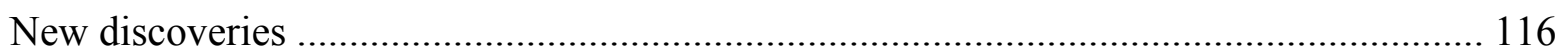

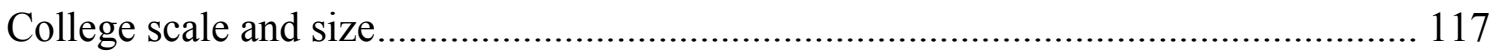

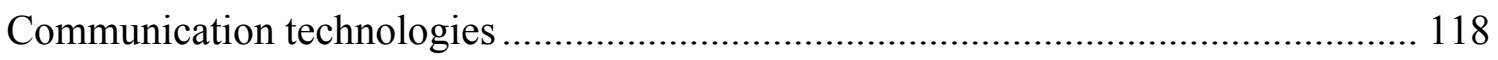

Personal transformation..................................................................................... 119

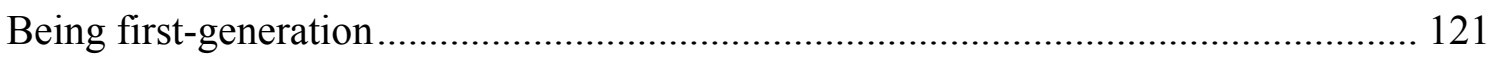

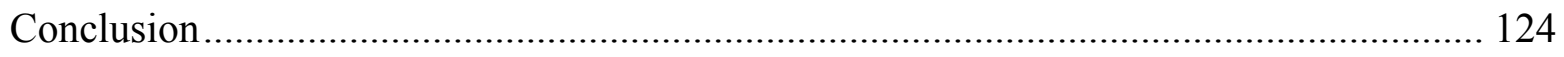

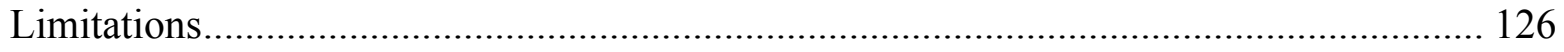

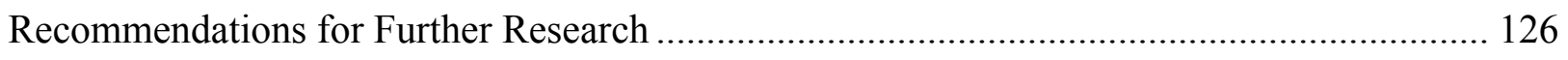

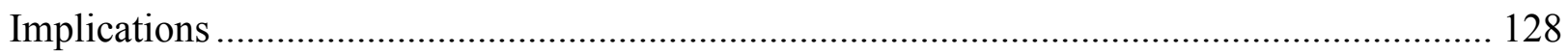

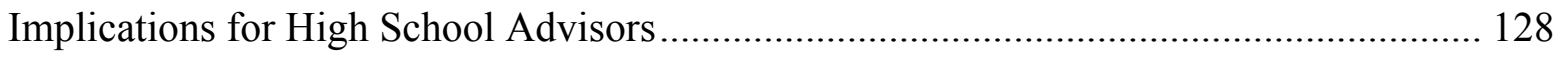

Implications for College Recruitment and Retention....................................................... 129

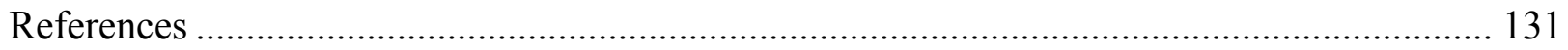

Appendices

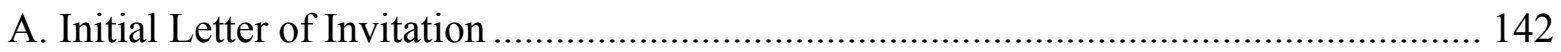




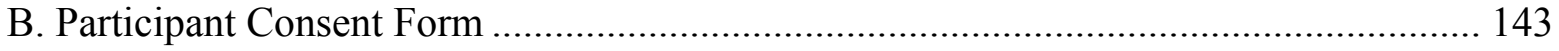

C. Participant Demographic Questionnaire ................................................................. 145

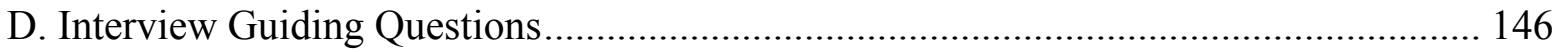

E. Interview Guiding Questions Rationale ............................................................ 148

F. Tinto's (1993) Longitudinal Model of Student Departure ........................................ 151

G. First-Generation Transition Theme: Separation .................................................... 152

H. First-Generation Transition Theme: Social Integration ....................................... 153

I. First-Generation Transition Theme: Academic Integration ...................................... 154

J. First-Generation Transition Theme: College Scale and Size..................................... 155

K. First-Generation Transition Theme: Personal Transformation ................................. 155

L. First-Generation Transition Theme: Communication Technology............................. 156

M. First-Generation Transition Theme: Being First-Generation ................................. 156 


\section{Chapter I-Introduction}

Today's college degree could be considered yesterday's high school diploma; it is a stepping-stone to opportunities for mobility, career choice, and a higher quality of life. A college degree can offer intellectual, social, and economic benefits, and for many it is a chance to break away - a chance to step towards a future far different than for those who remain at home. It may be safe, then, to assume that there are strong and sound reasons for which one decides to pursue a college degree, and equally safe to assume that almost none do so with the intention of dropping out. However, many do.

In the U.S., approximately 1.5 million students are admitted into four-year colleges and universities annually and, of those, only $77.1 \%$ will continue past their first year (NCHEMS, 2014). Alpha Beta University (ABU, pseudonym) admits approximately 400 first-time freshmen annually, of which only $57 \%$ return the following fall semester-- 175 leave before their second year (ABUOIR, 2015). It is estimated that only $15-25 \%$ of students are dismissed from college for academic reasons (Tinto, 1993), leaving the rest as voluntary withdrawals, and are the results of personally strong and sound reasons: adjustment problems, feelings of incongruence, and isolation (Lehmann, 2007; Tinto, 1993). Reason, Terenzini, and Domingo (2006) state that attrition of this sort reflects "an unacceptable and unnecessary waste of individual, institutional, and national talent and resources" (p. 150). Attrition of this sort also reflects a loss of time, a loss of financial investment, and a loss of a dream.

This study adopts Tinto's (1993) Theory of Student Departure as a theoretical framework, which emphasizes the interaction of the student with the college experience as an influencing factor in departure decisions of which the first year is a critical. From the very onset, students must adjust to a new life of social and academic pressures coupled with a sense of separation 
from home. Tinto (1993) describes the adjustment phase as the "first hurdle to college completion", and an inability to successfully navigate this phase greatly increases the risk of student departure (Inkelas, Daver, Vogt, \& Leonard, 2007; Tinto, 1993). Furthermore, factors affecting students during their first year may carry over into later years (Nora, Barlow, \& Crisp, 2005). In-as-much as the first year is difficult for students, for those who are first-generation (FG), the difficulties are greater (London, 1989; Terenzini, Springer, Yaeger, Pascarella, \& Nora, 1996; Tinto, 1993).

FG students are defined as "those for whom parents or guardians have a high school education or less and did not begin a postsecondary degree" (Inkelas et al., 2007, p. 404). They have been described as being over-looked and marginalized (Hand \& Payne, 2008), as "at-risk" (Lowery-Hart \& Pacheco, 2011), and as "educational pioneers"' (London, 1996, p. 11). Housel and Harvey (2011) describe their position as one of straddling two distinct cultures: academic and something other than academic. By entering college, FG students are leaving the "intergenerational continuity" of their traditional society and entering one of modernity creating a potential for "biographical and social dislocation" (London, 1989); they are "breaking, not continuing, family tradition" (Terenzini, et al., 1994, p. 63); and struggling to "maintain cultural identity while navigating the college experience" (Lowery-Hart \& Pacheco, 2011, p. 56). After accounting for pre-college attributes, FG status, alone, has a negative effect on first to second year persistence (Ishitani, 2003; Paulsen \& Martin Lohfink, 2005) and overall persistence (Choy, 2001; Nunez \& Cuccaro-Alamin, 1998). Even when these attributes are considered positive, such as high test scores, high GPA, and high income (Somers, Woodhouse, \& Cofer, 2004), FG students are more likely than NFG students to leave college before their second year. This 
suggests that there is more to the story; it suggests that there is something within transitional experience of entering and participating in college that affects FG students in a unique way.

\section{Summary of the Research Problem}

The literature on first-generation students and first-year experiences, respectively, is extensive. However, there are significantly fewer that examine the combination of the two, and the majority of those pertain to under-represented populations, such as Latinos and AfricanAmericans, and most often within urban contexts. Also, there are many studies that examine the community college student experience, as well as for non-traditional, adult FG students. There are relatively few studies that examine the first-year experience of rural, specifically, Appalachian FG students.

The Appalachia region extends from the southern tier of New York State to the northeast corner of Mississippi. Demographic data differentiates this region from national norms: its population is almost exclusively rural and White, it has a much lower socioeconomic status, and a lower level of educational achievement (Pollard \& Jacobsen, 2014). Approximately 29\% of ABU's freshmen class is first generation of which approximately 24\% from Appalachia (ABUOIR, 2015).

\section{Purpose of the Study}

The purpose of this study is twofold. The first is to gain a better understanding of the first-year experiences of first-generation students at an Appalachian university. This phenomenological research explores the experience of separating from home culture, and adjusting to university culture. Secondly, it adds to the existing literature and expands the understanding of first-generation students. 


\section{Significance of the Study}

This study adds to the extensive array of literature about first-generation student experiences, addressing a population that has received relatively little attention: first-generation students of Appalachia. The findings and insights of this study advance the scholarly understanding of how first-generation students experience their transition from home to university. It introduces new interpretations of Tinto's Theory of Student Departure as applied to this particular group, and offers higher education and secondary education policy-makers greater understanding of the first-year experience.

\section{Research Question}

The central purpose of this study is to explore perceptions of the first-year experience of first-year, FG students. This study is set against Tinto's (1993) Theory of Student Departure which states that a major factor in students' persistence rests in their ability to successfully transition from home culture into college culture. This study explores if they experience a sense of transition (separation and adjustment) from their home culture to that of the college, and, if so, how that experience manifests for them. This study attempts to answer the following research question: How do first-generation Appalachian students transition into a small, private college?

\section{Definitions}

For this study, the following terms need to be defined:

1. First-Generation Student - A first-generation student is one for whom both parents or guardians have a high school education or less and did not begin a postsecondary degree" (Inkelas et al., 2007, p. 404). 
2. College and University - For the purposes of this study, these terms both represent institutions of higher education. Although they are not synonymous, they are, at times, used interchangeably, reflecting usage in the research literature.

3. Appalachia - The 205,000-square-mile region that follows the spine of the Appalachian Mountains from southern New York to northern Mississippi. It includes all of West Virginia and parts of 12 other states: Alabama, Georgia, Kentucky, Maryland, Mississippi, New York, North Carolina, Ohio, Pennsylvania, South Carolina, Tennessee, and Virginia (Pollard \& Jacobsen, 2014).

4. Separation - the first stage of student transition in which students leave home and family to attend college. According to Tinto (1993), it "requires individuals to disassociate themselves, in varying degrees, from membership in the communities of the past, most typically those associated with the family, the local high school, and local areas of residence" (p. 95).

5. Transition - For the purpose of this study, transition has two specific meanings. First, the move from one community to another, from a non-academic community to college community: "A period during which the person begins to interact in new ways with members of the new group into which membership is sought (Van Gennep, 1960, cited in Tinto, 1993, p. 93)". It is also the second phase in student adjustment as identified by "a period of passage between the old and the new, before the full adoption of new norms and patterns of behavior and after the onset of separation from old ones" (Tinto, 1993, p. 97). 


\section{Limitations of the Study}

The study is a qualitative phenomenological inquiry, involving semi-structured interviews as primary method of data collection. It is interpretive in nature and explores the perceptions and experiences of 10 first-year, Appalachian first-generation students. All of the participants are from within three hours of their host university and site of this study, therefore information learned from this study may not be generalizable to the larger population, but may provide valuable insight to similar rural populations. 


\section{Chapter II-Literature Review}

\section{First-Generation Students}

First-generation (FG) students are considered an "at-risk" group (Lowery-Hart \& Pacheco, 2011) who are "situated in the margins, despite being in the same campuses and classes as their peers (p. 56). FG students are "an often-overlooked, marginalized group” and so, "because they don't look different from other marginalized groups, such as Hispanics or AfricanAmericans, they often aren't perceived as needing help" (Hand \& Payne, 2008, p. 14). FG students must straddle two cultures (Housel \& Harvey, 2011), and "live and share in the life and traditions of two distinct cultures" (London, 1992, p .7). The literature shows that FG status, alone, has a unique impact on the college experience, and negative impact on student persistence. To better understand FG status, this review examines the characteristics of FG students, Tinto's (1993) theory of student departure, and related literature pertaining to the transition — separation and adjustment - into college.

For the purpose of this study, FG students are, are described as "those for whom both parents or guardians have a high school education or less and did not begin a postsecondary degree" (Inkelas et al., 2007, p. 404). There are differences in reported percentages, but FG students appear to represent one-third of all students seeking higher education degrees in public and private sectors (Berkner, Choy, \& Hunt-White, 2008; Gibbons \& Shoffner, 2004; Martinez,

Sher, Krull, \& Wood, 2009; Nunez \& Cuccaro-Alamin, 1998), and their numbers are increasing (Ishitani, 2003).

Although this study will focus on first-time, freshman students attending their first semester, directly from high school, FG students tend to be older than their non-first-generation (NFG) peers (Inman \& Mayes, 1999). FG students are more likely to be older than NFG students. 
FG students are also more likely to be married (7\%) than NFG students (1\%), and more likely to have children (Warburton, Bugarin, \& Nunez, 2001).

FG students are also more likely to be female than they were in the past (Inman \& Mayes, 1999; Terenzini et al., 1996). Consistent with the change in FG student versus overall student proportions, 2005 CIRP data shows women represent a higher proportion of FG students than they did years ago. Out of all students in 1971, 40.3\% were FG men, and 36.4\% were FG women. After the 1980s, the trend shifted and in 2005, 14.7\% were men, and 16.9\% were women (Saenz, 2007).

First-generation students are more likely to be racial/ethnic minorities than non-firstgeneration students (Bui, 2002; Choy, Horn, Nunez, \& Chen, 2000; Terenzini et al., 1996). Considering the proportionally low education level of Hispanic parents, for example (39\% of mothers, and $41 \%$ of fathers with high school degree or less), and increased enrollment rates from 1976 to 2008 for all ethnic minorities (Aud, Fox, \& KewalRamani, 2010) this indicates a positive trend in educational aspirations for previously under-represented groups.

FG students tend to have lower socio-economic backgrounds (Bui, 2002; Chen \& Carroll, 2005; Horn \& Nuñez, 2000; Terenzini et al., 1996) but have more personal income than NFG peers (Inman \& Mayes, 1999). This is possibly due to being older or because a higher percentage of FG students held jobs during high school (Saenz, 2007). FG students, however report having major concerns about their ability to finance their education (HERI, 2013). Saenz et al. found that more than half (55\%) of FG students expect to work to pay for college expenses, and Bradbury \& Mather (2009) found that students worked 12-25 hours per week, which next to academic performance, they note, represented one of their greatest challenges.

Academically, FG students are less prepared for college (Chen \& Carroll, 2005), and 
although it is not well understood as to how academic preparation affects post-secondary persistence and degree completion (Warburton et al., 2001), Pascarella, Terenzini, Pierson, \& Wolniak (2004) believe poor high school academic preparation tends to give FG college students a distinct disadvantage. For example, there is a difference in high school academic rigor between FG students and NFG students which might reflect their weaker cognitive skills in reading, math, and critical thinking (Terenzini et al., 1996). The National Center for Education Statistics (NCES) data shows $40 \%$ of FG students completed a non-rigorous curriculum (Core New Basics or below) as compared to $28 \%$ of NFG students, and only $9 \%$ of FG students completed a rigorous curriculum compared to $22 \%$ of NFG students (Warburton et al., 2001). FG students are less likely to take higher-level mathematics courses in high school (Chen \& Carroll, 2005) as illustrated by NCES data for 1995-1996 cohorts showing that Algebra II was highest level of mathematics for the largest percentage of FG students (26\% FG vs. 19\% NFG). In contrast, for non-FG students, Calculus was the highest level for the largest group ( $31 \%$ NFG vs. $20 \%$ FG) (Warburton et al., 2001). This trend has lead to a "widening gap" in self-ratings of math and writing abilities for FG students (Saenz, 2007).

Beyond a less intense high school curriculum, FG students tend to have lower high school GPA (Gibbons \& Shoffner, 2004)--even for FG students who pursued a rigorous high school curriculum, their GPA still tended to be lower than for NFG students. In his 2008 study of FG students in New England schools, Drozd (2008) found FG freshman at Yale had lower high school GPA than their NFG peers. CIRP data shows that FG students' GPA scores continue to lag behind their NFG peers with increased difference from 7 percentage points in 1971 to 10.9 percentage points in 2005 (Saenz, 2007). Ironically, FG college students tend to graduate high school with higher class ranking than their NFG peers (Martinez et al., 2009). This may be due to 
a higher percentage of FG students (versus NFG peers) attending high school in small towns and from rural areas (Warburton et al., 2001).

In comparison to their NFG peers, FG students are less likely to take college entrance exams, and those who did tend to score lower (Chen \& Carroll, 2005; Drozd, 2008; Gibbons \& Shoffner, 2004). With SAT, 40\% of first-generation students scored in the lowest quartile, compared with $15 \%$ of their NFG peers. With the SAT II, first-generation students were more likely to score below 550 and less likely to score 650 or higher (Warburton et al., 2001). FG status also has an effect on the ability to qualify for college. Choy (2001) found that firstgeneration students were less likely to be "highly qualified" and 49\% were "marginally or not qualified" for admission. The percentages for NFG students were lower with $33 \%$ for those whose parents had some college experience, and 15\% for those whose parents with bachelor's degrees or higher.

College enrollment rates vary considerably between FG and NFG students and FG students are more likely to delay college enrollment (Chen \& Carroll, 2005). In 1999, 82\% of NFG students enrolled in college immediately after finishing high school versus only $36 \%$ of FG students (Choy, 2001). This difference persisted for the years soon after graduation as well. For high school graduates of parents with no postsecondary education, the likelihood of enrolling in college within two years was $43 \%$. For those with parents who attended college, the likelihood increased to $59 \%$ and $74 \%$ for those whose parents had a bachelor's degree or higher (Choy et al., 2000). Because FG students are likely to be racial or ethnic minorities, it is important to note that from 1980 to 2007 the rate of immediate enrollment after high school increased 12 percentage points for both Blacks and Hispanics (Aud et al., 2010). 
Reflecting their lack of academic preparation and lower test scores, FG students often need remedial work. $55 \%$ of FG students need remedial courses in college-mathematics and reading - as compared to $27 \%$ of NFG students (Chen \& Carroll, 2005). There are mixed findings on FG students' college GPA; some studies found no difference (Drozd, 2008) while others found FG students received lower grades (Chen \& Carroll, 2005; Orbe, 2004; Pascarella et al., 2004), and Chen \& Carroll found that their lower GPA persisted throughout their undergraduate career. Even when factoring for backgrounds, race/ethnicity, etc., they note that FG students tend to lag behind their NFG peers. FG students express a "fear of failing" and feel they need to study harder than their peers (Bui, 2002), and have lower levels of self-acceptance, personal growth, and positive relations (Bowman, 2010). FG students tend to be less committed (Orbe, 2004; Pascarella et al., 2004) and are more likely to withdraw from courses (Chen \& Carroll, 2005). Most concerning is that FG are much more likely than their NFG peers to leave college without a degree (Inkelas et al., 2007; Warburton et al., 2001) and Choy (2001) found that at four-year institutions, FG students are about twice as likely as NFG students to leave college before their second year.

\section{The Transitional Experience}

All students will experience some difficulty in their transition through college (Tinto, 1993), and it is their experiences within college - more than academic performance - that affects decisions to withdraw (Fischer, 2007). More than academic incompetence, adjustment problems, feelings of incongruence, and isolation have a greater impact on student withdrawal (Holmbeck \& Wandrei, 1993; Lehmann, 2007; Tinto, 1993). It has been shown that FG students are not at greater risk of early departure than NFG students (Pratt \& Skaggs, 1989), however, there is greater evidence to the contrary. For example, even after accounting for pre-college attributes, 
FG status alone has a negative effect on first to second year persistence (Ishitani, 2003; Paulsen \& Martin Lohfink, 2005) and overall persistence (Choy, 2001; Nunez \& Cuccaro-Alamin, 1998). Even when attributes are considered positive, such as high standardized test scores, high GPA, and high income, FG students are more likely than NFG students to leave college before their second year (Somers et al., 2004). This suggests that there is more to the story; this suggests that there is something to the transitional experience of entering and participating in college that affects FG students in a unique way.

In his highly cited book, Leaving College: Rethinking the Causes and Cures of Student Attrition, Tinto (1993) introduces a Theory of Individual Departure from Institutions of Higher Education, the most developed and commonly used conceptual framework to assess reasons for persistence in higher education (Metz, 2002; Nuñez, 2004). Tinto's interactionalist theory finds its roots in the work of ethnographer, Arnold Van Gennep, who describes rites of passage as a three-stage process (separation, transition, and incorporation) and sociologist Emile Durkheim's notion of egotistical suicide (resulting from an inability to integrate and establish membership within one's community). Tinto (1993) describes an "adjustment"—a longitudinal process of separation, transition, and incorporation (membership) that influences a student's decision to persist or voluntarily withdraw.

Tinto's theory is not without its critics. First it is limited empirical knowledge supporting his model across multiple institutions (Braxton, Sullivan, \& Johnson 1997). The model explains the various phenomena involved in the transition process, and emphasizes the interaction a particular student has with a particular institution, therefore the model is generalizable but each situation is not. Secondly, it is argued that Tinto fails to recognize cultural variables considering separation and integration (Attinasi, 1989; Braxton, Sullivan, \& Johnson, 1997; Guiffrida, 2006; 
Metz, 2002; Tierney, 1992). Guiffrida (2006) states that Tinto's assertion that students must "break away" from past associations and traditions is not always applicable to minority groups and Tierney (1992) notes that such separations could be harmful. Braxton, Sullivan, \& Johnson (1997) argue the importance of maintaining ties and that support from family and friends are paramount to persistence. Regarding social integration, Attinasi (1989) and Tierney (1992) argue that integration for minorities is not equivalent to that of White cultures, and that minorities must not only adjust to the college culture, but to the dominant culture as well. Although Appalachian FG students may be of the dominant culture in some regards (i.e. White), they are, to an extent also outside of it. As with generalizability, the model still represents the transition of individual students and institutions, but their arguments are just and further illustrate the need for more individual studies.

The focus of this study, adjustment--“first hurdle to college completion" (Tinto, 1993)--is the early period of a college career where students transition from home to college and must adjust to new social and intellectual life and culture. This period is typically brief and without much difficulty, however, for some FG students, it is a rough experience (London, 1989), and an inability to adjust, especially during the first year results in early departure (Inkelas et al., 2007; Tinto, 1993). According to Tinto, difficulties within the adjustment period stem from two sources: an inability to separate from former life and culture, and an inability to meet social and academic demands of college.

Separation. Tinto (1993) borrows from Van Gennep's notion of separation as a primary step in periods of change. Separation for Van Gennep (1960) "involves the separation of individual from past associations. It is characterized by a marked decline in interactions with members of the group from which the person has come and by the use of ceremonies whole 
purpose it is to mark as outmoded the views and norms which characterized that group" (as cited in Tinto, 1993, p. 93). College students are moving from one community to another: from home culture, family, and friends to the community and culture of the college. Breaking from the security of home culture can be especially difficult and painful for FG students (Tinto, 1993), and especially those from Appalachia (Hand \& Payne, 2008), leading to periods of confusion, conflict, isolation, anguish (London, 1989) and a sense of loss (Komada, 2002). Because the college community may consists of different values, norms, behavioral and intellectual styles, successful integration will require some rejection of norms of past communities (Tinto, 1993). By entering college, FG students are leaving the "intergenerational continuity" of their traditional society and entering one of modernity creating a potential for "biographical and social dislocation" (London, 1989, p. 167); they are "breaking, not continuing, family tradition” (Terenzini, et al., 1994, p. 63); and struggling to "maintain cultural identity while navigating the college experience" (Lowery-Hart \& Pacheco, 2011, p. 56).

Breaks with families, social circles, and communities however, can be intentional. FG students have created distance between themselves and their former communities in order to “escape occupational dead-ends and hopelessness" (Terenzini et al., 1994, p. 63), to "distance themselves from the poverty they'd grown up in" (Macy, 2000), and to participate more fully in the college life (Byron \& Simmons, 2009; Nuñez, 2005; Orbe, 2008). FG students express that family members and friends do not or cannot understand the nature of college life (Bryon \& Simmons, 2009; Phinney \& Haas, 2003), nor that they have new roles and responsibilities that come with college culture, which are difficult for parents to comprehend (Bradbury \& Mather, 2009; Orbe, 2008). Compared to NFG students, FG students shared college experiences with family and friends significantly less, and express a feeling of alienation (Barry, Hudley, Kelly, \& 
Cho, 2009). FG students express feeling uncomfortable sharing new views and ideas with family members (Byron \& Simmons, 2009), and fear a perception of alienating their roots (London, 1992). FG students reported less support (Choy, 2001), and a lack of encouragement from parents sharing comments such as, "They all said I could spend the same amount of time working and make money now instead of spending all that time in class" (Nuñez, 2005, p. 57). Some FG students express a great deal of pressure from family and community to succeed (Byron \& Simmons, 2009) and attend college not only for themselves but to establish honor for their families (Bui, 2002).

Other researchers, however, have shown that separation is not just unnecessary for successful integration, but that students benefit from family capital and support while in college (Andrade, 2013; Byron \& Simmons, 2009; Hand \& Payne, 2008; Hurtado \& Carter, 1997), and that high school friends have provided critical support (Bradbury \& Mather, 2009) and motivation (Nuñez, 2005) during college transition. Family ties can provide a basis for personal identity (Byron \& Simmons, 2009). Some family values and attributes provide benefits that lead toward greater persistence worth not rejecting during separation (Miller, 2007).

Whether or not complete separation is purposeful or a necessary step towards integration, there exists some form of dislocation--which includes some degree of separation--and an introduction to new cultures, ideas, and norms. Such "separation dynamics" are central to FG students (London, 1989) forcing them into conflicting roles (Bradbury \& Mather, 2009). Terenzini, et al. (1994) describe the entry into college for FG students to be a "highly interrelated, web-like series of family, interpersonal, academic, and organizational pulls and pushes" (p. 61) that affect student learning and persistence. Attending college, for FG students, "magnified something they always knew deep within themselves: They were different than many people in 
their families and communities" (Byron \& Simmons, 2009, p. 397). Entering college for FG students represents movement into some "other" culture, complete with personal and familial drama, and a necessity to "renegotiate relations with family members, friends, and in a fundamental sense, with themselves" (London, 1992, p. 6). For FG students, this "constituted a major disjunction in their life course", and they were "breaking, not continuing, family tradition" (Terenzini, et al., 1994, p. 63). Lowery-Hart and Pacheco (2011) found that FG students are struggling to "maintain cultural identity while navigating the college experience" (p. 56), which they identify as a dialectic tension of "in versus out", which represents a desire to be apart of and adapt to college culture while resisting, maintaining their roots. Orbe (2008) identified a dialectic tension of "independence versus interdependence", as FG students find themselves creating distance between themselves and family members, while trying to maintain family bonds. FG students report receiving mixed messages: parental support of college success and a desire for the student to return home, and suffer loneliness, both in the family and at college (London, 1989). This can be difficult because some students are or feel responsible for helping out at home (Bradbury \& Mather, 2009; London, 1989).

Adjustment. Academic and social integration, or involvement, is conditional for student success (e.g. Astin, 1993; Tinto, 1993), and the more academically and socially involved, the more likely students are to persist (Tinto, 2005). Academic performance has been shown to have less impact on voluntary withdrawal (Fischer, 2007; Tinto, 1993) than positive interactive experiences, which lead to greater social and intellectual integration, and lead to a stronger commitment to persist (Astin, 1984; Braxton, Milem, \& Sullivan, 2000; Davidson \& Wilson, 2013; Fischer, 2007; Hirsch, 2010; Inkelas et al., 2007; Tinto, 1993). Although it has been argued that complete integration, or assimilation, is not necessary for student persistence (Bryan 
\& Simmons, 2009; Tierney, 1992), research shows generating informal ties, such as making friends on campus, has a positive effect on persistence (Fischer, 2007), institutional commitment (Berger \& Milem, 1999; Braxton et al., 2000), and is critical to students' development and progress (Hurtado \& Carter, 1997). Moreover, an absence of connections (Fischer, 2007), isolation, and a sense of incongruence (Tinto, 1993) increase the likelihood of withdrawal. The combination of students' social and academic interactions may contribute to their sense of belonging (Hurtado \& Carter, 1997), which increases likelihood of graduating (Davenport, 2010; Paulsen \& Martin Lohfink, 2005), although, most first-year students experience learning in isolation (Tinto, 2005).

For FG students, social interaction with NFG students enhances motivation, degree plans, intellectual development, and personal growth (Moschetti \& Hudley, 2008; Pascarella et al., 2004) while academic integration contributes to higher GPA (Prospero \& Vohra-Gupta, 2007). Interestingly, academic and social integration experiences are different for men and women and are compensatory. Women's persistence decisions are more affected by social integration while academic integration has a greater effect for men. Also, for students with less social integration was more important than academic integration, and vice versa (Pascarella \& Terenzini, 1983).

For FG students, entry into the college environment requires a longer step, one in which they wrestle with dichotomies, such as, "integration versus segregation" (Lowery-Hart \& Pacheco, 2011), and "in versus out" (Orbe, 2008) - a desire to integrate against a fear of losing their identity. Also, FG students express a conflict of "talking versus silence" (Lowery-Hart \& Pacheco, 2011), which represents a desire to speak (and participate) against a fear of not being understood, or made fun of. FG students have expressed a feeling of self-doubt in ability to be successful in college and described feeling "terrified," "apprehensive," "overwhelmed," 
"unprepared" and "alone" during their initial entrance into college (Komada, 2002). FG students expressed insecurity from an inability to relate to the academic environment and an initial intimidation by their professors (Bradbury \& Mather, 2009). Terenzini et al. (1994) also discovered that FG students were also less likely to perceive faculty members as concerned about student development and teaching. Students have voiced that one of the most difficult aspects of adjusting to college was the distance they felt from professors (Nuñez, 2005) and perceived the college environment as less supportive (Pike \& Kuh, 2005).

It has been shown that FG students were more focused on academic transitions and were less involved in non-academic activities (Terenzini et al., 1994), and less likely to "successfully integrate diverse college experiences" (Pike \& Kuh, 2005). Lehmann (2007) found one of the reasons that students who left college did so because of "not fitting in" and "not feeling university". It goes without saying that a feeling of belonging is important for college students, however, for FG students, integrating into college is especially difficult (Bradbury \& Mather, 2009).

The FG student experience of attending college has been described as one of straddling two cultures (Housel \& Harvey, 2011): one of home and one of college. Each, they note, has its own social rules and cultural mores. This "cultural straddling" effect is greater for FG students than for NFG students, and they tend to experience a sense of 'culture shock' (Gofen, 2009). First-generation students have to adapt to a new set of academic, cultural, and social systems (Terenzini, et al., 1994) and may have initial difficulty with academic integration and engagement (Soria \& Stebleton, 2012). Phinney \& Haas (2003) note that although they have a desire to succeed, they do not know how. This affects their investment process (Gofen, 2009) 
and their commitment to their role as student (Soria \& Stebleton, 2012; Stephens, Fryberg, Markus, Johnson, \& Covarrubias, 2012).

\section{Appalachia}

Appalachia, as a whole, spans parts of 12 states from New York to Mississippi and all of West Virginia. Because Appalachia demographics are not representative of national norms, FG students from this region are not likely to fit the national profile. Appalachian Regional Commission data shows a disproportionate number of Whites (84\%) when compared to the rest of nation (64\%), and Hispanic (Latino) and Black populations are far lower in Appalachia than the national average with $4 \%$ versus $16 \%$ and $9 \%$ versus $12 \%$, respectively. Regarding income, Appalachia lags the nation by approximately $\$ 15,000$ in mean household income and $17 \%$ of the population lives below the poverty line (Pollard \& Jacobsen, 2014). Educational levels in Appalachia are also lower than the national average. 2012 estimates for those 25 years or older, $84 \%$ hold high school diplomas (vs. $86 \%$ ), and $21 \%$ have a bachelor's degree or higher (vs. 29\%). Ziliak (2007) positively links educational attainment and the economic status of individuals as well as communities, suggesting that greater education leads to greater economic prosperity. Considering these numbers, it is likely that many college students from Appalachia are first-generation, and because they are more demographically similar to their NFG peers, they are likely to be, as (Hand \& Payne, 2008) note, "an often-overlooked, marginalized group”.

\section{Alpha Beta University}

This study took place at Alpha Beta University (ABU), a small, private, not-for-profit, four-year institution located in a small town within central Appalachia. Facing low student enrollment and financial concerns, the institution sought new leadership and hired a new president in 2012. Originally founded as a Christian college, under new leadership, the institution 
adopted a university structure, loosened its ties with its religious past, and adopted an Affinity Bonding Model.

The Affinity Bonding Model was first developed and implemented at Allegheny College in Pennsylvania in 1995, and later in 2002 at Washington \& Jefferson College in Pennsylvania, in 2005 at Adrian College in Michigan. The model is designed to address enrollment dilemma for small colleges and universities while making the college experience more meaningful for students. By increasing investments in student activities, such as sport programs, marching band, cheerleading, and music programs, and simultaneously increasing recruitment goals, institutions can raise enrollment and provide greater opportunities for student and institution interaction. The theory behind the Affinity-Bonding model rests on the notion that students will develop a stronger attachment to a particular institution if they have positive interactions with a group of friends, or mentors that they can identify with—whatever their affinity might be.

Although the model does not specifically address FG students, the ABU president feels that because of their high attrition rate, it is incredibly important for this group. He states that whereas FG students may not have strong family understanding of college, or support, these students can benefit from positive interactions with mentors, such as a band director or a coach. In this way, the Affinity-Bonding model rests squarely within Tinto's (1993) Theory of Student Departure: greater opportunities for positive interactions between faculty (ie. mentor or coach) and students outside of the classroom support informal academic integration, and organized institutional activities (i.e. sports and musical ensembles) support formal social integration. Because ABU does not collect data specifically describing the performance of FG students, it is difficult to know how this model affects this group, but for FG students, the increased opportunities provided through the affinity-bonding model have the potential to make college 
more meaningful.

ABU does have two programs to assist students' transition through college, but they do not target FG students specifically. The first is a freshmen success course (GNST 101) that students elect to take or are placed into if they fall into academic probation, or arrive to $\mathrm{ABU}$ with two or more academic deficiencies. The aim is to make students more aware of timemanagement skills, of opportunities for academic assistance, and to introduce and promote membership into institutional groups and organizations. It also includes a peer-mentoring component, which although only lasts for one semester, can broaden the reach of Affinity Bonding Model. The second is a "living and learning" community which requires registration and participation in GNST 101, while providing separate "quiet" dormitories. This opportunity is offered to incoming freshmen that desire less distraction from academics, but also want to be a part of the university community.

Since the implementation of the Affinity Bonding Model, ABU has seen an increase in the student population (approximately 550 in 2011 to approximately 1200 in 2015), as well as a change in the student demographic profile (93\% White in 2010 to $67 \%$ in 2014). This change means $\mathrm{ABU}$ more closely represents the national demographic norms. Of approximately 1,200 students, FG students comprise $28 \%$ of the fall 2014 cohort. No data could be found that isolated race/ethnicity and gender from specific state origin, but for this same cohort at $\mathrm{ABU}, 67 \%$ were White, in-state residents who outnumbered non-residents by 7.4 percentage points, and males outnumbered females by 23 percentage points (ABUOIR, 2015). Although, FG students are disproportionately female and non-White (Choy, 2001), FG students of Appalachian origin at $\mathrm{ABU}$ are more likely to be male and White. 


\section{Summary}

First-generation (FG) student are those whose parents or guardians have not attended college, and they represent roughly one third of today's college student population. As a group, FG students have been described as "at-risk" (Lowery-Hart \& Pacheco, 2011), often overlooked, and marginalized (Hand \& Payne, 2008). Although cultures are complex and defined by an infinite number of attributes, academic attainment—in this case, higher education—defines the culture of FG students, and is what separates them from their non-FG peers. By pursuing a college degree, FG students are breaking family patterns and traditions. It is for this that Housel \& Harvey (2011) portray them as straddling two cultures.

Defining a group or culture in terms of deficit, can unfairly cast a light of inferiority and suppose that with adequate attention, they will meet standards of adequacy. In the case of FG students and academic preparation, their deficit cannot be overlooked. The literature has shown FG students to be less prepared for college (Chen \& Carroll, 2005), less qualified for admission (Choy, 2001), and those who are enrolled more often need remedial courses (Chen \& Carroll, 2005). On another scale, FG students express a "fear of failing", feel they need to study harder than their peers (Bui, 2002), and have lower levels of self-acceptance, personal growth, and positive relations (Bowman, 2010). Strangely, FG students with positive attributes, such as high GPA and entrance exam scores, are still more likely to leave college before their second year (Somers et al., 2004).

It is expected that all students will experience some degree of difficulty as they transition into college, however, it is their experiences within college - more than academic performancethat affects decisions to withdraw (Fischer, 2007). This phenomenon - the impact of student and institution interaction on persistence — was addressed by Tinto's (1993) Theory of Individual 
Departure from Institutions of Higher Education. Tinto describes the student's journey as one that includes separation, transition, and incorporation as they move from home culture to college culture. The first two of these, separation and transition, are an adjustment phase and must be successfully traveled before the student becomes incorporated into the college culture. Separation involves a break, to some degree, from the home culture; transition involves the social and academic interaction of the student and the college; and the quality of these two phenomena impacts the student's commitment to persistence.

Returning to a deficit model, in spite of its presumptions, students from Appalachia are further at a loss. According to the U.S. Census Bureau (2013), Appalachian students, as a whole, come from homes with lower socio-economic and academic achievement levels than the national average. With less available funds for schools, students may have less preparation for college, and with lower family academic achievement, the value of higher education may not be transferred or emphasized. Although no supportive data could be found, the high rate of college participation, and low levels of academic achievement, it may be presumed that many college students in Appalachia are first-generation.

Being first in their family to attend college offers FG students a chance to pioneer, to lead, and sometimes, to break family traditions and cycles of poverty. Responding to the literature, this study seeks to further understand the experience of transition from home culture to college culture for first-generation students. For this group, the reach for a college education can be further, more difficult, and more conflicting than for their NFG peers. Given the value of a college education for personal, intellectual, and social development; for social mobility, and future opportunities, a better understanding of separation and transition — their adjustment to college - is in order. Knowing their experiences, their struggles, their successes, and their stories 
will help all those involved to "flatten the road" for them and assist them in fulfilling their dream. 


\section{Chapter III-Methodology}

\section{Introduction}

My interest in this research stems from personal experiences as a student, educator, and community member. Individually, and collectively, these experiences have raised my awareness of the differences among college-educated and non-college educated families, and how those differences may affect educational aspirations.

To begin, I come from a family with educational differences: my mother's family is college educated, and my father's is not. I recall, as a college student, while interacting with each side, of having to walk (and talk) carefully as I crossed these lines. First, I became aware that there were differences in worldviews, ways of acting, and of speaking. Then, I needed to learn to navigate them, and learn how to speak and behave within each. I needed to learn which hat to wear when. Although I am not first-generation, my experience is not dissimilar to that experienced by first-generation students.

Much later in my life, I built a house, and settled in rural Preston County. As a doctoral student living in a community whose social capital was strong, but not academic, I was again reminded of the vast difference two cultures can possess in such a small geographic space. I discovered the difficulties of relating esoteric concepts to my friends and neighbors, and realized they may have had troubles relating to me. Again, I found myself in a position of cultural straddling.

Finally, as a graduate assistant, I taught a course designed to help undergraduate students develop academic strategies. Many of my students were first-generation, and it became clear that a difference existed between them and their non-first-generation classmates regarding skills associated with college success. It was then that I wondered if there was something inherent in 
first-generation status that affected successful transition into college. I thought about the cultural straddling that I had experienced, or perhaps it was something with the skillset, or tools that these students arrived with. Was it an intellectual or social misalignment that was affecting their success?

Throughout this research, I listened to the participants as they described their experiences, read and reread the interview transcripts in an attempt to answer these questions. My intentions were not to validate existing ideas, but to dig into the data and try to make sense of it. If I am to be honest, there were times where this was difficult—-times when I was surprised with what was turning up in the narratives of these students-however, these instances only served to underscore the fact that there is much to be learned about being a first-generation student.

Chapter III introduces the research design, participants, sampling procedures, data collection, data analysis, and the research question. This qualitative inquiry is phenomenological and follows precedents set by previous research and expert authors.

\section{Research Design}

As chapter II indicated, first-generation (FG) students begin their academic career with disadvantages. Their high school experience leaves them less prepared for college. FG students tend to have a less rigorous high school curriculum, have lower high school GPAs, and tend to score lower on standardized tests than non-first-generation (NFG) students. FG students are less likely to qualify for college acceptance, and for those who do, many need remedial courses to regain math and reading skills. Interestingly, these apparent disadvantages have less consequence than one might expect. With these potentially negative attributes factored out, FG students were still less likely to persist through graduation than NFG students. It appears that there is something unique to the FG student experience, in that FG status has a negative effect on 
persistence. This indicates that there is something more to this story than academic preparation.

FG students make up approximately $30 \%$ of first-year cohorts nationally, and $28 \%$ at ABU. It has been shown that FG students are most often of minority groups, such as Black and Latino, of lower-socioeconomic standing, urban, female, and older than typical first-year students. This is reflected in the literature. Appalachia's demographics, however, are not typical of the national norm, in the sense that $84 \%$ are White (Pollard \& Jacobsen, 2014) and the region is almost entirely rural. Because of these differences, FG students from this region are not well represented in the literature. What is known about Black and Latino FG students, who are from urban areas, may not represent this population. This study, therefore, is to examine the experience of Appalachian FG students in order to better understand their transition into higher education.

Because this study seeks to understand the process of transition as experienced by FG students, a phenomenological inquiry was the most appropriate approach. It is generally understood that Edmund Husserl first introduced classical phenomenology, which he described as "the science of the essence of consciousness" (Husserl, 1981 as cited in Grbich, 2007, p. 85), which explained by Grbich necessitates a "rigorous method to study experience both objectively and subjectively by going as close as possible to the experience of the things themselves" (p.86). Phenomenology according to Patton (2015), “explores how human beings make sense of experience and transform experience into consciousness, both individually and as a shared meaning" (p. 115).

Phenomenology, then, focuses on first-person experience and intentionality, that is, the directedness one has toward an object or event, and through phenomenological reduction, or bracketing pre-existing attitudes out, one can pare down an expression (i.e., narratives 
constructed from interviews) to understand the essence of something. In the case of this study, I suggested that there was something within the transitional experience of entering and participating in college that affects FG students in unique way. I sought to understand if these FG students experienced a sense of transition (separation and adjustment) from their home culture to that of the college, and how that experience manifested for them. Whereas Husserl sought to get "back to the things themselves", or as Van Manen (2014) interprets as "to somehow return to the world as we originally experience it, to what is given in lived prereflective experience, before we have conceptualized it, before we have put words or names to it” (p. 93), Husserl begins with presumption of consciousness. So, within the Husserlian point of view, according to Van Manen (2014), "anything that presents itself to consciousness is potentially of interest to phenomenology, whether the object is real or imagined, empirically measurable, or subjectively felt” (p. 94). I suggest in this paper that FG students, as they move through their transition from high school to college, inasmuch as they are aware of events and of their actions, may not be aware of their transition - meaning, they may be conscious of moving onto campus and living with a stranger, for example, but they may not be conscious of transition, in the larger sense. Thus, the nature of my interview questions were aimed not at retrieving the students' description of feelings or what living with a stranger felt like, but designed for the student to return, relive, and describe the event. In this way, I adopted a strategy more closely aligned with MerleauPonty's existential phenomenology, which reflects on what is prior to reflection-lived experience (Van Manen, 2014). Being aware of something, and naming something requires an understanding that it exists, which necessitates consciousness of it. Merleau-Ponty digs deeper, he suggests that we "begin by reawakening the basic experience of the world and by practicing a 'direct description' of this world (Van Manen, 2014, p.128). Merleau-Ponty states that efforts of 
phenomenology are:

concentrated upon re-achieving a direct and primitive contact with the world ... it also offers an account of space, time, and the world as we 'live' in them. It tries to give a direct description of our experience as it is, without taking into account of its psychological origin and the causal explanations ... (Merleau-Ponty, 1962 as cited in Van Manen, 2014, p. 128)

So, in order to understand how these FG students transition into college, in what ways this manifested for them, and what it meant, I had to get back to the "things themselves", a priori. My research strategy was to take them back in time to describe the events as they remembered. Through these descriptions came narrative, and collectively, a metanarrative, which provided a general understanding of their transition.

\section{Participants}

Alpha Beta University is a small, private university located in Appalachia, and hosts approximately 1,200 students from throughout the nation and internationally. Approximately 400 first-year students enroll each year of which approximately $43 \%$ are in-state residents and approximately $28 \%$ are first-generation. This research was conducted with 10 first-year, firstgeneration students who were actively enrolled at $\mathrm{ABU}$ and who met the following criteria:

1. Within the first generation of their immediate family to attend college;

2. Enrolled directly after high school;

3. Full time enrollment status; and

4. 18 years of age or older.

\section{Sampling Procedures}

Participants were selected through purposeful sampling that is both unique (Merriam, 
2009), and criterion based (Creswell, 2007). With purposeful sampling, participants are selected "because they can purposefully inform an understanding of the research problem and central phenomena in the study" (Creswell, 2007, p. 125). Merriam (2009) describes unique sample as having "unique, atypical, or perhaps rare attributes ... of the phenomenon of interest" (p. 78), and Creswell (2007) notes that criterion sampling is most appropriate when "all individuals studied represent people who have experienced the phenomenon" (p. 128). Regarding the sample size, the goal was to have as many participants as necessary to reach redundancy in the findings. There appears to be no consensus on the appropriate number for phenomenological research, however, by recommendation of the dissertation committee, this study involved 10 participants. At this point, it is important to note that the location from which the participants were selected differs from the approved dissertation proposal. Mountain University, a large land-grant state university centered in Appalachia was the intended site, and a procedure for securing participants (see below) was approved by dissertation committee. Arrangements were made with a student program rich with first-generation students, however, in the duration of securing IRB approval, policy changes prevented access to students. Attempts to find an alternative route were met with resistance by the college dean, and permission to locate an alternate site was granted by the dissertation committee chair and IRB. Being new faculty at Alpha Beta University, I approached the provost and was granted permission to select participants from ABU. The following describes the participant selection procedure, as approved by my dissertation committee.

An invitation to participate was offered to first-year students via email. A letter describing the study (See Appendix A), with participation parameters and researcher contact information, was delivered electronically through university email. I also visited sections of a 
first-year academic strategy course to introduce myself, the study, and recruit participants. 11 candidates volunteered of which 10 were selected (one was not FG). All were White, from within three hours of the university, and they consisted of six female and four males. In order to participate, students agreed to and signed consent forms (See Appendix B) that clearly described the study, and participant rights.

\section{Data Collection}

Data was collected through a demographic questionnaire and semi-structured interviews during November 2014, the $10^{\text {th }}$ week of the first semester. The questionnaire (See Appendix D) requests hometown, family, and participant high school information. This information helped to identify any patterns that existed between the students and their experiences, as well as any patterns that existed with this study and the literature.

The interviews followed a list of guiding questions (See Appendix E) designed to help the student relive the events and feelings that occurred throughout the transition process. Prior to the interviews for this study, the interview guiding questions were tested in a pilot-study to determine if they provided for a comfortable and fluid interview, as well as to determine if they elicit responses aligned with the research question in this study. The pilot-study was conducted between months of July and September 2014 with three first-generation students (at Mountain University, the original research site) who attended and successfully completed their first year (fall 2013-spring 2014). The purpose of the pilot-study was solely to gauge the quality of the guiding questions, and for me to become more familiar with the interview process. These pilot interviews were recorded (with permission) for the purpose of review and reflection, however the interviews were not transcribed. Appendix E contains a summary and rationale for the interview guiding questions. 
Participant interviews were recorded with a digital audio recorder and researcher field notes for later analysis. In accordance with the WVU Office of Research Integrity and Compliance, participant identities were kept confidential: pseudonyms were assigned to student questionnaires, electronic interview data, and interview transcripts. Digital participant data was kept on a password-protected computer. Backup files were made and stored on separate digital storage devices and were stored, along with printed transcripts and field notes in a locked file cabinet. Participant data will be destroyed (electronic files erased and paper documents shredded) after three years.

\section{Data Analysis}

A review of the literature on phenomenological research reveals that there is no single specific methodology for data analysis. There is, however, a general agreement to sequences, phases, and researcher behavior. Data analysis procedures followed a synthesis of guidelines as recommended by Merriam (2009), Hycner (1985), and Creswell (2007):

1. Interview data from researcher notes, and audio/video recordings were transcribed including literal statements as well as significant non-verbal communications. Prior to engaging with the data and reading the transcript, I, the researcher, attempted to "bracket out" my personal experiences, or epoche, and feelings in order to approach the data "with an openness to whatever meanings emerge" (Hycner, 1985, p. 280). This phenomenological reduction allowed general meanings to emerge. Although it is impossible to completely step away from my own history, a conscious awareness of prejudices or assumptions it is essential in order to focus on phenomenological meanings as they are to the participant. 
2. Once data interaction begins, Hycner (1985) suggests reviewing the data and reading through the transcripts multiple times to get a "sense of the whole". This not only includes the participant's statements, but also non-verbal, para-linguistic cues, such as intonations, emphasis, and pauses.

3. Once a Gestalt, or general defining pattern emerged, the data were sifted for significant statements, or segments that reflected how the participant experienced the phenomena. Without attempting to answer research questions, but against the context of the interview (Hycner, 1985), this phase, called horizontalization, was done to identify units of data having meaning, or potential meaning. Merriam (2009) notes that during this stage, all data is of equal importance and valuetheir significance was determined later when set in context of the research questions. The resulting "units of general meaning" may consist of a single word or several large passages (Merriam, 2009), however, they should be able to stand alone, and "be clearly differentiated from that which precedes or follows" (Hycner, 1985, p. 282). Open coding (Merriam, 2009) was then done and units were tagged to assist with later identification or to indicate their potential meaning.

4. After units were identified, they were filtered to eliminate redundancies, and according to their relevance to the research question. The segments, or statements, became "units of relevant meaning" (Hycner, 1985) and verified by trained expert as to their importance and relevance to the research question. The trained expert was a member of the dissertation committee and this effort validated the initial findings and challenged any researcher bias as a reliability check. 
5. After completing this process, analytical coding (Merriam, 2009) began, and the remaining units were categorized, or grouped. Units that naturally fell into or formed a theme were brought together forming clusters of meaning (Creswell, 2007), which spoke to the essence the phenomena.

6. These clusters were examined to determine if a central theme could be found that expresses the essence of the clusters.

7. After established clusters were named, and themes established, the process moved from inductive to deductive, and the rest of the data was be examined to determine if they fell into the clusters (Merriam, 2009). This process was done with all individual interviews in an attempt to identify common themes, as well as variations (Hycner, 1985). Finally, significant statements and themes were used to describe the participants' experience. Hycner (1985) describes this as the contextualization of themes, where themes are placed back into the context of the interview.

8. A composite summary was developed that describes the "essence" of the firstyear experience of separation and adjustment for first-generation students as well as newly discovered themes. Its focus is on the underlying structure (Creswell, 2007) common to this group.

\section{Trustworthiness}

To ensure validity, a qualitative analysis expert, and dissertation committee member analyzed two transcripts. The result of this second analysis validated my initial coding, interpretations, and themes. Also, this secondary analysis helped to ensure validity by challenging any biases that may have influenced interpretations of the primary analysis. 


\section{Research Question}

The central purpose of this study was to explore the experience of transition for first-year of first-year, FG students. This study was set against Tinto's (1993) Theory of Student Departure which states that a major factor in students' persistence rests in their ability to successfully transition from home culture into college culture. This study explored if they experience a sense of transition (separation and adjustment) from their home culture to that of the college, and how that experience manifested for them. This study, therefore, attempted to answer the following research question: How do first-generation Appalachian students transition into a small, private college? 


\section{Chapter IV-Data Analysis}

The central purpose of this study was to explore perceptions of the first-year experience of first-year, first-generation students. Primarily, it asked if students perceived a sense of transition, and subsequently, how these perceptions manifested for the student according to Tinto's (1993) Theory of Student Departure. According to Tinto, students arrive with initial dispositions (intentions and commitments), and backgrounds (e.g. social status, parental education, and size of community), personal attributes (e.g. sex, race, physical handicaps), skills (e.g. intellectual and social), financial resources, and precollege educational experiences and achievements. Although backgrounds are fixed, students' dispositions - that is, their intentions and commitments - are not, and based on their perceptions of transition, students' dispositions are strengthened or weakened. Thus, a major factor in students' persistence rests in their perception of successfully transitioning from home culture into college culture.

It cannot be assumed, however, that students will perceive this transition—some may simply move through various positions in this process without awareness of transition. Therefore, this study (1) explored whether or not they perceived a sense of transition (separation and adjustment) from their home culture to that of the college, and (2) how that experience manifested for them. This study, therefore sought to answer the following research question: How do first-generation Appalachian students transition into a small, private college?

To gain a better understanding, 10 first-generation students were interviewed. These interviews were semi-structured and each followed a set of guiding questions. The questions (See Appendix E) were designed to return the student to various points in his/her transition process, recall events that occurred, and to elicit anecdotal stories from which meaning could be derived. These interviews resulted in a large amount of data that was transcribed with InqScribe software, 
and coded with TAMSAnalyzer software. The coding was done in two phases: first, inductively, to identify generalized themes found throughout the data, and second, deductively, to identify meaningful data that fit Tinto's Theory of Student Departure. I approached the data in this manner because Tinto had not explicitly addressed the high rate of withdrawal for firstgeneration students. In other words, regarding first-generation, Appalachian students, what anything missing from Tinto's theory? This approach provided an opportunity to place the students' transition experience within Tinto's model (Appendix F), and also provided a wider view of the transition phenomenon, revealing new information.

In this chapter you will read the experiences of 10 first-generation students as separate narratives constructed from interviews and demographic questionnaire data. Each narrative was written to follow the structure of Tinto's (1993) Longitudinal Model of Departure from Institutions of Higher Education, and highlights the participants' transition into college through the following themes: intention, commitment, separation, social adjustment, and academic adjustment. Also included are, if they arose, themes of emotional support, personal difficulties, and personal transformation. Although this study has a more narrowed focus (separation and adjustment), a wider array of factors help round out the participants' stories and lead to new insights beyond separation and adjustment. Because the guiding interview questions were openended and designed to elicit a specific response, participant responses varied greatly, emphasizing moments and feelings that were important to them or that represented their understanding of the nature of the question (This combination revealed insight into impact of various points of transition). Thus, the reader will see a consistent storyline, but the descriptions of experiences are as unique as the participants themselves. I felt it was important to construct and include these narratives because they give context to the data and represent each 
participant's personal story. It is important to note that although the narratives contain direct quotations, these excerpts were edited to remove utterances, and hesitating phrases such as "I mean, like, you know, um, etc." Also, some mechanical corrections were made, for example, "wanna" changed to "want to", and "doin" to "doing" This was done to increase readability, and has not affected the meaning or nature of the excerpts. If some utterances hesitating phrases, mechanical errors, or bracketed descriptions were left in, it was because they provided value or emphasis to the excerpt.

Next, I reviewed the themes of separation and adjustment (social and academic integration) from Tinto's model and identify participants' representative excerpts extracted from interview transcripts. Viewing the data from this angle allows the reader to see these firstgeneration students fit within Tinto's model, and how they move through the transition process. Participant responses were grouped according to likeness and patterns are easily identifiable. Tables (Appendices G-M) are provided to succinctly represent the data.

Finally, I provided new discoveries, or information found that was not emphasized in Tinto's model, or that represents changes that have occurred since his theory was presented. Perhaps the most interesting section of this chapter, as this information may answer the question of "is anything missing in Tinto's theory?" This section contains participant excerpts and representative tables as well.

\section{Participant Narratives}

The following section contains the stories of 10 first-generation students and their transition into college. The stories resulted from information learned through interviews and each follows a consistent, albeit loose, path representing intention, commitment, separation, social integration, and academic integration. Each story has its own feel, which represents the nature 
and emphasis given by the participant, and each represents my interpretation of the participants' perceptions of transition, as I understood them.

Michael. Michael comes from a small town located in the western part of the state. He is the middle child of three and, prior to leaving for college, lived with both of his parents. His family has traditionally gone into the "workforce", or been employed through the military--these two options were too limiting for him to create more options for his own children. Perhaps because of this, or in spite of this, early in his high school career, Michael made the decision to attend college. For him, college was a path to self-improvement and a way to prepare him for future employment opportunities. Although he stated that he was interested in pursuing degrees in ministry and in elementary education, his goals did not appear to be purely occupationally driven, "I mainly decided I wanted to go to college earlier in my high school years because I just didn't want to go out into the workforce not having more education and I wanted to like have more skills." Just as he sees college as an institution for personal development, he also sees his choice to attend college as a break from family tradition, and a pioneering moment. "I just wanted to have more skills, and be the first person in my family to go to college" he stated, and followed by noting that this felt "weird" for him. Although it may have felt weird, his language indicated that he perceived himself as a college student when we spoke, and even before arriving at school:

I felt excited and can't wait, and then as the summer slowly went away, and it got closer and closer to school, I started getting, the same feeling that most college kids get: nervous and not knowing what to expect and how our lives are about to be turned around and flipped, and everything was about to change. 
He stated that his nervousness came from, "not knowing to what to expect and not being able to foresee anything, like friendships, or the type of people I would get to know, and classes." However, he was fully committed, "I'm going to college and just going to do my best and study and if that means not being that social with people, and being one of the most popular kids to get studies and homework done, I'll do whatever it takes."

Issues of separation did not appear to be a problem for Michael, and he expressed that he had support from friends and family. He stated that the night prior to arrival was "very emotional because that would have been the first time I've been away from family and friends for this long”, he didn't linger on this thought, but rather identified a feeling of, “everything being my responsibility now." When we spoke, he demonstrated a practical understanding and ability to deal with separation, stating that he was only three to four hours from home, and "I'll still be able to go home for school breaks and so it's not like I'm being away for forever." This practicality combined with his recognition of personal responsibility was best modeled in his first few weeks on campus. When I asked if he called home on his first night away from home, he said, "Not that night. I [pause] for me, if I call home, as soon as I go away, that'll just make me more homesick and sad." On this decision, he continued, "So, I have to [long pause] for me, I have to be out of touch for a little while so I can get used to everything and get used to everything on campus and everybody else." Ten weeks into the semester, he continued to be sensitive to his separation from family, but without allowing it to deter him: "Once I like end the call, I'll have that thought for a second, but then I remember what I have to do here, and why I'm here, not to get too distracted by everything at home and be more focused on my work here." Clearly, Michael perceived a sense of separation in the early part of his transition into college, but consciously answers with a rational and practical solution that not only indicates self-awareness, but also, discipline and 
commitment. Most of his friends from home also went to college, and he waited two weeks before contacting them, as well. Now they talk regularly through group sessions on Skype, which are supportive and assuring. When I asked him about these Skype sessions, he stated, "It's exciting, so that we can--so I can talk to all of them again, and, plan things to do on breaks and just seeing their experiences for college.”

Regarding academic integration, Michael has done well with his adjustment. Although he stated, "I was expecting [classes] to be harder than what they are", ironically, he identified issues with time management as a cause of, and difficulty with, his success. He described these:

In high school, you always had the people that would help you and get everything done and people waking you up for classes, and breathing down your neck for, like school work, but now a lot of those people won't be here, you can still find a few of them here but it's mainly on your responsibility. We have to get used to doing everything on our own now with schoolwork.

He continued and shared some of his success:

At first it was difficult because I always had these people to keep reminding me of everything but now I'm being better about it because--pretty much my entire side of like my dorm room has sticky notes everywhere reminding me about [laughing] everything, its like this homework for this class, this meeting, and all of this stuff going on.

Formally and informally, Michael's social integration had been positive, and had exposed him to new cultures and ideas. Organized efforts have provided him some integration with the campus and surrounding community, and allowed him a feeling of membership. He recalled: 
Last week we did an activity as a building--a trick or treat thing for the community. It was good--being able to dress up and like scare people [laughing] and just seeing little kids enjoying themselves with it and all of us just hanging out and planning for it.

Although most of his interactions and new friendships have come through campus religious groups, such as the Baptist Campus Ministries, and Fellowship of Christian Athletes, his exposure to new people and people outside of his faith had broadened his understanding of others:

One of the main reasons why I came here was because it was a private Christian school but, honestly I actually like it better like this because I'm learning to be a missionary and this can become a mission field, being able to talk to people and getting to know their religious beliefs instead of just telling them they're wrong about what they believe.

Informally, he has also enjoyed his exposure and growth. Because Appalachia is limited in its cultural diversity, he has only met one international student before, during high school. This exposure was greater and more influential for Michael. For him, he stated, "it's [meeting international students] interesting because I get to know them and try to find out more about their culture, and their traditions, and I'm starting to learn Mandarin now."

Throughout our discussion, Michael alluded to a sense of personal growth—assuming personal responsibility and becoming more mature. When asked about what he identified as most difficult about college, he responded that it was, "Mainly just starting to take responsibility of everything that you have to do." Taken in the light that he was initially nervous about "being on his own", his ability to embrace change and assume more responsibility indicates not only an initially successful transition, but also some personal change. These changes manifest in his academic (assuming personal responsibility for time management) and social integration 
(embracing new understandings of cultures and religion). To this he states, "it was a very interesting transition, seeing all the changes that's about to happen, and that's happening now and, like this is going to help me in the future." He perceived his own transition and identifies these changes as, "responsibility, time management, social life changes--getting to know new people."

Lastly, and importantly, Michael perceives himself as a pioneer, and his transition as a first-generation as a way of breaking tradition. "I'm not, like, doing what everybody else didI'm doing, what I want to." This sense of pioneering was further expressed when discussing what it means to break with tradition. He stated:

For me, being the first person in my family to go to college means a lot because--well, with me going to college, I'm hoping that one day, when I get married and have kids, that they will also be inspired to go to college and chase after their dreams and do what they want to do, instead of either going into military or workforce like pretty much all my other family has done. [long pause] They should do--by doing what they want to. When we spoke, it was clear that he was transitioning well into the college life, and that he was conscious of his transition and his personal transformation as becoming "more mature and more as an adult." He experienced some initial difficulties with separation from family and friends, but through practical measures, he was able to overcome them. He perceived college to be a matter of personal choice, and perceived his academic and social transitions as positive, and as means to personal growth. Although it cannot be determined to what degree his experiences have affected his decisions to persist, his commitment was strong. To the challenges and responsibilities he now carries he responds, "it's just motivating me to get it done and just helping me go forward." 
Kayla. Kayla comes from the eastern part of the state where she grew up in a large family of 16 , of which she is the second oldest. As with many people in this region, poverty was familiar to Kayla, and she felt that one way to break its cycle, was through higher education. Stating her motivation to pursue a degree, she stated, "The way society is, I feel like it's almost a push, like you have to go to college if you want to get out of poverty." Her intention was not only aimed at pulling herself out of poverty, but to give back to her community as well. Recognizing the opportunities her own education will open, she indicated that she would like to teach in her hometown because, "They only have one permanent math teacher right now. Every year they get new teachers, then they quit before even half the year."

Kayla was aware of the necessity, as well as the benefits of a college education, but her family's financial circumstances created problems. Inasmuch as she had a desire to move on, as well as her family's support, financial issues created challenges. Kayla's answer to these challenges was to make her own path. She shared, "They (family) asked me if I'd like to go, and I said I really want to but money was an issue, so I studied really hard and ended up getting a good bit of scholarships and have almost a full ride." Kayla was not convinced that she would be accepted into college, but her commitment to pursue and her commitment to [current institution] was evident when she stated, "I had a few other colleges that I tried but I wanted to go here more and if not, then I was going to--I worked two jobs my whole summer, and I was just going to keep that and save up money, and maybe better luck next year [laughing]." In the end, her determination paid off, but for a first-generation student this was a turning point; she was permitted to pursue a dream, but in a direction far different than her family's path, and for many in her community, was historically out of reach. For Kayla, this moment was exciting and filled with joy. She colorfully described her reaction to reading her acceptance letter, "I literally just 
ran back to the house as fast as I could just waving it around kind of like Willy Wonka waving the golden ticket!' Indeed, she had a metaphorical 'golden ticket' and embarked on her new journey.

For Kayla, this was a new experience in many ways. One of which was being physically away from home, "I've never really been away from, like away." Overall, separation from family and friends was not difficult for Kayla. One aspect that may have eased Kayla's transition was the size of the college and its surrounding community. Intuitively, she made a choice early on to find a school that reflected the size and scale of her home community, and one that fit her. She reflected on her friends' reactions to her choice of college, "They were just surprised that I ended up here, everybody in my class was, "woo, [state college], [large state university] [laughing], but I need someplace smaller and quieter." As much as she may have sought a place like home, her experience away from has changed her perception of home and left her with a different perspective. Sometimes, I mean, sometimes I go back home and it's kind of like, 'what is this place?' [laughing]."

Another aspect easing her transition may have been her parents' supporting her moving on with, and moving up in, her life. She recalled showing the acceptance letter to her mother, "When my Mom got home, I showed it to her and she almost cried, she was just so happy!" She also shared a moment between she and her mother when she first arrived on campus:

She was really happy I got to go. She was unpacking my stuff for me and everything. [laughing] she was like, 'Now, being an adult, I'll do this for you and then you're on your own', kind of this last little shove out of the nest [laughing].

Keeping in frequent contact may have also eased the transition through separation for both Kayla and her family. She spoke with her parents at least once a week, and frequently 
"chatted" with her sister on Facebook. These connections allow her to share her college experiences, and provide some reassurance for her family. They were able to talk about, "anything that's going on. Maybe what we did in class that day, or what me and my friends were doing that day, how work is going, making sure my schedule's not too crazy--my mom's really worried about that."

Kayla's lack of difficulty with separation may also be due to making a quick and strong social integration. Proactively, she and her roommate had gotten to know each other earlier and recognized the good fit, "we had talk most of the whole summer, and we're actually really, really close--we connected right off the bat!" Beyond the connection with her roommate, Kayla's social integration was slow, but successful. Introspectively, she reflected, "I'm not very good at meeting new people and making friends right off the bat, so it was kind of nice to come here and see how friendly everybody was and everything." In line with this she again reflected on herself, but also illustrated the strength of positive social integration, "I thought I'd be more--kind of keep to myself, but really, the whole third floor of [her dorm] over there--it's literally a familywe all sit in the kitchen every night, we got a little study group and everything." Her use of "family" demonstrated a feeling of acceptance, of belonging to a supportive group. When I asked what surprised her the most, she mentioned this same feeling of acceptance, "It became a second home really fast, really--all the people--I wouldn't even call them friends, they're family now. It's a really nice place. I really like it up here!” The effect of her positive social integration and its ability to ease any difficulties with separation from home are perhaps best illustrated in her statement, "I hate to think about leaving for Christmas break--I don't want to leave the people!" If she had doubts about becoming a part of the college culture, it appeared that she had made the 
crossing. It also appeared that she has experienced not only a positive social integration, but also a transition from preconceived expectations to a newly found reality.

Academically, Kayla's transition had also been different than she expected. "It's better", she stated, "I thought it was going to be a lot harder." She did well in high school, and found she could achieve without much effort, "I was one of those kids in high school that never had to study, never had to study for the ACT or anything like that, I just knew it." Consequently, this may have not prepared her for the personal management aspect of academic integration, and she noted that "time management is definitely crazy." This was understandable when considering that while at college, Kayla also worked at a local convenience store, and with demanding work schedule. She described one scenario:

You know I stay up late at night doing homework, if I'm not working, then I might sleep four or five hours, get up for class and go to work right after, and not get off till 11-sometimes not get off till 5 in the morning, and get two hours of sleep, and get right back up for classes.

Kayla was the first in her immediate, and extended family to break away and pursue her goal of attaining a college education. Unlike other family members, about whom she said, "They wanted to go, but there was always something that stopped them or they decided against it or just--they didn't want to", she remained committed. This notion of being a pioneer and its importance was not lost on her. About her experience she stated:

It was something completely different, something nobody else in my family ever experienced it so it was kind of like 'okay, I'm the test subject now, like 'what's it going to be like'--like my experiences are going to reflect on everybody else. 
Ultimately, Kayla's transition has been a positive experience, and when asked about how she felt about returning for the next semester, she stated enthusiastically, "I'm excited for it!"

Krystal. Krystal is the oldest of 4 and lived with her mother and father in the eastern, central part of the state. Her hometown is small and rural, with a fifth of the population living below the poverty line. From an early age, Krystal's parents, impressed upon her the value of a college education, and when she shared with them her interest in looking at colleges, it came as no surprise - from her parents' position, it was, she said, "not an option.” Because of her abilities, and her accomplishments, she knew it was likely that a college education was not only in her future, but that she was directing the course of her future, "I kind of knew, but it's still exciting, knowing that I could start my future."

For Krystal, her intentions for moving on and attending college was as much about her own future as it was about her family's future. Recognizing a difference in the career options of those around her, and her own ambitions, she understood that a college education was her best path. "I was definitely going, there was no other way. I don't want to do manual labor my whole life, or have to work at McDonald's or something, so I just decided that it was probably the best option", and beyond her own interests, she considered the needs of her family:

My mom and my siblings--I feel like they're going to need me one day, so I need to do something good--just in case something happens to my mom--so I can take them in. That's my biggest pusher, for sure.

This sense of empowerment and responsibility towards her younger siblings was evident when she stated, "I'm definitely like 'Mother Hen."”

To achieve her goal, Krystal worked hard throughout high school; she accumulated a high GPA, scored high on her ACT, and was awarded a state sponsored scholarship towards 
college. Although she prepared a path of entry for herself, a lack of knowledge about the application process, and all of its details, remained an obstacle and a source of frustration for her and her family, "I mean it's definitely difficult--way harder than I thought it would be. I didn't have help doing anything, like I remember just nights where I would just sit and just break down because I--I had nobody to ask."

Krystal recalled turbulent experiences with her mother during that time:

My mom had no clue. She tried to help me, and it was a horrible time. We ended up fighting about it probably at least five times before I got everything done and decided where I was going. It was difficult, that's for sure.

As much as her mother knew that college was a necessary step in Krystal's future, she was unprepared to assist. Krystal continued, "she wanted to help me so bad, but she just had no idea how. She had not been through it, so, she just--there was nothing she could do.” Krystal was determined and undeterred by these early difficulties, bolstered by her own commitment, but also with the support of her family, "I pushed myself to come and my family definitely pushed me too." In the end, it was this support of her family combined with her own commitment, "I was definitely going, that there was no other way", that helped her persevere and left her feeling empowered and moved to assist her sister in ways that her parents could not help her. Fulfilling the role of 'mother hen' she self-identified with, she proclaimed, "I'm definitely really going to be there to help my sister, that's for sure. She's not going to have to struggle like I did."

Drawing on the theme of not having a collective past experience to draw from, Krystal recalled her feelings from when she contemplated the idea of actually leaving going away to college: "I was excited and nervous. I guess I didn't really have anyone to tell me that it was going to be okay because nobody had been through it." She continued, "I almost--I didn't really 
talk myself out of going, but I just kept saying, 'is this the right decision? Am I sure this is what I want to do?' because I was going to take a semester off." When I asked about what it was that was making her feel nervous. She replied, "I don't know. I guess being away from home.”

Perceptions of separation from family can affect a student's commitment to persistence. These can be of a direct nature, such as the student finding it difficult to be away from family, or indirectly, as in Krystal's case. For her, it was her mother who was having difficulties, and indirectly, this affected Krystal. Although she promoted and supported Krystal's education, and was excited by the news of Krystal's acceptance, her reaction was more revealing. Krystal described her mother's reaction upon hearing the news, "She was upset—she wasn't upset that I got accepted-she was upset that that--because I'm the oldest, so, I'm the first to go. She took it really hard." Later, when they arrived on campus it continued, "she just got upset, and-especially on move-in day, she was a basket case, crying the whole time." Krystal attributes this to a tradition of families staying within the community and close to home, "she lives, probably five minutes from her mom, so, you know, never really had to leave my family before", although it could also be due to their close relationship, "we're like best friends." Regardless, it had an effect, "My Mom, she was upset, so that kind of tore me down a little bit."

Concerning difficulties with separation, Krystal was self-aware, and this affected her decisions regarding location, and types of college communities that might be best for her. After ten weeks away from home, her statements indicated that her insight was correct, "even just being like 45 minutes away, it's still hard because I've never been without. So, I like to go home every weekend. I don't think I could have lived any further away.” Even though she was relatively close to home and visits frequently, Krystal has constant contact with her family. She talks with her father "maybe twice a week", but between her mother and her, they text each other 
daily, “we just talk about everything. It's never really about school. If I have a problem, I'll tell her, but usually, it's nothing about school. We just talk about normal, everyday stuff." Most likely easing difficulties with their separation, these conversations also provided some emotional support for Krystal, "I usually try to talk with my mom, even though she can't help me, she listens."

The effect of small town life, and tight communities was not lost on Krystal, and she felt her choice of a small college in a small community was the right decision. Along with her commitment to attaining a college degree, was Krystal's commitment to this particular institution, "I got accepted everywhere, but I chose to come here.” Introspectively, as she understood herself, she felt that a college and community that more closely resembled her home would be a better fit for her. Although she was accepted, and had even registered for classes at a large state university, she ultimately withdrew and redirected her energy to attending her current university. She explained:

I wasn't ready for that. No. Especially going by myself from a town of, I mean--there's not even a stoplight in my town, so going by myself somewhere that's like thirty-plus thousand students--I couldn't even [laughing] think about it!

Her thinking was understandable; with no prior knowledge or experience to draw on, it was difficult for a first-generation student to predict the college experience, regardless of size. Her expectations, based mostly on media, thus, are likely to be different than what she realized. She explained her thinking,

It's so laid back here, and I love it, but I expected it to be, I guess way different. I just expected--I know it's like a 'dry' campus, or whatever, but I expected people to be a little more wild than they are. I'm glad it's not, but definitely expected it to be a lot different. You just see all 
the movies about college. How the sororities are crazy and stuff like that--that's not how it is at all here.

As it turns out, this was a good decision for Krystal. When I asked if this was a disappointment for her, she replied, 'No! I'm glad! Like if I would've wanted that I would've stayed at [large state university], that's for sure!"

In spite of a lack of wildness, Krystal's social integration had also been without difficulty. This was, in part, due to having her best friend from home as a roommate. For her, this "kind of helped ease my anxiety a little", but looking at her language, having her best friend at her side may have kept her from feeling isolated and alone. Describing her first day at school, she said, "then my mom left, and her mom left, and it was kind of an emotional time, but we got through it [nervous laugh]." Using "we" in place of "I", she continued, "We just stayed up talking all night because we were excited by that time. Yeah, it wasn't bad." Inasmuch as having a friend from home accompany her helped to ease her initial anxieties, it may have also lessened Krystal's need to reach out socially. Reflecting on her social integration, she said:

For a while there, we really didn't have anyone, because we're not-- I'm not out going, she's kind of outgoing, but I'm not, so I don't like to meet new people. I don't like change at all, so it's hard. Everything's a big adjustment.

Ironically, it was Krystal's friend who initiated a wider social scene for her, "finally she drug me out, and we get along with those girls, so we do stuff together now all the time."

Krystal did well in high school, and continues to do well in college. Commenting on her academic progress, she said, "I don't have any Fs or Ds, or anything like that, but I would assume that my GPA is pretty good." Academic rigor was not a problem for her, but rather, a lack of, "I expected it to be, like a challenge, and it's really not yet--I'm sure it will be, but just not at this 
point ... It's just boring--it's all too easy." However, as with her high school experience, and now with college, she had not developed other necessary skills. She described her difficulties with time management and setting priorities, "I don't know how to study, I've never had to, so, it's hard to know how long to study and when I can go out. That kind of thing is difficult." Although she described herself as independent, it was apparent that she recognized that she was in a new position in life — one in which she must make her own choices and decisions. By speaking in past tense, it may be that she had already begun to assume more independence, "I wasn't ready for [laughing], definitely wasn't ready for someone, you know not to be on my back all the time, telling me, 'you need to do your homework, you need to do this, you need to get this done'."

Krystal knew early on that a college education was likely a part of her future. Without family experience, but through family encouragement, she set out to make that happen. She had struggles, but overall, her transition into college had been positive. Her intentions and ambitions were partly to empower herself, but also to lead the way for her siblings. When I asked her about returning for the following semester, she replied, "Yeah. I'm definitely not going to not finish college--I have to finish. Not only for myself, but I definitely don't want to disappoint my family. There's no way."

\section{Braelynn.}

Braelynn first considered attending college while in a mentoring program in her senior year of high school. Her family not only supported the idea of college for Braelynn, but her grandparents had established a college fund for her. However, they all allowed her to make her own decision: "they've always been leaning more towards going to college, but they were okay with whatever decision I made." The decision for Braelynn was not always clear, but the factors 
affecting her decision were pragmatic and reflected an understanding that cost of college was not something to take lightly. She explained, "up until about senior year, I'd say I didn't want to go to college, I don't know what I want to do, there's no point in me wasting money until I figure out what I want to do." After considering her parent's life, she knew that a college education was, for her, a path out of poverty. Reflecting on her mother and her stepmother's life, she described the difficulties of not having career options: "My mom doesn't do anything with her life--she's always just working from job to job to job, and my stepmom didn't go to college but she has a pretty steady job, but it's still hard for her." She continued, "I just want be able to go do something if I want to go do it, and I don't ever want to have to struggle, I want to be able to be financially independent, on my own.” Braelynn was clear to note that she had not lived in poverty, but it was apparent that she saw in her family a lack of career options, and a lack of security. Braelynn decided on a career in nursing and began looking for schools. Not seeing the value of a college education while a high school student resulted in a low high school GPA, which worried her, but she applied regardless. She was ultimately accepted, she and her family worked out a financial strategy, and she was on her way.

Regarding separation, it was clear that not only being away from her family, but being on her own, also concerned Braelynn, "I've only been to like 4-H camps, that was like a week from being away from home, and it was just weird to come [to college] and know that I wasn't going to be going home for a while." And it was weird enough for her that on her first night on campus, she called her grandparents and asked if she could leave and stay with them - they would have none of it. She described the conversation:

I still wasn't really comfortable being here yet, and we got back to our dorm and I called my grandparents and told them I wanted to come stay with them and they wouldn't let me 
come, they made me stay — at first they said 'call me back if you decide you're going to come' and I called them back and they didn't answer the phone.

Perhaps understanding her nature, and believing that she needed immersion into school, her grandparents applied some "tough love" and it ultimately worked. Later in our discussion, Braelynn implied that she has overcome her need to be with family, "I try to go home-well, I work at home--so I almost go home every weekend, and sometimes every other, but I don't stay at home." Even with her friends from home, separation has not only been without difficulty, their conversations have been reassuring. She described these, "we still like talk here and there, but not like what we did in high school" and continued with an example of how she and her friend share experiences:

. . basically, just seeing how each other is doing. One of my friends, her name's Bethany, she went to [local university] and I was explaining something to her and she was telling me about how she had almost the same experience, so [quietly] we just talk about stuff together.

For Braelynn, separation was an initial issue, but with time, she became comfortable on her own, and without being with family. As she said, "it just made me nervous because I knew I was growing up. It's just a big change.”

Braelynn's roommate was also one of her best friends from home. This may have eased her difficulties with separation from home, but it is not clear how it may have affected her social transition into college. She described herself as a "confined" person, and stated, "I don't talk to many people." Although she was from a small town, and on a small campus, the social transition was new for her: 
It's a big change to be here with people, running around the hallways, everybody trying to come talk to you and I'm like 'I don't know you, you're talking to me right now?' It's a change from growing up to knowing everybody from the time that you're in kindergarten.

But Braelynn gradually made her transition and has come to be open with new people, "I met more people, talked more, and got comfortable with other people around ... I talk to a lot of people now." What was not clear was the depth of her social transition. Inasmuch as she talks to people, and may have made friends, Braelynn still goes home every weekend for work and visits with her grandparents once per week as well. Adding to this was her admission that she does not feel as if she was missing anything about college while being away, "the only thing I'm missing is football--so far the football games, and I don't like football, so I really haven't missed that much, I don't feel like.”

Academically, she attributed some of her difficulties to growing up in a small town: I guess from where I came from is such a small community I don't feel like I have as many tools as a lot of the other people. Yeah, like I don't--like history is one of my really bad subjects right now, and I just didn't really learn anything from any of my [high school] history teachers ... So, I feel like that's a weakness and just coming from a small community I feel this. I had a class of 12-15 compared to some people who had big classes--who had lecture--and I just did worksheets all the time.

Ironically, it was these same teachers that told Brianna of the difficulties that she would face in college, and astonishingly, that she would not do well. For a period, she did struggle, but she pushed herself back on track, "I started failing a class [laughing] and I decided I needed to do better." She recognized her responsibility in her academic success in two ways. First, she needed to adapt to the college classroom, as she stated, "my biggest problem was learning the teachers' 
teaching style ... like lecture is a real big thing for me because, like I said, we always just did PowerPoint and I did worksheets on what we just learned." Another was her own organization skill:

it's just hard for me to be like 'well you have to do this cause it's due this day' ... I don't have very much time management because I'm like 'oh I have time, I don't have to do it right now' and I really do need to do it.

In spite of how college was portrayed by her former teachers, Braelynn attributed some of her success to the qualities of her current teachers, "my professors have not minded helping me get caught up, if I have a question, just stay after class or make office hours, and that really-really surprised me, that they were so helpful."

Braelynn understood that coming to college involves a transition, and that with time, things become easier. She recalled conversations with friends who were having doubts about returning, and described her counsel to them:

I'm like, 'well everybody's had a first semester because that's like what most people say, it's like they worry ... I tell them 'come back next semester and if you still don't like it next semester, then don't come back next year.'

Jesse. Jesse's story was interesting because his inspiration and initial intentions, his "driving factor" for attending college were solely sports related. Starting at around 12 years old, he recalled, "I always watched the college lacrosse games and I wanted to go and be one of those players. I wanted to play at the next level.” This was his inspiration and founded his commitment, "I was like, 'Yeah, I'm going to do what it needs, do what I need to do in order to get to college."' Jesse's commitment to play lacrosse in college was not only a driving factor, if he could not attain a scholarship, he felt a college degree was not worth the cost, "if I hadn't 
gotten a scholarship, I don't think I would've came to college, I would've gone straight into work. It was all or nothing, either go to play lacrosse, or I wasn't going.”

Jesse did not directly experience difficulty with separation, but experienced it indirectly, through his mother. He recalled when he left for college that she was having a hard time, which he described as a bunch of crying. As Jesse understood this, "She was just flippin' out, because I was the first one to go to college in the family", he also shared with me that she and his father had recently divorced, and that Jesse felt some responsibility to keep things together at home. But for Jesse, his lack of difficulty with separation may be due to his not feeling as if he has really left. With his GPA and entrance exam scores he had his choice of schools, but location was a primary qualification. His biggest concern when applying was, "Just making sure everything fell into place in order so I could come here, because, I didn't want go to far away from home." Explaining that this was because he liked to hunt and fish, he noted, "I'm literally like thirty minutes from the house, so like whenever I want to leave, I can just go home.” It may be that Jesse continued to feel connected to home - he and his mother text each other daily, and he goes home often, which he described, "It's good--I mean it's [pause] because they're not long extended periods of time where I'm gone, we don't really skip a beat. I just come back home, and [it's] like nothing has changed."

Another factor that allowed Jesse to feel connected to home was having his best friend as a roommate at college. This had provided some comfort and security for Jesse during his transition. He told me about his first night on campus, which for many students, has a strong impact:

It was just us, and we didn't know what to expect, but I don't--I think it's just because were so close to home, we know that it's there. [long pause] So, it really wasn't a big deal, 
and it was pretty much like any other night because it was pretty much like spending the night at his house, only it was like our house now.

His statement indicated some security with have a familiar person with him, but also indicated an awareness of change - an awareness of transitioning into the college life.

Jesse also did not seem to have difficulties with being away from his friends from high school - most of who went directly into the workforce. When he was home, he did not seek them out, but prefer to spend time with his family. "I only have a weekend, so I want to spend it with family. I'll stop by every now and then, or if I see them, like in a store or something." He indicated that he does keep in touch with them - mostly through text and Facetime, but because they don't have a common experience with college, he keeps the conversation centered at their interests. Jesse described the nature of their communications: Just how their work's going and [laughing] how much money they're making, and like how lacrosse is going here. We don't really talk about academics just because it's like, school, but athletics and stuff we'll talk about, especially the girls on campus, and stuff like that--we'll talk about that [laughing].

Jesse's social adjustment was slow to start, but has been successful. Initially, he spent his time solely with his best friend from home or with his teammates. When he was not visiting home, he and his roommate would travel to a nearby city to spend time with high school friends attending college there, and in his spare time the two of them would be out "hitting baseballs." Jesse reflected on his social transition and described awareness of his social limitations, his dependency on his best friend, and his transformation: 
I was shy because it was all new, so you just stay in your comfort zone. I feel like-because now it's fine, because I'm out of my comfort zone now, but I'm comfortable because I got out of it, made friends and stuff.

Interestingly, they provided familiarity and comfort to one another, but Jesse and his best friend also pushed each other to widen their social circle:

Me and my friend, we just went everywhere and talked to each other, and that was pretty much it, and then we're like, 'alright, we need to expand this', and so we started talking to different people in classes and stuff, and adapted that way.

Leaving his "comfort zone" paid off for Jesse, and expanded his awareness of the students around him, and the nature of the campus. About this, he said:

Yeah, it's pretty nice, because most people don't really judge you here. You just do whatever. In high school, if you wear a certain thing, or something like that, people judge you but here, it's just--there's so many different walks of life that came here so it's just like everyone accepts everybody, pretty much. So, in that aspect, walking on campus, you could pretty much walk up to anybody and talk--especially since it's such a small college. Jesse's academic adjustment was not difficult intellectually, but with the use of his time. He was initially concerned that sports, and its demanding schedule, would interfere with his academics, but he found that it was largely a matter of self-control. "The classes aren't too bad, it's just changing the way you study and how--spending more time studying than high school." He differentiated college from high school as:

You don't have somebody sitting there, like telling you that you have to do your work, like in high school, your mom is like, 'alright, sit down and do your homework', and you get it done. Here it's just like, 'oh, hey you want to do this?' and you're like, 'yeah', 
because you don't have to ask anybody to do anything. So you're just like, 'yeah, let's go do it!' and you get back and it's midnight, and you're like, 'Oh my god, I have a paper to write or something like that and you're like 'aghh!' [Laughing].

Not unlike many students, Jesse's difficulties with academic adjustment lie outside of intellectual ability and reflect a lack of preparation, and a lack of readiness for independence.

When looking at Jesse's social and academic transition, and his adjustment to separation over time, there was very little change in his overall commitment to persistence and his goals. $\mathrm{He}$ began his journey early in life, and was still on course - he was in college to play lacrosse at the college level. There seems to be no higher ambition for him, and when asked about how he felt about returning for the following semester, he replied, "I'm trying to stay here all four years with lacrosse but, I'll be excited next semester, because that's like when our season is."

Brianna. Brianna grew up in a small town in the central part of the state. She did not have strong intentions for attending college, but she knew that it was a better path for her. When she reflected on people from her community who had not gone to college, but straight to work, she implied that she did not want to be part of that group, "There's a lot of people that didn't go to college back home. I mean, you can pretty much tell, like back home, which ones were going and which ones weren't." As much as she knew something had to change, it was her parents, who provided direction, "I honestly didn't know what I was going to do, and my mom was pretty much like, 'Hey, you're going to college!' Neither one of my parents went to college, so they wanted me to go to have a better future." Brianna lacked strong or even specific intentions for attending college, but she and her parents recognized that a degree would provide her with better opportunities. Her lack of intention was clear, even at ten weeks into the semester, "I mean I was so stuck. I was like, 'I don't know WHAT I want to do with my life' and I honestly still have no 
idea. I just think athletic training might be a place to start, I guess.” Brianna's intentions were not tied directly to a career, but her commitment to attain a degree was apparent, "I'm like, 'oh my gosh, this is going to be SO HARD' and I'm like, 'either way, I go' because if I don't at least have a major in athletic training, then I don't know what to do."

Brianna experienced very little difficulty with separation from family or from friends. Her parents, on the other hand had difficulties, however they did not appear to affect Brianna's commitment. She described the night before leaving for college:

My mom went upstairs to my room, because my room was--I mean I had stuff everywhere, and it was just empty and she kind of broke down on me. [We] woke up the next morning, bright and early, hopped in the car, and it's like the whole way there she was just kind of like sobbing out [laughing], and when we got here, she just didn't really want to leave [sighs] and she told me that when they left, she told me that my dad cried a little bit.

Perhaps this was less about separation, but more about not wanting to let go, but based on Brianna's telling, Brianna was okay, "she was happy, but she wasn't like uber-excited to [laughing] leave me [laughing]." Outside of her integration into college life, the separation between her and her mother may have been eased by their constant communication. Brianna stated that she texts her mom often, and keeps a friendly, casual conversation, "If it's important, I'll call her, but if it's like, 'oh, guess what happened at lunch today', I'll just text her.”

Brianna also did not appear to have any problems with being separated from her friends, and she frequently corresponds with them using Snapchat (a smartphone application). It's in her description of these conversations that Brianna demonstrated, indirectly, her commitment to college and the value of a positive college experience. She grappled with understanding that two 
of her friends were dropping out of college, and stated about the first, "It surprised me because Logan, back in school was really smart, and was all for college. I don't think he liked it because it was more strict than back home. Like he would actually have to try to do something" and the second "I think it's because she hasn't really had the college experience. I feel like if she would get away from home, then go somewhere, she would be like, 'Oh wow!'”

If Brianna had any difficulties with separation, they existed before arriving at college, were in anticipation with leaving, and they quickly dissipated. She described the transition:

It was kind of sad because I was going to have to leave everybody, because everybody was going to a different school and I came here by myself, and everybody else have friends that-at least, at least one person that went with them to another college, and I was all by myself, but, now I'm here, I'm like, 'ah, this is awesome!

When discussing the upcoming college break, Brianna indicated a lack of difficulty with separation, and a successful social transition into college, "Yeah! I mean people are like, 'oh my gosh, I can't wait to go home!' and I'm happy to go home but I don't want to leave my friends here. I don't know. I've gotten really close to people here.” Further indicating a strong connection, her use of "we" showed her as feeling a part of the social fabric of college as she describes events within her dorm, "Our suite, it's kind of like the place to be, so we always have all kinds of people in there. We're always playing music and dance around, so it's always fun!" As much as it has been fun for Brianna, her social network has helped to provide a well-rounded experience. She described the activities they typically find themselves doing, "We'll get together and go play basketball in the gym, and we have a study group that we all get together in one of the suites and study." She emphatically described the impact that her social adjustment has had 
on her, "I'm really surprised that I like it as much as I do. I don't know why I do. I mean I knew I was going to like it here but I didn't realize that I was going to LOVE it here!"

Brianna's academic adjustment was similar to other many students'; intellectually she was capable, but lacks practice in self-control, "I expected it to be harder, a lot harder but just like the way that college classes are, I guess, some of that, it's really hard and difficult." She continued by describing the difficulties she has found, but in a manner that indicated comfort with her growth, "If you fail an exam, then you're done [laughing], you have to stay up, and study and you have to get all your work done on time, no late work, it's serious [laughing]." Brianna attributed her high school experiences to the difficulties she faced in college, "Some of the things we did kind of relates to this, but I don't feel like I was well prepared for college." She also stated that time management was one of her biggest issues, but had taken measures to correct this by keeping a calendar, "I write everything down, like everything. I have to write it down. If not, I will completely forget about it, and then I just mark it off as I go [laughing].” Her recognition of a problem and her desire to solve it reflected her commitment to succeed, and her belief in herself, as she stated with laughter, "I'm pretty confident in myself. I'm like, 'I can do this'."

Overall, Brianna's college experience and transition had been positive and had expanded her perception of herself and her community. When trying to describe this, she stated, "I can definitely tell that I've changed, but if I was to go back home, when I do go back home, it's just going to be like, 'Hmm, this is different' [laughing]." She continued with her statements, but also illustrated a consciousness of change in her identity:

I feel like when I do go back home, everybody is just going to be sitting around watching me, kind of seeing, you know? They're definitely going to be able to tell, like, 'whoa, 
who is she?' [laughing] you know? But also, I feel like things back home will click, and I'll be like, 'oh, this is what we do', and like 'this is how you act, this is how you'--you know, stuff like that'll click in.

It was evident that Brianna recognized change within herself, and that her role at school was different than her role while at home. She stated that she feels like a role model to her siblings, and no longer saw limitations that once existed:

People back home, they're just like, 'You graduated from [home] county, you stay in [home] county--don't leave.' I used to want to stay back home, I wanted to go to college and come back and just live in [hometown], but now I'm just like, 'I'm not living in [hometown] anymore.'

The transition into college--and the personal transition for Brianna--has been positive. As she succinctly stated, "I feel like coming here is like opening the world up a little more."

Shane. Shane is the youngest child in his family, and grew up in a small town, which significance he referenced by its proximity to the nearest Wal-Mart. His mother died when he was two, and he lived alone with his father, and close to his grandmother. Shane's family had a long history of serving in the military and it was expected that he would choose this for his career, as well. Shane, however, wanted something different for himself, and broke with this tradition. As he reflected on his father's life, he saw that he wanted more for himself, and was willing to break away from tradition, “My dad doesn't have any education other than high school. He doesn't make the money he wants to make, so I thought, 'I'm not going to go into the military, it's not what I'm interested in." He was interested in more for himself, "I decided to go to college to become a better person, get an education, and make more money." The problem was, without any family experience to draw from, he was poorly equipped to make this happen, "I 
Just had to figure out where I was going to go and how I was going to do it." Ultimately, it was sports--and the persistence of college football coaches--that paved the way for him, to college.

When Shane was a junior in high school, he applied to college, but was not accepted. He was motivated by his high school coaches and a mentor teacher to try again. Determination was a reoccurring quality of Shane; he worked hard, raised his GPA and was accepted on his second application. Being rejected had an effect, however, "[it] was just kind of a kick in the butt, you don't want to go through that. I wish I wouldn't have went through that. It just brings a lot of doubt onto yourself." Even after being accepted, which was a turning point for him, “[receiving his acceptance letter] made me realize that it was actually going to happen!" he continued to question his new direction. Shane's determination ultimately won out when he questioned himself, “'am I ready for this?' It's a giant step in your life--you can't be prepared for it, but you try your hardest."

First-generation students are, inherently, pioneers - they are setting off on a course without guidance or experience from family. Another aspect of this group was that they were breaking with family history, which may or may not be celebrated by family. This was the case with Shane, as he expressed, "I think the biggest thing for first-generation students--the transition of your family tradition and then going against it--doing something completely different." For Shane, this resulted in less than enthusiastic support for his ambitions from his grandmother and his father. When we spoke, she was beginning to accept his decision, but failed to share his vision, as Shane expressed, "I wouldn't say she fully supports it, but she understands what I'm doing in life, and I think she just happy to see that I'm happy." This was an improvement from before, and Shane interpreted her reluctance as a hold on tradition, and a lack of understanding of 
the demands of today, "she's old and she's set in her ways in different things, and she believes if your family tradition does one thing, you got to follow it."

Shane's father's reaction was similar, but more self-centered. When Shane shared the news of his acceptance with him, he recalled that his father was initially happy, but Shane was not convinced that it was genuine, "I don't really know if he was fully into it or just supporting me--my decision." He paraphrased his father's reaction as, "basically what makes you happy, go for it and don't let things hold you back in life" but his father's true feelings began to reveal themselves over time. As Shane understood, "there's part of him that still wishes I went into the military but the other part's happy that I went to college to make something of myself" and eventually, "he still says 'you should have went into the military."

When considering difficulties with separation, in this case, the difficulties existed with his father, and indirectly became Shane's. For example, when his father drove him to college, and in the limited times they talk over the phone, his father questioned his commitment:

'You're three hours away from home, is this what you want?' ... he just kept asking me and made sure I want to do this--because he was all ready for me to go home, he just wanted to make sure I was actually committing to this.

His father's work schedule did not allow frequent phone calls, but Shane described the nature of their communications, "he'd call me sometimes and ask me how I was doing and make sure I didn't want to come home or not." Shane understood what was driving his father's reaction:

It's just me and my dad living at home, so he has to go home and really get used to me not being there. My mother passed away when I was two, so after that I was the only thing he ever had. 
This weighed on Shane, "all I really cared about was my dad's opinion" however, he inherited his father's resolve, which influenced his commitment to completing his degree, "he says, 'you got to do one thing one way and not the other' so, if I go to college, I got to stick with college."

Outside of his feelings around his father's issues with separation, Shane did not directly experience much difficulty with separation in his transition into college. Concerning his father, Shane expressed empathetically, an understanding of his father's situation, but has not let it deter his course, "I think that's really hard on him. In some ways I think it's harder on the parents than it is on the students." Regarding his friends and his girlfriend, Shane stayed in contact with them often through texting and Snapchat (smartphone application). He stated that his girlfriend provided support and encouragement. With his friends, they rarely spoke about college, with the exception of sports and girls, and kept the conversation focused on things they had in common.

Shane's social transition into college went well. First, he came to school early with the entire football team. Having a tight schedule may have occupied his mind, but having the team with him provided some comfort. He told me, "You have kind of a comfort zone of being around football players cause they're going through the same thing you are. So you're all going through the same thing at once." This had a positive effect on Shane, evident in his description of their interactions, "So we all got along, started telling stories, which made it easier. You make friends fast and it's just-it's a relaxed place to hang out with people that you don't know." Ironically, because of an injury, he could no longer play. Although he stated that it's difficult for him to lose access to football, it has opened more social opportunities for Shane. As he described:

It's changed the way I've went about my day. Used to just go to school, go work out, never hang out with anybody--just me and school and working out, sports. Now, it's me, 
school, I work out, then if I have time I hang out with people, I talk to people, I'm more social now, and I'm not focused primarily on one thing.

The second aspect that affected his social transition was the nature of the school and community — particularly their size. Having continuity of scale between home and college seemed to ease his transition, as Shane expressed:

I don't like being away from home--I'm more of a homebody, and the only thing that comforts you around here is if you're from a small town, in the country. So it kind of gives you that feeling like you're home.

Academically, Shane felt some initial doubt about his ability. Immediately, he perceived a difference between his experience with high school and that of college, "the high school kind of class and the college kind of classes are a lot different." Consistent with his personality, and his commitment to completion, he focused on his work. He proudly described his efforts on a demanding midterm exam:

We had a four-day accounting midterm, which when I went into it and didn't know what I was doing. Over the four days I had to study during--every time I got done, I had to study more, and I ended up getting a 96, so it kind of boosts your morality [meaning morale]. Shane also attributed qualities of the faculty, in part, to his success, "I'd have to say the biggest surprise of coming to college is how the teachers interact with you." He compared his experiences with those of his friend who attended a large university, and highlighting differences, "he has a class of 250 , and doesn't really get help with his teachers cause they're always busy and they leave right after class. Here you can get help and they stay after class for about twenty minutes to help you." Shane's experience and interaction with college faculty made an impact on 
his academic success and an impact on him, "It seems that they want you to actually shoot to succeed here, instead of just paying to come and they get paid and not care."

It's clear that Shane's father's issues with separation weighed on Shane, but he was determined to complete his education. When asked how he felt about returning the following semester, he stated, "I like it so I'm going to stick through with it. It's not the easiest thing in the world but it's education and it's not supposed to be easy." Consistent with his determination, in general, to completing commitments, he concluded with, "It's kind of one thing you start you kind of have to finish sometimes, once I start things I have to finish them cause I don't want to feel like a failure, so yeah, I'm returning."

Alex. Alex is a student-athlete who comes from a far eastern part of the state where he grew up in a moderately large town of 17, 000 people. There, he lived with his mother and three other siblings, of which he is the oldest. He is close with his family and demonstrated a sense of respect towards his mother understood as an old-fashioned sense of "wanting to do right" by her.

Alex never saw college in, or, as a part of his future. For his family, his friends, and himself, becoming a successful student came almost as a surprise, and reflected a shift in his thinking. He expressed to me, "I didn't think college was going to be a thing for me. I just kind of thought, "I'll just go to work." When Alex discussed work, the image he conjured was that of his high school friends, which he described as a "hard-working, back-breakin' job." After college football recruiters approached him, he spoke with a teacher-mentor, and he began to consider the idea of attending college. Alex said his thinking "changed just like that" and decided that a college education was a good investment of his time and energy, and would provide him more opportunities. He addressed the logic behind his intentions for attending college, "that kind of 
got me into, 'well maybe I should look around to see about the college.' I mean going to college and getting a degree makes it ten times easier to find a job that pays well."

And so it was his football talent that made college a consideration, but, not only was the notion of attending college a new idea for Alex, the process of securing scholarships was also new. Without any family experience to draw on, the process of attaining, or the notion that scholarships were available was beyond him. He explained his frustration, and wished there was "some type of way of me or my mom finding about the scholarships they offered in the school, [and] stuff like that, because I had no clue about any of that." He went on to illustrate a situation common to many first-generation students:

My friends who went to high school, when we had our senior awards, they're getting five, six scholarships, you know, [and] I'm like 'how the heck did you get those?' 'Oh, I wrote a one page essay', 'Well, when did I know about that?'

Ultimately, it was the college football coach who guided him, and he was offered a scholarship to attend.

Although his mother supported his decision, her support was, initially, not entirely enthusiastic. Her response, he said were along the lines of, 'you can go to college, but if you don't, I'm not going to say nothing to you--if you want to, that's great", and "well if you want to go to college, you go." It appeared that his mother was not firm in her faith that he would complete college degree, and urged him to consider other options, "she wanted me to go to like a tech school and do something I liked doing if I'm like not going to go to a four year college." It appeared that Alex was also not firm in his faith in himself. He recalled moments of secondguessing: 
Before I came up here, I always thought, 'am I putting me in the right spot, and my mom in the right spot?' Like, that's a lot of money to fork up if I don't succeed, so, I was always thinking about that, so it was just [long pause] it was always in the back of my head, 'do I--should I go through with this?'

His mother, however, came around to support his decision and his ability, "I actually sat down and talked about it with her, and she said, 'I think you should do it.' She said she knew I could do it."

The support from his friends — his "back-home friends"- - was, at first, also less than enthusiastic. "I don't have many friends that are in college", he told me, and attempted to explain their perspective, "they just--they weren't into school. I mean, they did what they did in high school to get by, but they were these kind of kids" and later, "they only knew a handful of people even to go to college." It appeared that when I spoke with him, Alex had begun to see himself with a different mindset and moving in a different direction than his friends, and perhaps, his former self. He described the nature of their support, "they didn't say nothing too bad, they're just like "well you should probably think about it before you just go and do it." Convincing his friends and communicating in a way they could understand, was his reply in the following exchange: “They said 'well, at first you didn't want to go to college', I was like 'yeah, but I didn't want to stop playing football either."' Alex understood that he had taken a direction different from theirs, but saw that with their friendship, came their support, "we've been friends since we were little, and I've always ran around with them, and they're like, 'if that's what you want to do, then it's a good choice." Their support increased, and he proudly told me how he and they reacted to the arrival of his acceptance letter: "we all took a picture with my acceptance letter 
and put it on Facebook!" In the end, it was his same "back-home friends", along with his mother who helped him pack and brought him to school.

It was clear that Alex maintained a close and loving relationship with his mother and his friends. Describing move-in day, before they left him alone at school, he said:

My mom, leaving, she was having a rough time. She always, I mean, anything I do, she's always had that sympathetic look in her eyes, you know [long pause] it was kind of hard seeing them go, but I knew that they liked, they liked that I'm here.

Having their support seemed to ease the transition for Alex, and when we spoke, he did not appear to have difficulties dealing with separation from his family, nor from his friends. $\mathrm{He}$ had been able to return home a total of five days since arriving, which was comforting, but also seemed to highlight a difference in his new knowledge and that of his family. "Being the first in my family to go to school, it's like, they're always like when I come home, 'how's college?' you know? Everyone asks me that. I'm just like, 'it's college', and they're like, 'what does that mean?' Further highlighting his new knowledge and their preconceived idea of college-likely influenced by popular media — he continued, "and I have to go on this talk about what I do, you know. They just ask me the stereo-typical questions, you know, "parties", and I'm like there's not even parties like that at [current university]" In the same vein, when discussing interactions with his friends from home, it seemed that he perceived a sense of transformation, but did not want to appear different from who he was to them, "Sometimes we talk about college stuff, but not that much, I mean, because they've never been, so they don't know what it's really like, but they ask me, sometimes, and I'll just answer the questions they ask." Conscious of his new role, and that others are paying attention to his journey, he was calculated and careful. "I went home and told 
them how good I was doing, they were really excited. [It] put a smile on my mom's face, and that's what I try to do."

Although he did not have many opportunities to return home, he has kept in contact with his mother and his friends regularly. His mother called him about every night to check in and remind him to stay on task. As he described the calls, "She's making--keeping me in check, making sure I'm doing everything I'm supposed to be doing." Although they talk only a couple of times a week, his friends text him daily, and this contact was important to Alex, "it means a lot that they try to stay in contact even though I'm not there. I mean I knew my mom would do it, but my friends-- I would've thought they would, but it surprised me that they actually do.” The support from his friends was encouraging, and although they are physically apart, the difficulty was not enough to deter him. Alex demonstrated faith in their friendship, and was committed to his future in college:

I always had that feeling like I even have now, I mean my friends are back home, but you know, I'm always going to see them when I have breaks and stuff, but [trails off], you know, just, this is--I feel like this is worth--it's worth coming. I mean my friends are always going to be there if they're going to be real friends.

Another factor that eased Alex's transition to college was having high school football teammates as suitemates. As much as they may have helped with any separation difficulties he may have had, and eased his transition into college, he has been able to branch out as well. He described his social transition:

I thought I was going to stick with the kids from my high school, but I've met multiple people that I'm now friends and it's been pretty good. I never thought that I'd be hanging out with someone I never knew at the beginning of the--when we first moved in, but I 
hang out with a person I just met--what ten weeks ago so, it's pretty good, you know, I like it.

Alex had found that in spite of it not being a party-school, the small size of the college eased his social transition, "it's like a high school--my high school's bigger that this school ... I mean you know just about everyone, so, it's a fun time."

Academically, his transition was not without difficulties, but required Alex to examine his skills and strategies. This came as a surprise for him:

I got to sit down and actually have to study, I can't just walk through class, write a paper in fifteen minutes and it be good enough to get a B and pass it on. You have to actually sit there and do work when you could be out playing video games, or something like that, you actually got to sit down and do it, and study.

Being aware of how he applied himself in college, from how he applied himself in high school had been effective, "I feel like that now I actually do sit down and take time out, I'm doing a lot better than I was in high school because I actually sit down and give it time.” Recognizing his situation and changing his approach with academics helped to erase some of the self-doubt he had and left him feeling good about himself, "I didn't even get a midterm deficiency, so, I was really proud of that."

Alex was invited to college because of his football skills, and was able to attend with some financial support from his mother. He struggled with getting emotional support from his mother and friends, but ultimately they came around. For Alex, separation was not difficult in the sense of physical distance, but he recognizes another form of separation - a separation from his former self as he transitioned into a college student. He was aware of this when interacting with family and friends from his past, and adjusted accordingly. He was also aware of how this led to 
his becoming a role model — a responsibility he carried with pride. Talking about his mother, he said, "she's told me this before, that she's glad to see that I set an example for my brothers. Yeah, my mom said that, so that kind of made me feel good."

Sandy. As with so many people from this rural region, Sandy identifies a specific county as her home place - this was understandable in a region of so many small towns. Her specific town is an unincorporated community located in the center of the state, so small that an Internet search reveals only that it has a zip code and a post office. She grew up there as a middle child of seven with both of her parents. Currently, her three older siblings are out of the house and unemployed.

Sandy perceived herself as an intelligent person and felt that a college education would lead to greater independence and empowerment:

I like to provide for myself, so I just figured that I didn't want to depend on someone else to provide for me if--I'm not sure if I'm always going to have someone to provide for me, so I'm going to make sure I had a way to provide for myself.

Beyond this, her intentions appeared vague, but aimed towards employment, "the way I look at it, there's better jobs and there's more a guarantee if you have a degree.”

Among to her attributes, Sandy was an athlete, and it was because of this that she was able to attend college. Once she realized that sports could make college a reality for her she began searching for opportunities, "so I was thinking, 'yeah, if I could just get a couple scholarships, it should be no problem.'" It was clear that she was eager to attend, but difficult to determine Sandy's commitment towards her current college, "I knew I wanted to go to college, I just didn't know where.” In truth, she was offered incentives from another college and was prepared to commit when, as she said, "[Coach] got a hold of me and he was like, 'well, we're 
really looking forward to having you here. It would be awesome, we've never had a pole-vaulter or anything like that before', and then he gave me a better offer, and all my schooling here was covered." Of course financial incentive may have influenced her choice to attend, but it was the scholarship and that [her current] college was small and located in rural community—a factor that provided familiarity for Sandy, "I decided this is kind of where I wanted to go ... I really liked it here because it was like back-home: there was mountains, small town.” As comforting as familiarity was, without a college sports program, and its incentives, Sandy's commitment to persistence did not appear strong. When asked about returning the following semester, she hesitated, and replied, “I don't see why I wouldn't come back, just because it's all paid for, I'm getting a good education, I'm still in sports, so, I mean, I don't really see too much of a reason to leave" and followed with, "So, yeah, I think I'll probably be here all four years, I mean, at least, that's what I'm going with for now [laughing]."

Some explanation for her lack of strong commitment may stem from her separation from home, and ironically, the demands of the college sports program. Sandy's parents supported her decision to attend school, however, she stated that she was initially concerned about their reaction, "When I told my parents that I wanted to go to college, I really didn't know how they would take it, but I'm just really glad that they were excited for me and wanted me to." Indeed her parents were excited, but it appeared she felt her father was more encouraging of her branching out, while her mother was a little more reserved. Recalling her father's reaction, she stated that when she announced her acceptance, he immediately called her grandparents, and proudly shared the news. Regarding his support, "My dad was always like, 'I know--I know you can do it. You know it's not that big of a difference. You have to study but I know you can do it!" Complicating the separation issues for Sandy were her mother's issues of separation: 
My mom [pause] my mom, she's happy for me. She just--I guess she didn't really want me to leave just because I was the first one to go out of my house and be away, so, she's just--I think she's happy but worried, because she didn't know how to react.

Additionally, there was her little sister, who she stayed in touch with most often, and whom separation from was difficult. She described their long distance relationship:

My little sister asked if she could come and stay the night with me in my room and I was like, 'Yeah'. She really misses me. She--she's probably kept in contact the most.

Everyday, before she goes to school, and after she gets home she always messages me. She's like, 'how you doing? I love you. I miss you. When are you coming home?' And that's probably the hardest.

Sandy's home was less than two hours away and when I asked her what she saw as the most difficult aspect of college, she responded, "probably not getting to see my family. Just because every weekend we're away somewhere." Ironically, it was sports that brought her to school and it was sports that keep her from visiting family. She described the intense and demanding sport schedule, but rather than perceiving it as stealing away her academic time, she sees it as taking away opportunities to be with her family. She stated:

This weekend we're going to Indiana, and I'm not going to be back until Sunday morning-and it's a two hour drive there and a two hour drive back, that's four hours, so plus you got to sleep and eat, so it's like you maybe see your family for like two hours and you have to turn around and come back. So, that's probably the biggest thing. I'll see them on Thanksgiving, and then Christmas, so hopefully it won't be too hard coming back. Sandy recognized that being first-generation left her without much guidance: 
I was trying not to worry about it, because I really didn't know what to expect. I didn't have any elder siblings or anyone who had been to college before me so I didn't know how much different it would be. I didn't know if I'd have a lot of trouble or anything like that.

It was clear that she understood herself, and her connections to home. Before summer was over, she anticipated problems with separation, and so in a proactive way, she made a plan to ease her transition away from home:

"I kind of prepared myself and I started staying away from home more to see--hopefully, I wouldn't get homesick, and that went pretty well. It was to a point--my parents were like, 'are you coming home this week', and I was like, 'yeah, I'll come home and see you guys!' I tried to get away earlier and, just help me with the transition. I tried to stay with friends and stuff like that to get used to it.

Sandy was conscious of her situation, and knew that she needed to withdraw from family: siblings, parents and grandparents. Her statements regarding staying with her grandmother, "well if I go there it's just like being at home", indicated that she was conscious of a need to change. Sandy was perceptive to her separation difficulties and understood this was a part of her growth: I'm going to have to get over it eventually, because I'm not always going to be at home. Eventually I'm going to start my own life, so might as well stay here and tough it out [laughing] and get used to it.

However, the large amount of time she spent discussing her separation indicated that there remained more growth to go.

Sandy described herself as "naturally smart", however, she anticipated some academic difficulties before arriving, "I kind of psyched myself out and I was like, 'I'm not going to be 
able to do it, it's so hard, it's going to be so hard." When we spoke, however, this appeared to have resolved, as she stated, "I figured classes were going to be way harder." Paralleling this progression was her perception of the formal academic structure. This was evident in how she described the feelings she had before and after attending college. Before attending, there were feelings of isolation and vulnerability, "I just figured nobody was going to help me, like I was just going to be on my own", and after, more comfort and security, "the teachers are--most teachers are willing to help you if not then there's a tutor . . so, it's actually way better than I thought." Perhaps this came from being aware of her lack of preparation for college level coursework. High school came easy for Sandy. About this she claimed, "I don't have to apply myself much", and "I could probably pass high school without cracking a book." The lack of challenge for her may attribute to her inability to focus and manage her time effectively. When asked about what she would change with her college experience, she stated:

Probably how much time I put into things--I do a little bit of this, a little bit of that, and so, just focusing on one thing and getting it done, and moving to the next. I'm kind of like everywhere. Sometimes it's frustrating and stressful. So, probably putting more time into one thing at a time instead of several different things.

Although she did not attribute her academic problems to being a first-generation student, when asked to tell me about being first-generation, it was apparent that they fit. Sandy stated: I just feel like it's a lot harder just because you don't have anything to go off of. You don't have parents to tell you how hard it's going to be because they don't know, they just go by what everyone else tells them and you don't have any elder siblings that--if you're having trouble with a class, you can be like, 'did you have this class?' or 'did you have problems with it too?', and get their advice on what to do about it or anything like that. 
Perhaps more collected experience from parents and siblings would have eased her transitional stress, and made Sandy's academic integration smoother.

Outside of missing and feeling separated from her family, Sandy's social integration was without difficulty, but did not appear strong. She did not mention making new friends, and her friends at college were her friends from high school: "a lot of my close friends actually come here." Old friends, close friends, and strong pre-established bonds may provide some comfort and help to reduce initial anxiety during the first days of college. She described feeling bored during her first week—before her roommate arrived—when a one friend texted her to "hang out a little bit." He introduced her to his suitemates, they watched a movie and, "just every night we'd go eat dinner together or we'd go eat lunch together, so it was kind of--it was a way to keep company, I guess." Sandy's lack of enthusiasm diminished as she voiced the positive influence these friends provide, "we're familiar so we kind of hang out and just talk over what we do and if another one needs help the other ones try to help them, so it's actually been a cool thing." Inasmuch as her existing friend-set provided comfort and support, such a group may prevent a perceived need for more social integration within the college. It was difficult to determine if she was responding to or projecting, but when asked if college was the way she expected it to be socially, she replied, "I just figured there'd be your different groups, kind of like high school-everybody groups themselves off with who they're familiar with, so yeah, it's pretty much what I expected." Later, she indicated that she had reached out to some degree: "I mean, it's not like, 'Oh you can't be in our group because we don't know you', if you actually start talking to someone else and you get to know them they're just as friendly" but her overall emphasis was not on making new friends, and not representing a strong social integration. 
Kathleen. Kathleen is a quiet and artistic student, who appeared to be contemplating more than speaking. She comes from a border town of moderate size, located on the far western part of the state where she participated in theater and choir. She is the youngest of seven children, all of whom are either working blue-collar jobs, or had joined the military. Both of Kathleen's parents have high school level education, however, she never mentioned her father-only her mother, who she considers her emotional support.

Although she did well in high school, her decision to attend college came late for Kathleen - November of her senior year, and seemed to come from a desire to rise out of the frustrations of financial insecurity. When asked how she came to make the decision to attend college, she said:

I saw a lot of my family members ending up jobless, not a lot of money, and I wanted to have more out of life than to always having to ask other people for things, and I wanted a stable foundation.

Although she had a backup plan to work as a model, she knew even that was unreliable, and without any particular career goal, she put her focus towards college: "I didn't know what I wanted to be, I didn't even know if I was going to go to school or anything. I just knew that I had to get a good--I don't know--a good future?" For Kathleen, she felt an uncertainty or insecurity she ascribed to "family things." She stated, "There was a huge doubt that I wouldn't get any scholarships or that I would even get accepted to any school." She was accepted and because of her high GPA and test scores, she was able to receive financial assistance. This was a great relief to her mother, who although demonstrated support, also continuously conveyed financial concerns. She described the day her acceptance letter arrived: 
I was opening it and I was crying because I was afraid that I didn't get in, but as soon as I opened it, like tears started pouring out when I read it because I was really happy, and then my mom--my mom when she saw me, she asked what was wrong, and then she started crying when she read the letter as well. And then, we opened the packet, and it was a huge emotional mess for both or us because we didn't realize that I could have gotten any scholarship from them.

Ironically, the impetus, and the hurdle for Kathleen both stem from financial issues, and if it were not for her academic efforts, she would not have an opportunity to break free-she would have been stuck.

Issues of separation for Kathleen began after her high school graduation, and they were mixed:

I'm getting more and more anxious. I'm starting to fear going because it's something different, something I'm not used to, but at the same time I'm super excited to get out of the town that I was from ... [big breath] and when a week comes before it I'm ready to go, I'm finally ready to go. But before that it was like the most stressful time ever because I was afraid to leave what I'd already found.

She anticipated missing home and the things she came to know and as she described them, it was clear that this separation still affected her: "the theater programs there, all of my friends were there. There was this little girl that I used to play with. A lot of things like my family, my friends mostly, though." Like a bad relationship, the value of leaving was countered with the comfort of familiarity. The night prior to leaving, she couldn't sleep, "I was just so anxious I started crying, but then I finally got some sleep and when I woke up, I felt like a new chapter was about to begin, and I was determined to leave, [softly] that's basically it." 
Upon arriving on campus, things started falling in place, partly due to her best friend, who arrived on campus a week earlier. Having him by her side made her initial transition "comfortable, in a way, but also very new", and Kathleen soon found a sense of freedom and empowerment, "I felt like I finally had decisions I could make on my own." One of the decisions she made reflected a recognition that she needed to take some control over her feelings of separation in order to establish herself in her new community. To that, she resisted contacting her mother and friends:

I thought it would be easier to detach myself from them for the first three days because I didn't want to be reminded that I can't see them for a while and those first three days I had to form some sort of founding, so I didn't text them at all.

For Kathleen, it was difficult to know if this strategy worked. She had made friends and participated in college life, but she expressed difficulties with separation. When asked what was most difficult about her experience—a completely open-ended question—she stated, "The most difficult thing? It's still really difficult being away from home ... my Mom and my cats, it's really difficult to be away from them." At the time that we met, she spoke with her mother every couple of days; however, she found it difficult, because she felt that when she tried to explain things, "they don't exactly understand."

Making her separation more complicated, Kathleen sensed financial tensions from home: "My mom always feels like I'm asking her for money even though I'm not [laughing sigh] [long pause]. I try not to bother her because I know it's really stressful back home." She was cognizant of her mother's financial problems, which created some of the stress Kathleen felt with college, and although she talked around it, possibly feelings of guilt. When she described the source of 
some her stress she stated, "my Mom's really pressuring me on this one too, cause—I know she's not financially stable, and she's paying my tuition instead of paying the bills, sometimes."

The social integration for Kathleen had been a positive experience. Some of this can be attributed to having her best friend attending school with her, but it was also through her own self-awareness and efforts. Perceptively, she stated, "I'm always going to feel some sort of distance cause that's just my personality, but I'm closer to a lot more people here that I thought I would be." She continued, and underscoring Tinto's emphasis of the interactivity between student and institution, stated, "I didn't think that you could find so much support in a small place, because in high school I'd been so bullied, but there're so many nice people here, it's so different, so much more relaxing." Inasmuch as Kathleen may be quiet and distant, to leave an institution in which she felt bullied and to arrive in one of support must have a profound effect on her sense of belonging and fit with the college.

Kathleen pulled herself out of a financially strapped life with few options and charted her own course. She understood that a change needed to happen and against self-doubt and uncertainty, took a chance. About college and her choice to attend, she said:

It's scary at first, but it's actually a great place. It's a great experience-it's one of the best, actually. It's a little stressful because you're the first person to actually make something happen, but in the end it'll probably work out ... that's advice to myself, by the way.

Although she struggled with issues of separation, it appeared that she felt that she made the right choice and was committed to completing her degree, "This is definitely the right decision to make ... the struggle's worth it." 


\section{Chapter V-Discussion}

This chapter synthesizes the above findings as a collective. It reflects the findings through the lens of Tinto's (1993) model (separation and adjustment), as well as new discoveries that resulted from the analysis.

\section{Separation}

The analysis of interview transcripts revealed that issues of separation vary greatly among the participants. Some students became aware of difficulties once in college, and others had anticipated difficulties that had not come to be. A deeper analysis revealed that these issues could be considered direct and indirect. Indirect difficulties with separation are those that are held by significant people in their lives but not by the participants themselves. Direct difficulties are those that the participant was experiencing. For this group, both existed. For Jesse, Shane, and Kathleen, the weight of their parents' difficulties appeared to affect them.

Jesse, whose parents had recently divorced, expressed a sense of responsibility to his mother, and to continue his role of "man of the house", as expressed in the dialogue below:

Jesse: So, it was pretty much like getting my stuff together, and mom trying to cope with it, because she was a mess [laughing].

Researcher: What's going on with mom?

Jesse: She was just flipping out, because I the first one to go to college in the family. Researcher: And what does flipping out look like?

Jesse: [pause] a bunch of crying [laughing]. I don't know, because we're real close, and my three sisters, they don't really get along with her too well--like they get along with my dad better than they do her, so she was just kinda upset that I'm leaving, because I'm the one that--I keep the girls in line so they don't back-sass her too much or anything. 
Researcher: mhmm

Jesse: Because I'm close to two of my sisters so they'll respect me--the other one, she does whatever she wants, she doesn't care, and so. I keep three under control, and then she just worries about the last one, so.

Shane also has a single parent left at home - his mother died when he was young, and by leaving for college, he left his father alone. On their way to campus and throughout the semester, his father continued to check Shane's commitment to being away from home:

My dad was with me. We were--he was in his car and I was in my car. We stopped in [nearby town], and he kept asking me if this is was what I really wanted. He said, "you're three hours away from home, is this what you want?"

In what was typically an emotional day for students and parents, although usually positive, this was not the case in Shane's experience with his father. After what appeared to be a difficult day for Shane's father, he suddenly left, unannounced, leaving Shane alone. During my interview with him, Shane described the situation:

Shane: Yeah, he's helping me out--basically I'd bring stuff in and he'd go through it and make sure I had stuff, and after we got all done, he got in his car and left.

Researcher: Just like that?

Shane: Just like that--he didn't say goodbye, and then he called me at night and he's like, "oh yeah, I forgot to say goodbye".

Researcher: He just left?

Shane: Yeah. I don't know if he didn't want to show emotion, but I came home for fall break and he was loving having me home.

Researcher: Yeah. 
Shane: But, he'd call me sometimes and ask me how I was doing and make sure I didn't want to come home or not.

Researcher: mhmm

Shane: Of course you [participant] want to go home.

Researcher: So you turned around and he was gone?

Shane: Yeah, I turned around because I was going to give him a hug and say goodbye and stuff, and he was just gone.

Researcher: Where are you now--what's going on with you?

Shane: Ah [pause] I was upset.

His father's difficulties continued throughout the semester. Although his father showed support for Shane's ambition, he continued to check his commitment. Shane said, "He would call, sometimes, and ask me how I was doing and make sure I didn't want to come home or not." He is aware of his father's position, but it was apparent that this situation was difficult for Shane, "I think it's harder on him sometimes, than it is me, because he's used to me being home, having someone there, having someone to talk to and now he doesn't. He just has work and sleep."

Inherent in the stories of Jesse and Shane, and dealing with indirect issues of separation, was a desire to help a helpless situation, and perhaps some feelings of guilt. This was also the case with Kathleen, whose mother did not overtly present her discontent, but was living with financial difficulties. This was difficult for Kathleen who considers her mother her emotional support:

We talk every couple of days. My mom always feels like I'm asking her for money even though I'm not [laughing sigh], um [long pause] I try not to bother her because I know it's really stressful back home, but when we talk it's always okay. 
This weighed on Kathleen, and she brought the point back again when discussing pressures she felt, "I know she's not financially stable, and she's paying my tuition instead of paying the bills." On top of this, Kathleen had also expressed difficulty with feeling separated. When asked what was most difficult about her college experience, she volunteered, "The most difficult thing? It's still really difficult being away from home. That's the most difficult thing I can think of right now."

When the same question was asked to Sandy, her reply was the same, "It's just--the hardest part is just being away from home, so far, I can't just visit any time I want." Specifically, Sandy missed her little sister, with whom she was in constant contact:

She [little sister] really misses me. She's probably kept in contact the most--just everyday, before she goes to school and after she gets home, she always messages me. She's like, "how you doing? I love you. I miss you. When are you coming home?" And that's probably the hardest...

Krystal, who spoke longingly about those left at home expressed similar sentiments. For her, the close proximity of the college was a major factor in choosing a school, but still expressed difficulty with being apart, "and even just being like 45 minutes away, it's still hard because I've never been without [them]. So I like to go home every weekend. I don't think I could have lived any further away." Adding to Krystal's situation was an indirect difficulty of wrestling with her mother's emotionally expressed sense of being separated, "my dad side of the family, they were all excited, but my mom, she was upset. So that kind of tore me down a little bit."

The remaining participants, however, appeared to be well adjusted to being away and feeling separated from friends and family. Michael and Alex described a very pragmatic 
perspective reflecting an understanding that college requires a commitment and sacrifice, and that normality will return. Michael stated, "I'll still be able to go home for school breaks and so it's not like I'm being away for forever.” Alex, who spoke at length of his high school friends, reflected with confidence about their bond, "My friends are back home, but I'm always going to see them when I have breaks. I mean, my friends are always going to be there if they're going to be real friends, so.”

For Brealynn, the first night on campus was difficult, and she called for her grandparents to come get her. They let her stay and struggle through it, and she appeared to have adjusted well. When we spoke, she shared that she goes home frequently, but only for employment reasons, "I try to go home--well I work at home--so I almost go home every weekend, and sometimes every other, but I don't stay at home." It may be speculated, then, that she has adjusted to being separated and being on her own.

Kayla and Brianna had very little difficulties with separation. Both students had adjusted well on campus and keep in touch with family on a regular basis. Kayla described the nature of their communication, "I just called and let them know that everything was okay, I was doing okay, that I wasn't getting too terribly homesick." Further indicating positive adjustment, her return trips home had become less frequent, and dependent on campus activities, "I tried to go every other week, but it's got to the point now, I might go weekend out of the month, it kind of depends on my paycheck and stuff, and if there's a game or something going on." Brianna, had mentioned that her parents were emotional about leaving her on campus, but it appeared to not be self-centered, or destructive, just growing pains. She did have initial concerns about being away from home, however, but those had quickly dissipated. With enthusiasm, she described her thoughts: 
I was like, "oh man, I'm going to have to leave home, this is a really far drive, I'm going to be all by myself, I have nobody that I'm going with", and then I got here and I was here for the first week and I was like, "alright, this is pretty cool"

Brianna indicated no problems with being away from home, and continued with enthusiasm about her college experience. When asked about going home for winter break, and returning the following semester, she replied:

Yeah! I mean people are like, "oh my gosh, I can't wait to go home" and I'm just like, I mean I'm happy to go home but, I mean, I don't want to leave my friends here. I don't know. I've gotten really close to people here!

Overall, these participants did not express overwhelming difficulties with separation from home and community. Jesse and Shane felt some pull from home, as did Kathleen, to an extent. Krystal, Sandy, and Kathleen identified separation as the most difficult aspect of college, however it did not appear to be enough to pull them away. Michael and Alex understood separation as a part of the process, and that it would resolve itself in time. Braelynn overcame her initial difficulties, and was able to return home without needing to be with family. Kayla and Brianna had the fewest difficulties with separation, and appeared to have adjusted well with being away from family and friends.

\section{Adjustment}

The second phase of transition is the period of adjustment, which involves the students' experiences with social and academic integration.

Social integration. Five of the participants attended college for sports or with a sports scholarship, but only four spoke in ways that suggest an impact of sports on social integration. Alex, who would not have considered attending college if it were not for an invitation to play 
football, had his high school football teammates as suitemates. Initially, he figured that he would have limited his social circle to this group, but was surprised at how well branched out. He attributed his social integration to the small scale of the college and being able to "know just about everyone." He described his social growth:

I thought I was going to stick with the kids from my high school, but I've met multiple people that I'm now friends with and it's been pretty good, you know. I never thought that I'd be hanging out with someone I never knew at the beginning of the--you know when we first moved in, but I hang out with a person I just met--what ten weeks ago so, it's pretty good, you know, I like it.

Shane also attended with a football scholarship, and he found that sports eased his initial transition, "Everybody got along because the first week--we were just football players, so we all got along, started telling stories, which made it easier.” Ironically, Shane was quickly listed as ineligible due to injuries, but found that this increased his social integration. Without having a demanding football schedule, he found more time:

It's [not being able to play football because of injury] changed the way I've went about my day. [I] used to just go to school, go work out and never hang out with anybody_-just me and school and working out, sports. Now it's me, school, I work out, then if I have time I hang out with people, I talk to people, I'm more social now, and I'm not focused primarily on one thing. Jesse, whose primary intention of attending college was to play lacrosse also found the sports program demanded much of his time, "was like five things a day that we had to do ... and we'd have things on the weekend we had to do ... that was probably the biggest thing, how much time it took up." Jesse recognized that he was slow to reach out for friends; early on, he mostly socialized either with his team or with his best friend, also his roommate. He described 
his transition, “you just stay in your comfort zone. I feel like, because now it's fine, because like I'm out of my comfort zone now, but I'm comfortable because I got out of it, like made friends and stuff." Both Jesse and his roommate came out of their "comfort zone" together. He told a story of how they each came to the realization that they were missing out on a social aspect of college:

I feel it was a mutual thing, because we're just sitting there one day and we're like, "God! we're bored" and we were like, "we need something else to do besides just chill in the room." So we talked about it and then like a week went by and I made friends in a class and he made friends in a class, and then it was just like we're hanging out as a group-type thing.

Jesse also appreciated the small size of the college, and its diversity of students, differentiating it from his memory of high school:

Yeah, it's pretty nice, because most people don't really judge you here. You just do whatever, like in high school, if you wear a certain thing, or something like that, people judge you but like here, it's just like, there's so many different walks of life that came here so it's just like everyone accepts everybody, pretty much. So, in that aspect, yeah, walking on campus, you could pretty much walk up to anybody and talk. Especially since it's such a small college, it's not just, like thousands of people, like there's only a couple thousand people here.

This was not the case with Sandy, who attended on a track scholarship. As with Jesse, Sandy found that sports demanded much of her time- however, when she did find free time, she would meet her coach to talk, or play basketball, "usually, there's sport involved, or studying." Sandy perceived a sense of exclusivity, in general, on campus, one in which groups of friends primarily stayed with one another. "I just figured there'd be your different groups, like high 
school: everybody groups themselves off with who they're familiar with. So, yeah, it's pretty much what I expect." Along with Sandy came five of her close friends from high school, and it was with them who she primarily spent her time:

A lot of my close friends actually come here ... we all kind of--we're familiar so we kind of hang out and just talk over what we do and if an other one needs help the other ones try to help them, so it's actually been a cool thing.

Inasmuch as this has provided her a strong social connection, it was not necessarily a connection with the college or the wider student body.

Brianna attended with scholarship to play basketball, but when speaking of her social connections, did not emphasize her team. She instead, spoke of a transition, in which social connections came easier than she expected:

I was kind of sad because I was going to have to leave everybody, because everybody was going to a different school and I came here by myself, and everybody else has friends - at least one person, that went with them to another college, and I was all by myself, but now I'm here, I'm like, “this is awesome!”

She later enthusiastically described the nature and quality of her new social connections: "I live in [dorm], so we always have all kinds of people in there. We're always playing music and dancing around, so it's always fun!"

As with Jesse, Krystal and Braelynn had best friends from home as roommates, and although this eased their initial transitions into college, and as with Jesse, it slowed their social outreach. Braelynn attributed her small-town upbringing to her slow social transition: 
It's a big change to be here with people, running around the hallways, everybody trying to come talk to you and I'm like 'I don't know you, you're talking to me right now?' It's a change from growing up, knowing everybody from the time that you're in kindergarten. She did, however, reach out, and stated, "Yeah, I talk to a lot of people now." Regarding Krystal, when we spoke, it appeared that she had made good social connections, but it did not come easily and was initiated by her roommate:

Lately we've been hanging out with these other girls in our hall, so that's getting definitely better. For a while there, we really didn't have anyone, because we're not--I'm not outgoing. She's kind of outgoing, but I'm not, so I don't like to meet new people. I don't like change at all, so it's hard. Everything's a big adjustment but finally she drug me out, and we get along with those girls, so we do stuff together now all the time. We make late night McDonald's runs [laughing] sometimes.

Also, as Jesse did, Kathleen and Michael each compared their college social world to that of high school. Both described high school as a less than pleasant experience, and appeared to have found a sense of social ease with college. Michael, who felt forced by the state to attend public school, described his college social environment as, "a lot less drama than high school because everybody here's a lot more friendlier and everyone wants to get to know everybody unlike in the high school." He was proud to count as friends, two students from Hong Kong, who inspired him to begin learning Mandarin.

Although Kathleen had her best friend from home at college, she still was slow to develop relationships. About herself, she said, "I'm always going to feel some sort of distance because that's just my personality, but I'm closer to a lot more people here that I thought I would be." For Kathleen, the social transition into college was akin to a refuge, "I didn't think that you 
could find so much support in a small place because in high school I'd been so bullied, but there're so many nice people here, it's so different, so much more relaxing."

Kayla claimed to be "not very good at meeting new people" and did have initial social difficulties, "it was definitely really hard the first few weeks until I started making really close friends." In a single statement, Kayla described the essence of positive social transitionexpressing expectation, change, and a positive result:

I thought I'd be more--kind of keep to myself, but really, like the whole third floor of [dorm] over there, it's literally a family. We all sit in the kitchen every night; we got a little study group and everything. It became a second home really fast, really. All the people--I wouldn't even call them friends, they're family now. It's a really nice place; I really like it up here.

Whether it was through formal social activities, such as student orientations, dormitory functions, and sports program, or informal social activities, such as in dormitory life, all ten participants appeared to have had positive social transitions. For Alex, Jesse, Shane, and Sandy, although they may have slowed the natural speed of social connections, the sports programs provided a transitional ease and some comfort of familiarity. With the exception of Sandy, who appeared to stay within an existing friend group, participants who had a good friend from home with them during their first semester, faired well. As with sports, these friends may have slowed outward social outreach, but eventually, these participants found meaningful relationships. Contrasting with their high school experience, Jesse, Michael, and Kathleen found the college social scene liberating and accepting. Finally, Kayla, who overcame initial expectations of social difficulty, discovered friends she considered family.

Academic integration. Of these first-generation students, none experienced any 
difficulties with academic integration regarding rigor, however most had difficulties with organizational skills and time management. Many had said that their teachers in high school had warned them about the difficulties of college, however this group suggested that this was not the case, creating for students an unrealized expectation. For example, Braelynn shared:

They [high school teachers] made me feel like college was going to be super hard I wasn't going to be able to do it and now I'm here and I'm like, "this isn't much different than what I've done before, it's just a little more in depth"

This was echoed by Krystal, "It's just boring--it's all too easy. That's my biggest surprise, probably. I expected it to be a challenge, and I'm really not yet--I'm sure I will be, but just not at this point." Kayla stated, "I thought it was going to be a lot harder", as did Michael, who said, "I was expecting them [classes] to be harder than what they are", and Brianna, "I mean I expected it to be harder, a lot harder."

Sandy and Alex demonstrated a realization of growth and accomplishment. Sandy, realized her expectations were unfounded, and that she could find help when necessary:

I kind of psyched myself out and I was like, "I'm not going to be able to do it, it's so hard, it's going to be so hard" but really if you just talk to who--whoever--if you're having trouble somewhere, somebody can help you somehow.

Alex was concerned that he would not be able to maintain academically with a demanding football schedule:

I thought--I thought it was going to be, you know, I though I wasn't going to do that good, with football and all that, but, I'm doing alright, so I guess I'm doing better than I though I was going to do. 
Between balancing classes with sports schedules, social life, and academic demands of college, time management was an issue for almost all participants. Brianna expressed, 'It's not a problem for me to get my work in, it's a problem, like sometimes so many things are due at the same time." It appeared that these students had not had adequate independent experience to manage without supervision, as was expressed by Jesse, “you don't have somebody sitting there, telling you that you have to do your work." Krystal echoed similar statement, "I wasn't ready for someone not to be on my back all the time, telling me, 'you need to do your homework, you need to do this, you need to get this done." Braelynn also stated these sentiments, "I don't have very much time management because I'm like, 'oh I have time, I don't have to do it right now' and I really do need to do it!" Michael had also expressed issues with time management, but had begun self-organizing:

At first it was difficult because I always had these people to keep reminding me of everything but now I'm being better about it because--pretty much my entire side of like my dorm room has like sticky notes everywhere reminding me about [laughing] everything, its like this homework for this class, this meeting, and all of this stuff going on.

Several students stated that high school had been easy for them, or that high school was not intellectually demanding or challenging, leaving them unprepared. For example, Kayla stated, "I was one of those kids in high school that never had to study" and Sandy, "I could probably pass high school without cracking a book." Alex had also realized a necessary change in his discipline, and academic strategies. For him, this was effective:

I got to sit down and actually have to study. I can't just walk through class, write a paper in fifteen minutes and it be good enough to get a B and pass it on. You have to actually 
sit there and do work when you could be out, you know playing video games, or something like that. You actually got to sit down and do it, and study.

Braelynn, revealing that in high school, her teachers often resorted to teaching through PowerPoint and worksheets, stated, “I feel where I came from is such a small community I don't feel like I have as many tools as a lot of the other people." For this reason she felt her biggest problem was "learning the teachers' teaching style ...I'm still trying to figure out how I can take notes and learn the way I need to."

For this group of first-generation students, academic rigor was not a problem, but they indicated a lack of effective organization and time management strategies. Whether it was due to being from small rural communities, or having ineffective high school teachers, these students were capable, but lacked adequate techniques. Fortunately, many were self-aware, and if nothing else, acknowledged that changes need to be made.

\section{New Discoveries}

Analysis of the interview transcripts revealed insights that were not emphasized or not discussed in Tinto's theory. Thematically, these were college scale and size, personal transformation, communication technology, and being first-generation. These themes resulted from an inductive analysis of the data and provided an interesting look at the transition experience into college for these first-generation students.

College scale and size. Most of the participants were from small, rural communities, and sought a school that reflected this. Several participants remarked on the size and scale of the college, and how that had a positive effect on them. Shane expressed this, "I like small colleges . .. I know people that went to big colleges and they don't like it because it's always loud and partying all the time." Comparing a large university that his friend attends, with his own, he 
continued, “He has a class of 250, and doesn't really get help with his teachers because they're always busy and leave right after class. Here you can get help and the stay after class for about twenty minutes to help you." Kayla stated that her friends were surprised with her choice of college, but she felt she made the right choice, "Everybody in my class was, "woo, [state college], [large state university], but I need someplace smaller and quieter.” Shane stated, “I wanted to go to a small college, I didn't want to go to a huge college . . . I don't want to be a number, I want to be a person in the room." Alex, visited the school the previous year, and liked it. Comparing it to a large university that he also visited, he said, "I've been up to [large state university] multiple times. I couldn't go there . . but I like this - I like the small, you know.” About choosing her current school, Sandy, too expressed a preference for the small scale, "I really like it here, just because it was mainly like back home - there was mountains, small town." The same was true for Krystal, "I'm used the small atmosphere. I wasn't ready to go into something as big as [large state university], because I was accepted there ... especially going from a town of - there's not even a stoplight in my town! So going by myself somewhere that's like thirty-plus [thousand] students-I couldn't even think about it!"

These students recognized something in themselves, a desire for small scale, for quiet, and for personal that they found in their current college. Many understood, intuitively, that they preferred or would need an experience that was more like home, and more suited to their nature.

Personal transformation. Another interesting discovery was the way in which the participants perceived personal transformation. Throughout the majority of the interviews, the participants discussed their lives, the people in their lives, and events that occurred. This section describes how participants expressed awareness of changes within themselves. Because a perception of personal change results from recognizing patterns within a chain of events, it was 
difficult to isolate, and identify what changed, specifically. This was best illustrated in Brianna's statement about herself, "I really don't know how to explain it, I just know that I'm different now that I'm away—that I'm me. Yeah, I'm just out here doing 'me' now.” At close inspection, themes arose, such as maturity, independence, and identity, but when viewed as a whole, it is best to see these as transformation.

Their sense of personal change and of transformation can be heard in their statements. Kathleen stated, "I felt like I finally had decisions I could make on my own." Sandy too recognized a change in responsibility, "it's pretty awesome, you know, you're taking that step and making that decision for yourself." Krystal saw her transformation as less parental oversight and as opportunity for self-governance, "I'm kinda independent now, I don't really have any rules to follow, so I make my own schedule." Michael saw his college experience as "helping me just become more mature and more as an adult." This was also reflected in Braelynn, who said, "I knew I was growing up. It's just a big change.”

For Brianna, Alex and Shane, the college experience differentiated them from those of their home community. Brianna stated, "I can definitely tell that I've changed. If I was just to go back home - when I do go back home, it's just gonna be like, "Hmm, this is different." She later added, "I feel like coming here is like opening the world up a little more." Along very similar lines, Kayla voiced, "Sometimes I go back home and it's kind of like, “what is this place?"” Alex shared statements that reflected some changes in self-perception and ability, "I didn't think college was going to be a thing for me. I just kind of thought I'll just go to work." He was also conscious of his unique experiences and underplayed them when speaking with his friends. He said, "Sometimes we talk about college stuff, but not that much because they've never been, so they don't know what it's really like, but they ask me, sometimes, and I'll just answer the 
questions they ask." For Shane this underscored differences in his home and college selves, "It's just a giant difference you have adjust to. You go home every summer, and you get back in your routine of being at home, then you come back here. It's just a constant thing of getting used to it."

Only Jesse, who came to college to play lacrosse, discussed no awareness of personal transformation. Being only thirty minutes from home, he visits frequently. He attributed this to not changing, "because they're not long extended periods of time where I'm gone, we don't really skip a beat. I just come back home, and nothing has changed." Later, he did report some sense of change, not existential, but physical, "I feel like I'm the same person. Probably in better shape maybe [laughing], but that's about it."

Nine of the ten participants voiced some sense of transformation. It may be assumed that most college students will change as a result of attending college - they are aging, and they are exposed to new information and experiences. Critical to their commitment to persistence, was that they perceived this transformation, and perceived it in a positive manner. For this group, these transformations were perceived positively.

Communication technology. Tinto's theory of student departure was most recently published in 1993, and since then, there have been many advances in society_one specifically in the lives of students: communication technology. Anyone walking onto a campus will see the ever-present cell phone (smart phone) in the hands of today's student. This ubiquitous technology was absent from Tinto's theory, and may have a positive effect on separation issues for students during transition into college. Students and families in this study were able to remain in contact, regardless of time or location, and maintain an emotional connection. Many students reported frequent conversations and texting episodes. For example, Brianna stated, "I don't really 
call home - I text my mom a lot", and Jesse stated, "me and my mom text on the daily, so we pretty much stay in contact all the time." For Alex, the ease of communication kept him in contact with family and friends: "she [mother] calls me about every night, and my friends call me three or four times a week to see how I'm doing." Some talked about using Facetime and Skype (real-time video and audio applications) to maintain connections with family and friends. Jesse stated, for example, "I don't really talk on the phone too much, but we'll text and Facetime every now and then, and see how things are going." Similarly, these applications helped Michael stay in contact, "about once a week me and a few friends will get on Skype and have a group chat, [and] talk to everybody."

The effect of communication technology may best be illustrated with Shane, whose father experienced difficulties with his son being away from home. Because of his father's work schedule, Shane found it difficult to maintain frequent contact and, at 10 weeks into the semester, had only talked to him two times: "by the time gets home it's about 8 or 9 at night, and he's just tired, so he just goes straight to bed." In contrast, he maintained frequent contact with his girlfriend, especially on his first night alone, and after his father left without goodbyes, "the first night all I did was lay in bed and talk to my girlfriend on the phone--either it was texting or Snapchat."

Current communications technology represents a new influence on Tinto's theory, regarding separation, specifically. At some point during the interviews, all participants referenced some form of cellular phone, or computer communication with family or friends.

Being first-generation. Leaving home to attend college involves transition for all students, as Tinto illustrated. For first-generation students, there is the added piece of being first in their family, of experiencing something unique, and of exploring territory without the benefit 
of family knowledge. Because of this, first-generation students are pioneers, but as pioneers, they must break family cycles and family traditions, often without guidance, and sometimes without support. The following excerpts reflect what it means to be first-generation for these participants. These excerpts include the participants' direct understanding of being first-generation, but also feelings, motivations, and experiential anecdotes.

Braelynn and Kathleen saw financial difficulties and a lack of opportunities in their families. "I see how difficult it is for my mom" stated Braelynn, and "I just want be able to go do something if I want to go do it, and I don't ever want to have to struggle, I want to be able to be financially independent, on my own." Kathleen stated, "I saw a lot of my family members ending up jobless - not a lot of money — and I wanted to have more our of life than always having to ask other people for things, and I wanted a stable foundation.” For her, being first-generation involved stress, but her experience had been positive, "It's scary at first, but it's actually a great place. It's a great experience; it's one of the best, actually. It's a little stressful because you're the first person to actually make something happen.”

Being first-generation also means that one is breaking family tradition. All of the participants, in one form or another have taken routes that have previously not been taken in their families. Most of the participants felt fully supported by family to move in new directions. For example, Jesse stated that even though he aimed toward college since he was young, "once I made it, they were proud." It was only Shane who felt resistance. He saw the issue of firstgeneration as breaking family tradition as a problem, not for the students, but for those left behind. Inasmuch as their support was important to the student, it was a matter of acceptance for the family, not the student. Shane, who identified the issue with first-generation students as, "[there is] the tradition of your family tradition and then going against it--doing something 
completely different" and felt resistance from his grandmother. About her, he stated, "she's old and she's set in her ways in different things, and she believes if your family tradition does one thing, you got to follow it." He continued, "that was a little difficult, [but] she finally saw it my way, and you got to get out of the old times."

For Brianna, Alex, Kayla, and Michael, being the first meant that others were watching, and learning through their experiences. Speaking about herself, Brianna stated, "You're a role model" and Alex, speaking about his mother, stated, "She's glad to see that I set an example for my brothers." Seeing herself as a test model, Kayla stated, "It was something completely different, something nobody else in my family ever experienced it, so it was kind of like, 'Okay, I'm the test subject now, what's it gonna be like?' My experiences are gonna reflect on everybody else." For Michael, this meant modeling for his future children:

Being the first person in my family to go to college means a lot. With me going to college, I'm hoping that one day when I get married and have kids, that they will also be inspired to go to college and chase after their dreams and what they want to do, instead of either going into military or workforce, like pretty much all my other family has done. As first-generation students, they are inherently pioneers - they are venturing into unknown territory without the benefit of family experience to draw on. Such experiences might have helped these students with processes and procedures, with expectations, and with situations within the college experience. For Alex, who was proud to feel as a role model, there was frustration with a lack of knowledge about the application process, specifically attaining scholarships. He stated that he wished that there was "some type of way me or my mom finding about the scholarships they offered in school because I had no clue about any of that, like nothing, and my mom didn't either." He continued, "my friends who went to high school, when 
we had our senior awards, they're getting five, six scholarships [and] I'm like, 'how the heck did you get those?"' Krystal also found the entry process isolating and difficult, "it's definitely difficult, [and] way harder than I thought it would be. I didn't have help doing anything. I remember nights where I would just sit and just break down because I had nobody to ask." Even as her parents lacked the practical experience to guide her, their inexperience also left her parents with an inability to emotionally guide her: "I didn't really have anyone to tell me that it was going to be okay 'cause nobody had been through it." The lack of family experience, even as college was underway, created difficulties for Sandy, who felt alone and with no one to seek counsel. Comparatively, she stated:

I just feel like it's a lot harder just because, you don't have anything to go off of. You don't have parents to tell you, how hard it's going to be, just because they don't know; they just go by what everyone else tells them and you don't have any elder siblings that if you're having trouble with a class, you can be like, "did you have this class?" or "did you have problems with it too?" You know, get their advice on what to do about it or anything like that.

Being a first-generation student - the first in family to attend college can mean many things for students, but always it means breaking patterns of one form or another. For these students it meant creating future opportunities of security and independence. It also meant being a role model, and setting an example for others to follow. For others it meant struggling without guidance. Finally, for one student, it meant breaking family tradition.

\section{Summary}

Ten first-generation students were interviewed during the tenth week of their first semester at college. Reconstructed from the interviews, narratives of their journeys were 
presented, illustrating the uniqueness of each life, as well as their shared commonalities as firstgeneration students. Excerpts were extracted as they fit into areas of separation, academic integration, and social integration. New discoveries were identified and evidential excerpts were used to illustrate perceptions of: college scale and size, personal transformation, attending with friends, and being first-generation. 


\section{Chapter VI-Conclusions}

This study was conducted to better understand the process of transition into college for first-generations students. In order to better understand their experiences, 10 first-generation students attending a small, private liberal arts Appalachian university were interviewed during the tenth week of their first semester of college. I analyzed the data from these interviews in two phases. In the first phase, I examined the transcripts through the lenses of "separation and adjustment" which Tinto (1993) describes as the "first hurdle of college completion." Specifically, I looked for instances of separation, social integration, and academic integrationhow they manifest for the student, and how perceptions could impact student persistence. The second phase took an inductive approach that allowed themes that were not emphasized in Tinto's model to emerge. I categorized these as New Discoveries (see below), in which themes of college scale and size, personal transformation, communication technology, and being firstgeneration emerged. To ensure validity, a qualitative analysis expert, and dissertation committee member analyzed two transcripts. The result of this second analysis validated my initial coding, interpretations, and themes.

I believe that one's perception of an event—of a phenomenon—informs one's understanding of that event. In a sense, we create stories of events based on our understanding, and our interpretation of those events. Without reflection and a context to fit such perceptions, we come away with generalized feelings, and these feelings may influence future actions, as Tinto (1993) states, "what one thinks is real, has real consequences (p. 136)". Regarding students, they may not understand that they are transgressing, and doing so through specific stages of transition, but they aware that they feel something. Tinto (1993) states that the more satisfying experiences are, the more likely they are to influence persistence in college. If students were able 
to place generalized feelings into contexts — stages of transition — they may be more able to create a more accurate story, respond more appropriately.

A phenomenological study attempts to understand what an experience is to an individual, and this study attempts to understand what the transition into college—separation and adjustment — means for first-generation students. However, students may not perceive transition much less articulate the various stages; they may simply be leaving home to attend college, and this either feels satisfying or not. However, they understand that they are experiencing an event, and one, which, within their family, is unique to them. By looking through the lens of Tinto's model of student departure, I was able to place the participants into a context, thus giving consistent form to each of their unique stories. This study sought to answer the following research question: How do Appalachian, first-generation students transition into a small, private college? The following conclusions answer that question.

To begin, the experiences of this group did not appear to represent those of other FG students. Based on the literature and personal experiences, my assumption was that FG students were at a deficit, and their transition into college was more difficult than for their non-firstgeneration peers. Lowery-Hart and Pacheco (2011) class FG students as "at-risk", and Hand and Payne (2008) describe them as an "often-overlooked, marginalized group" (p. 14). There exists a presumption that for a myriad of reasons, entry into and persistence with college is more difficult for FG students. My analysis confirmed this presumption, but only to a small extent; in more ways than not, the transitional experience for these ten participants was no more unusual, and not unlike that of any typical college student. Perhaps because these students were from rural Appalachian communities, attending a small, rural private Appalachian college, there transition 
appeared without much difficulty; it involved, high and low moments, doubts and reassurances, fears and success, but overall their experiences were satisfying and positive.

\section{Separation}

The literature shows that breaking from the security of home culture can be especially difficult and painful for FG students (Tinto, 1993), and especially those from Appalachia (Hand \& Payne, 2008), leading to periods of confusion, conflict, isolation, anguish (London, 1989) and a sense of loss (Komada, 2002). These participants did endure some difficulties with separation, however, with the exception of Shane, their experiences were not unlike any student leaving home for college. A closer examination of their difficulties with separation, two sub-themes emerged: direct and indirect difficulties. Direct difficulties are those experienced and perceived by the student, while indirect difficulties are those experienced by another, yet perceived by the student.

Five of the ten participants did not perceived great difficulties with separation. Michael and Alex perceived their separation as a necessary, albeit, temporary part of their college experience. The security in their relationships allowed them to transition easily into college, without being subsumed with a sense of loss. Braelynn went home often not to be with family, but to work, and Kayla's visits home became less frequently over time. Frequent trips home could indicate less connection with the college culture; however, both participants expressed positive growth in their new relationships. Brianna had initial fears of leaving family and being alone, however, these quickly vanished, and she came to embrace the college culture. The experiences of these five participants do not match those described in the literature concerning first-generation students and in this way may be closer to those their non-first-generation peers. 
The remaining participants did have some difficulties with separation, however, with the exception of Sandy, they did not appear to affect their desire to persist. For them being away from home and family was difficult; they missed being close and having family accessible. It was Sandy who appeared to suffer more than the rest, and her difficulties with separation appeared to influence her commitment to persist. When asked about returning the following semester, her answer was pragmatic yet without conviction:

I'm going to have to get over it eventually, because I'm not always going to be at home. Eventually I'm going to start my own life, so might as well stay here and tough it out and get used to it. So, yeah, I think I'll probably be here all four years, I mean, at least, that's what I'm going with for now.

Inasmuch as these participants experienced some difficulties with separation, these experiences do not match those found in the literature concerning FG students. Rather, these experiences appear normal to all students who leave home to attend college. With the exception of Sandy, the participants perceive separation as difficult, but normal and something that must be tolerated. It is important to note that each had the support of family and friends, which may have made their transition more tolerable. The power of such support is supported in the literature (Andrade, 2013; Bradbury \& Mather, 2009; Byron \& Simmons, 2009; Hand \& Payne, 2008; Hurtado \& Carter, 1997).

The sub-theme of indirect separation difficulties emerged as I continued to hear stories of suffering or loss regarding those left at home. If the above difficulties with separation appear normal to any transitional experience, those that are indirect that appear most unique to FG students. For Kathleen, whose mother was suffering financially, yet assisting with her tuition, this was expressed as a form of guilt. Consistent with findings of Bradbury and Mather (2009), 
and London (1989), Krystal and Jesse identified responsibilities at home of which they were no longer meeting.

Most notable are the experiences of Shane, which reflect much in the literature concerning FG students. As noted by Terenzini, et al. (1994), being a first-generation student, by default means breaking traditions, and for Shane this meant not going into the military. As a result, he was unable to gain the support of his grandmother and his father - two central figures in his life. Although he felt that his grandmother was behind the times, thus not recognizing important changes in today's society, his father's lack of support clearly weighed on him. Byron \& Simmons (2009) note that family ties can provide a basis for personal identity thus promoting persistence, however, as a result of his break with tradition, Shane was forced to find a new identity. London (1992) found that the choice to leave home and enter the college culture creates a necessity to "renegotiate relations with family members, friends, and in a fundamental sense, with themselves (p. 6)" This was evident with Shane, who not only broke family traditions, but left his father, a widower, alone. Empathetic to his father's needs, and no longer providing companionship for his father also weighed heavy on him. However, as noted by Miller (2007), some family values and attributes provide benefits that lead toward greater persistence, and for Shane, this family value was grit: "Once I start things I have to finish them cause I don't want to feel like a failure, so yeah, I'm returning."

In reviewing the findings regarding separation, I was surprised with the ease that most participants had in separating from home. Each was geographically close to their family and friends, but separation entails more than proximity. The literature had portrayed these transitions as more traumatic, and stepping away from the familiar into the unknown can be daunting, however, it appears that frequent communication with loved ones from home, eased their 
transition. When viewing separation as a stage of college transition and the effect of modern communication technology, one may consider Bowlby's Attachment Theory, which states that ("all human beings are biologically programmed to seek comfort and safety through proximity to a reliable and protective caregiver", but equally important is the "need to separate and explore the world" (Gold, 2011, p. 272). Gold further explains that negative experiences associated with separation may lead to sadness, anxiety, and depression—clear signs of separation difficulty. Cundy (2015) applied Bowlby’s theory to students' departure for college and the impact of digital communication, stating that students can:

connect with them in times of illness, fear, or stress is reassuring and enables us to get on with exploring the world, confident of support if needed. Young people studying away from home can enjoy the education and social opportunities afforded them if they have people to whom they can turn when problems arise (p. 2).

This is consistent with the findings of Green (2007), who found that cell phone connections allowed students the ability to share college experiences and continue an emotional closeness and understanding (p. 18), and "allowed parents the ability to be emotionally present, although physically absent" (p. 21). In light of the development of communication technologies (also discussed below) and psychological attachment theories, I believe the impact and associated qualities of Tinto's (1993) separation stage need to be reexamined. Tinto (1993) states that central to the separation process is a student's "rejection of attitudes and values" of past communities. Based on evidence from this study, I agree with critics (Andrade, 2013; Bradbury \& Mather, 2009; Byron \& Simmons, 2009; Hand \& Payne, 2008; Hurtado \& Carter, 1997; Nuñez, 2005) who suggest that separation and rejection of past values are not only unnecessary, but maintaining connections may be beneficial to student success. The evidence from this study 
suggests that students and parents sought to maintain their ties throughout the semester, and that the use of communication technologies eased difficulties throughout their transition into college.

\section{Adjustment}

Beyond separation, the analysis examined circumstances of adjustment to college life. Following is a discussion of that adjustment, namely social integration and academic integration.

Social integration. I was pleasantly surprised at the level of social integration expressed by the participants of this study. Again, contrary to the literature, the majority of this group expressed ease with engaging and developing social bonds. Lehmann (2007) found one of the reasons that students who left college did so because of "not fitting in" and "not feeling university". Bean (2005) writes, "Having close friends on campus and feeling supported increase a student's self-confidence. Where satisfaction and self-confidence are found, students believe that they fit in. Friendships and fitting in are tightly coupled" (p. 228). It goes without saying that a feeling of belonging is important for college students however, Bradbury \& Mather (2005) found that for FG students, integrating into college is especially difficult. Lowery-Hart and Pacheco (2011) found that FG students struggle to "maintain cultural identity while navigating the college experience" (p. 56), which they identify as a dialectic tension of "in versus out", which represents a desire to be apart of and adapt to college culture while resisting, maintaining their roots. With the exception of Sandy, who returned home frequently and kept within her preexisting friend-set (high school friends that attended college with her), these participants described healthy and supportive friendships.

One interesting development was the affect of attending college or rooming with high school friends. Having a best friend as a roommate, or on campus provided a sense of familiarity and comfort, and eased students' transition into college. At first glance, I saw this as a benefit, 
however it also slowed their integration into the college culture. Ultimately, all participants reached out and developed social bonds, but for those who already had strong bonds, this took longer.

Academic integration. There is much in the literature that suggesting FG students are academically under-prepared or ill prepared for college (Chen \& Carroll, 2005; Terenzini et al., 1996; Warburton et al., 2001). My analysis of the experiences of these participants agrees with past research, but not to the extent suggested, and not to an extent that greatly differentiates them from their NFG peers. These participants lacked any familial experience with college, and therefore created unreal expectations - expectations that it would be more difficult than it was. Without family experience, their expectations were based on comments from high school teachers. For example, Braelynn had said:

They [high school teachers] made me feel like college was going to be super hard I wasn't going to be able to do it and now I'm here and I'm like, "this isn't much different than what I've done before, it's just a little more in depth.”

Most participants echoed similar comments. There is no doubt that college is more difficult and involves more depth and rigor than high school, but unreal expectations such as these fostered unnecessary anxiety and self-doubt.

When lack of preparation was evident, it was a result of low expectations and little rigor during high school. For example, Sandy stated, "I could probably pass high school without cracking a book" and Kayla: "I was one of those kids in high school that never had to study." Comments such as these suggest that they were underprepared; the lack of challenge in high school left them without skills and strategies for academic success. Most notable was Braelynn, who felt her rural upbringing left her lacking. Correlating small communities with resource-poor 
schools and inadequate teaching, she stated, "I feel where I came from is such a small community, I don't feel like I have as many tools as a lot of the other people" and "my biggest problem was learning the teachers' teaching style ... like lecture is a real big thing for me because, like I said, we always just did PowerPoint and I did worksheets on what we just learned." However, as a college professor I have found this not to be a unique quality of first-generation students; many students arrive to college lacking such skills. The upsurge in freshman orientation and academic success courses is indicative of more students arriving less prepared.

Time management skills was a sub-theme common to many participants. Predicting time needed, planning, preparing, and focus were lacking for these participants. Frequently, these students stated that completing tasks independent of reminders from parents and teachers was a problem. For example, Krystal said, “I wasn't ready for someone not to be on my back all the time, telling me, 'you need to do your homework, you need to do this, you need to get this done."” Again, this is not a problem unique to FG students. As an assignment in an education technology course, one of my first assignments with spreadsheets involves students tracking their use of time throughout a week, and many students are surprised to find how little time they spend on academic activities. Prior to this revelation, students felt they had too little time to complete tasks, or acted as if they had plenty of time. Without an accurate understanding of time required to complete an assignment, and without an accurate picture of their time use, many fail to complete assignments on time or at a quality matching their potential.

\section{New discoveries}

Tinto's (1993) theory of student departure emphasizes the interaction of the student and the institution, specifically with regards to social and academic integration. It implies that students must negotiate separation from their home community, and where after, the quality of 
interactions with the institution affect and influence the student's commitment to persist. These points determined the themes that I initially used to analyze data from student interviews, and this approach provided a convenient model to view the transition of these FG students. Beyond these initial themes, new patterns emerged that gave better understanding of this transition, which became four new themes: college scale and size, personal transformation, communication technology, and being first-generation.

College scale and size. My initial analysis looked for instances, inferences, and indicators of issues of separation, academic and social integration. A secondary analysis found that consistent in each of these themes was the scale and size of the institution and its hosting community. Many participants selected this particular institution because of its size; for them, intimacy was important. Best summed by Shane, who stated, "I wanted to go to a small college, I didn't want to go to a huge college ... I don't want to be a number, I want to be a person in the room." Shane's statement reflects a sentiment shared by many of these participants, and represents an insightful decision on their part, which may be attributed to their positive integration into college. It has been shown that because they have greater resources for programs targeting FG students, and greater diversity of students which afford more opportunities to develop friendships with peers of similar backgrounds an greater institutional size positively affects persistence for FG students (Lohfink \& Paulsen, 2005; Tinto, 1993). This, however, feels counterintuitive, and runs counter to my findings. For these FG students, the scale of the college provided a more intimate and emotionally safe setting, perhaps because it reflected the scale of their home community. Supporting this is Krystal's statement about choosing between two school of which she was accepted: 
I'm used to the small atmosphere. I wasn't ready to go into something as big as [large state university], because I was accepted there ... especially going from a town ofthere's not even a stoplight in my town! So going by myself somewhere that's like thirtyplus students-I couldn't even think about it!

The shift from a small rural community to a large institution may be difficult, as well as intimidating foe Appalachian FG students. For high school counselors advising FG students, the glamor of large institutions might best be underplayed to the benefits of integration in smaller institutions

Communication technology. As I've stated multiple times, this study follows Tinto's model of student departure, however it is important to note that he first published this in 1987, and his latest edition was in 1993. Since then, there have been many changes and one notable change has been in communication technology. The emergence of the cellular phone and Internet has greatly increased our ease and ability to remain connected with family and friends. For students leaving home to attend college, having convenient and always-available access to family and friends may reduce the anxiety and difficulties associated with separation.

Cummings, Lee, and Kraut (2006) state, "Physical proximity is conducive to the growth and maintenance of personal relationships, whereas physical distance leads to their dissolution" (p. 812), thus being separated can have a detrimental effect on relationships, causing suffering on both sides of relationships. The authors further state that relationships maintained through communication are less likely to decline. Ramsey et al. (2013) found differences in the use and effect of texting between students and parents. In a 2009 study, students who communicated with parents via text experienced more loneliness, anxiety, and conflicts with parents, however by 2011, texting had no maladaptive outcomes. As stated in Chapter IV and in the discussion on 
separation, the participants in this group did not express a strong degree of difficulty with separation from family and friends. Many of the participants spoke of frequent texting, "chatting" via Facebook, and interactive sessions via Skype and Facetime. The luxury of available access to family and friends allowed these students to maintain their relationships at home while continuing to integrate into the social fabric of the college.

These technologies did not exist when Tinto wrote his theory, and although their presence does not affect the importance of the separation stage, there is no doubt that their use affects the impact of separation on students and families. The easy availability of access to loved ones left at home surely has an impact on FG students' separation and integration into college culture.

Personal transformation. The third theme of new discoveries that emerged was that of perceived personal transformation. Nine of the ten participants alluded to or discussed transformation regarding their own growth and maturity, or divergence from their former self. I felt this was an important theme because it indicated self-awareness on the students' part, and it directly addressed the research question.

The first of the two concerns the participants' perception of their own personal growth. Five participants directly discussed ways in which they felt they had gained more autonomy and independence. The discovery of independence and responsibility is a common theme in college transition (Keup, 2007), and not unique to FG students, however its emergence indicates successful progress for these FG students. For example, when discussing independence, the emphasis was not indicating feeling alone, or left alone to decide, but in having autonomy and making responsible decisions. Michael, for instance stated, "[attending college] is helping me become more mature and more as an adult" and Krystal stated, "I'm kind of independent now, I don't really have any rules to follow, so I make my own schedule." These findings are consistent 
with Byrd and MacDonald (2005), who found self-advocacy to be an important skill for FG students who lack background knowledge common to most NFG students. Beyond making decisions that serve their interests, and self-directedness, the notion that perceptions of their own growth in a positive light indicates awareness and recognition of their personal development, autonomy, and self-responsibility.

The second sub-theme of personal transformation is directly applicable to being a FG student. I identified this as "break from former self" and this represents their perceptions of selfchange resulting from attending college. Housel and Harvey (2011) and London (1992) identify the one condition that is unique to FG students: by becoming college students, they become members of two cultures. Awareness of this condition manifested in two ways for members of this group, and both involved identity. Brianna and Kayla previously related their identity to their home community, and by becoming members of the college community, began to separate their identity away from home. Kayla's simple statement best illustrates the transition in her identity: "Sometimes I go back home and it's kind of like, 'what is this place?"”

Alex and Krystal perceived changes in how they interacted with their home community. I empathize with these participants in this regard; I am a member of the higher education community, and a member of rural Preston County community. I am aware of the distinction, that the respective cultures do not always blend well, and so to remain in good standing in each, I accommodate by adjusting language and mannerisms. Bryan and Simmons (2009) describe this as having separate identities, where students felt as if they were often "two different people, one at home and one at school (p. 397). Alex and Krystal had become aware that two cultures existed, and they were members of both. Critical to this is not that they accommodate, but that they perceive themselves as members of two cultures now: home and college. They were aware of 
their membership in their home culture and recognized themselves as college students.

Being first-generation. Most pertinent of the new discoveries regarding transition into college for this group concerns what it means to be a first-generation student. Each participant was aware of their status, and their uniqueness, but what it meant to be FG emerged as three subthemes: breaking traditional cycles, role model, and lack of family knowledge.

London (1989) states that by entering college, FG students are leaving the "intergenerational continuity" of their traditional society and entering one of modernity, creating a potential for "biographical and social dislocation" (p. 167). For most of these participants, that was the point: break the cycle and find their own direction. With the exception of Shane, all participants found encouragement and support from family and friends. Breaking traditional cycles enabled these students to break new ground and establish a direction of their own. FG students have been said to diverge in order to "escape occupational dead-ends and hopelessness" (Terenzini et al., 1994, p. 63), and to "distance themselves from the poverty they'd grown up in" (Macy, 2000). However, Dennis, Phinney, and Chauteco (2005) found that personal motivation for attending was related to adjustment and commitment to persist. I found similar motivations with the participants I interviewed. Kathleen stated: "I saw a lot of my family members ending up jobless — not a lot of money — and I wanted to have more out of life than always having to ask other people for things, and I wanted a stable foundation." Braelynn too, wanted move in a direction that provided more opportunity: "I just want be able to go do something if I want to go do it, and I don't ever want to have to struggle, I want to be able to be financially independent, on my own." The findings of Dennis, Phinney, and Chauteco (2005) are encouraging, it is important to remember that although many students enter college in order to better themselves, or to define 
a career, FG students often come from difficult situations marked with hopelessness and cyclical poverty, and therefore have more at stake.

Consistent with Byrd and MacDonald (2005) and Gofen (2009) for participants of this group, being a FG student also meant being a role model. I found the emergence of this theme to be encouraging in that it meant these participants had identified and accepted themselves as pioneers, and that they were setting an example for their younger siblings. Of all the participants, Michael was most eloquent with what it meant to be a FG student:

Being the first person in my family to go to college means a lot. With me going to college, I'm hoping that one day when I get married and have kids, that they will also be inspired to go to college and chase after their dreams.

His statement indicates that he perceives himself not as a student with deficiencies, but as a leader. As an educator, and as a researcher, I feel this represents another-and more positiveperspective from which to view these students.

The final sub-theme of being a FG student relates to a lack of family knowledge. FG students are those whose parents have not attended college, and therefore lack direct personal knowledge of the transition into college. Although they may offer financial and emotion support for their children, parents of these participants were unable to assist in ways that parents who had experienced the transition into college could. The effect of lack of family knowledge was evident in the early stages of transition (application process and tuition assistance procurement) and while students were away and immersed in college.

Parents who have not pursued college degrees may not make the connection of high school experiences as preparation for college. FG students tend to take less rigorous courses in high school (Chen \& Carroll, 2005; Warburton et al., 2001), which may indicate parents not 
understanding or not seeing the value of rigorous study as preparation for higher education. The literature shows FG students having lower GPA that their NFG peers (Drozd, 2008; Gibbons \& Shoffner, 2004; Saenz, 2007), and although I can only speculate, this may indicate a lack of involvement in educational activities. Directly related to attending college is the Standardized Achievement Test (SAT), typically offered during the junior year of high school, which FG student are less likely to take (Chen \& Carroll, 2005; Drozd, 2008; Gibbons \& Shoffner, 2004). It is beyond the scope of this study to know how parents of FG students are thinking, or how they value a college degree, but the existing research indicates that, in general, FG students are not getting appropriate guidance if higher education is a goal. It is fair to assume that most parents wish success for their children and will attempt to guide them in directions that give them the greater opportunities in life. However, without explicit knowledge of college experience, they are ill equipped to guide them.

The participants in this study spoke of difficulties with the application process, and expressed frustration with lack of knowledge and guidance. Krystal described the frustrations she and her mother experienced: "she tried to help me and it was a horrible time. We ended up fighting about it probably at least five times before I got everything done and decided where I was going. It was difficult, that's for sure.” Alex and his mother experienced frustrations with not knowing how to find financial assistance. He said, "[I wish there was] some type of way me or my mom finding about the scholarships they offered in school because I had no clue about any of that, like nothing, and my mom didn't either." The struggles these two families experienced are a result of parental lack of knowledge, and a lack of effective communication between high school personnel and colleges, with families. Recent research has shown that first-generation students and their parents often lack important "college knowledge" about the process of preparing, 
applying, and paying for college due to the lack of experience with postsecondary education in their families (Bryan \& Simmons, 2009; Choy, 2001; Oliverez and Tierney, 2005; Tornatzky, Cutler, and Lee, 2002; Vargas, 2004). If "college readiness" is, in part, a goal of high school curriculum, then consideration of FG parental knowledge and greater levels of communication with all family members would make the efforts of high school advisors more impactful.

\section{Conclusions}

The purpose of this study was to answer the following: How do Appalachian, firstgeneration students transition into a small, private college? Because they are unaware of Tinto's (1993) theoretical lens, they were unable to specifically identify their perceptions within the research context, however, in one manner or another, they spoke of events and feelings that directly fit within the contexts of separation, academic integration, and social integration. It was shown, that for most, their transition was without major difficulties, their transition was progressing in ways not unlike their non-first-generational peers, and their experiences were positive and for their short period of immersion, successful.

Regarding the separation phase, two discoveries I found interesting were the use of modern communication technologies, and having a high school best friend as a roommate. I believe these two factors eased the separation phase for these participants. The ability to communicate (talk, text, and chat) with family members, regardless of time and location, provided a link for families and participants to stay emotionally connected in ways that did not exist when Tinto published his theory on student departure. Having a best friend as a roommate also eased transition for these participants. In some instances, having a strong preexisting relationship did slow the speed of social integration, but as with communication technologies, it reduced the initial shock of cultural immersion, and allowed the continuance of relationships. 
Regarding positive social integration, another influential discovery I found was the size and scale of the college. Because the campus and surrounding community is small, in many ways it mirrored the communities from which these participants came. This too eased the initial cultural shock they may have felt attending a large university, and may have helped to reduce anxieties they may have had. Although the participants did not reflect on this to a large degree, as faculty at small, private university, I can attest to greater personal relationships, and more student focused attention found on this campus in comparison to large universities, also noted by Tinto (1993). When advising FG students with college goals, high school councilors should consider the impact of college scale and size on FG students from small rural communities.

Regarding academic integration, these students were not unlike their NFG peers; the greatest difficulty they faced was academic time management. In my experience with working with college students, I have found this to be a consistent problem. Learning to assess the complexity and time necessary for assignments is an important skill and one that can be developed during high school. Scaffolding and guided exercises combined with reflection can help students evaluate their tasks and strategies used to achieve them. Incorporating the value of non-cognitive skills, and modeling strategies to develop them, teacher education programs can prepare high school teachers to better equip FG students in this regard.

Finally, it is important to understand what it means to be a first-generation student. I cannot conclude without commenting on the admiration I have for the participants in this study, and for all FG students. They are pioneers, and inherent in pioneering is risk. For these students it was necessary to move beyond family traditions, and break family cycles to secure a better future for themselves and those who follow. They did so without family experience or informed guidance. They understood where they had come from, and gambled on a college education to 
create better opportunities. Like pioneers these participants also saw themselves as role models, leading the way for their siblings; they were aware that eyes were on them and that their steps would influence those who follow.

If they are to be portrayed as deficient—as much of the literature suggests, then it should mean that their reach for a college degree is longer, and with wider consequences. I would urge higher education policy to make efforts to connect with FG students and their families throughout the entire transition process. The delicate, yet critical step FG students are making would benefit greatly from thoughtful and informed counsel and guidance.

\section{Limitations}

As a result of this study, I have learned much concerning the first-generation student's transition into college. However, the major weakness of this study is that it resulted from a single interview session. There were questions that arose as I analyzed the transcripts that I would have liked to followed in more depth. A second interview would have allowed me to return to the participant for more detailed descriptions and perceptions of events $\mathrm{s} / \mathrm{he}$ described during the initial session. Also, there were events and circumstances that were initially outside of my guiding questions and that collectively, across the transcripts, began to form patterns. Only after multiple analyses of the transcripts did I notice these patterns. Finally, a second interview session would have allowed for member checking — validating my understanding of responses by checking with the participants.

\section{Recommendations for Further Research}

This study contributes to the understanding of transition into college for first-generation students, illustrating their struggles and success within the context of separation and adjustment. 
As much as this study gives better meaning to their journey, it also raises more questions, indicating a need for further research.

The first area for further research I recommend involves the awareness of members of secondary and higher education institutions and their degree of communication with FG students and their families. Many students indicated frustrations during the initial entry process regarding college choice, application process, and identifying financial assistance. It would be beneficial to study the degree of awareness these institutional members have regarding the unique circumstances of FG students, specifically families’ level of knowledge. For example, are high school counselors and college advisors sensitive to the needs of FG students who wish to go to college and the lack of guidance family members are able to provide? Secondly, studies that look how these institutional members interact with FG students and families would help to identify gaps in communication. The largest gaps appear to exist in the expectations during initial stages - separation and adjustment. More informed counselors and advisors may provide more realistic descriptions of what students and families can expect during this phase, preparing them for what is to come and reducing preconceived anxieties.

I also recommend studies that examine the influence and impact of having a best friend from home attending and/or rooming with FG students. This phenomenon emerged as I analyzed the transcripts and I although I was not able to understand conclusively, it appears that there may be benefit from having the security of familiar friendship. I found that having a friend helped to reduce initial shock of separation, however it might have an effect on the student's social integration. Future studies could uncover the long and short-term effects of attending with a friend. 
Lastly, this study should be repeated and extended to follow the students through their entire college career. Tinto's (1993) theory is longitudinal and the brief glimpse of student transition I provide here fails to capture the entire transition. There is much to be learned about FG transition as these participants mature personally, and as college students. Future studies that follow students over a longer period of time would provide a much richer and deeper understanding of how FG transition.

\section{Implications}

Based on the conclusions of this study, I have identified actions that could be taken to address the needs of FG students. These actions, which are relatively simple and can begin immediately, address the work of high school advisors, and college recruitment and retention programs.

\section{Implications for High School Advisors}

First, high school advisors need to be cognizant of students whose parents have not had college experience, the ways in which FG students may lack an understanding of the route to college, and fill in the gaps regarding preparation for college in ways that parents of FG students cannot. Regarding academic rigor, the literature show that FG students are less likely to challenging courses (Chen \& Carroll, 2005; Warburton et al., 2001) which Saenz (2007) believes has led to a widening gap in academic abilities. Several students in this study indicated that high school was easy for them, and required little effort. The lack of rigor required of these students during high school left them ill prepared for the demands of college. The implication here is that high school advisors need to impart the value of rigorous courses that provide opportunities to develop successful academic strategies through productive struggle. This should take place early in the students' high school career, perhaps as early as their eighth-grade pre-registration session. 
Also, FG students are less likely to take college entrance exams, and those who do tend to score lower (Chen \& Carroll; 2005; Drozd, 2008; Gibbons \& Shoffner, 2004). Because parents of FG students may not understand the value of exams such as PSAT and SAT, students may be less inclined to participate, thus miss opportunities for merit-based scholarships. There is no doubt that high school advisors promote test taking, however, it is not known whether the value of these tests, regarding future opportunities, are imparted onto FG students. The implication is that when working with FG students and parents, high school advisors need to explicitly make known the value of PSAT and SAT.

Lastly regarding high school advisors, FG students and their parents need guidance during college selection and application process. The lack of parental college knowledge leaves parents without an understanding of application procedures, of financial assistance options, or of college selection and fit. Several students in this study expressed difficulties and frustrations regarding this process, further complicating their journey towards a college degree. High school advisors should consider developing multi-stage programs to meet and assist students and families as they work through this process.

\section{$\underline{\text { Implications for College Recruitment and Retention }}$}

As discussed in Chapter II, ABU adopted an “Affinity-Bonding” Model in 2012 to address low student enrollment. Designed to increase opportunities for a wider range of students, and strengthen student-to-school connections, the Affinity-Bonding Model integrates the efforts of recruitment and retention programs. Since its adoption this model has been successful, however it does not specifically target FG students, nor take into consideration the unique needs of this group. ABU's recruitment program does not include FG status in a student's profile, and retention programs do not specifically target FG students. One year after I interviewed the FG 
students for this study, I discovered that 6 of the 10 students had not returned the following year, and two had dropped out during the spring semester. A $40 \%$ retention rate of FG students is considerably lower than the university's overall retention rate of $56 \%$, indicating a gap in the university's efforts. Based on the conclusions of this study, and ABU admissions data, the second implication recommends that recruitment and retention programs at $\mathrm{ABU}$, and other universities, develop programs and policies targeted at FG students. 


\section{References}

ABUOIR. (2015). Alderson Broaddus University - undergraduate first-generation headcount enrollment fall 2014. Philippi, WV: Alderson Broaddus University Office of Internal Research.

Andrade, M. S. (2013). I can do everything: Family influence on American Indian women's educational aspirations. Journal of American Indian Education, 52(1).

Astin, A. W. (1984). Student involvement a developmental theory for higher education. Journal of College Student Development, 40(5), 518-529.

Attinasi, L. C. Jr. (1989). Getting in: Mexican Americans' perceptions of university attendance and the implications for freshman year persistence. The Journal of Higher Education. Vol. 60, No. 3, pp. 247-277.

Aud, S., Fox, M. A., \& Kewal-Ramani, A. (2010). Status and trends in the education of racial and ethnic groups. NCES 2010-015. National Center for Education Statistics.

Barefoot, B. O. (2008). Collegiate transitions: The other side of the story. New Directions for Higher Education, (144), 89-92. Retrieved from RIS Format UTF-8 database.

Barry, L. M., Hudley, C., Kelly, M., \& Cho, S. (2009). Differences in self-reported disclosure of college experiences by first-generation college student status. Adolescence, 44(173), 5568. Retrieved from RIS Format UTF-8 database.

Berger, J. B., \& Milem, J. F. (1999). The role of student involvement and perceptions of integration in a causal model of student persistence. Research in Higher Education, 40(6), 641-664. doi:10.1023/A:1018708813711.

Berkner, L., Choy, S., \& Hunt-White, T. (2008). Descriptive summary of 2003-04 beginning postsecondary students: Three years later. Aurora, 202, 502-7334. 
Bowman, N. A. (2010). The development of psychological well-being among first-year college students. Journal of College Student Development, 51(2), 180-200.

Bradbury, B. L., \& Mather, P. C. (2009). The integration of first-year, first-generation college students from Ohio Appalachia. NASPA Journal, 46(2), 258-281.

Braxton, J. M., Milem, J. F., \& Sullivan, A. S. (2000). The influence of active learning on the college student departure process: Toward a revision of Tinto's theory. Journal of Higher Education, 71(5), 569-90. Retrieved from RIS Format UTF-8 database.

Bryan, E., \& Simmons, L. A. (2009). Family involvement: Impacts on postsecondary educational success for first-generation Appalachian college students. Journal of College Student Development, 50(4), 391-406.

Bui, V. T. (2002). First-generation college students at a four-year university: Background characteristics, reasons for pursuing higher education, and first-year experiences. College Student Journal, 36(1), 3. Retrieved from RIS Format UTF-8 database.

Chen, X., \& Carroll, C. D. (2005). First-generation students in postsecondary education: A look at their college transcripts. Postsecondary education descriptive analysis report. NCES 2005-171. National Center for Education Statistics,

Choy, S. P. (2001). Students whose parents did not go to college: Postsecondary access, persistence, and attainment National Center for Education Statistics, US Department of Education, Office of Educational Research and Improvement.

Choy, S. P., Horn, L. J., Nunez, A., \& Chen, X. (2000). Transition to college: What helps at-risk students and students whose parents did not attend college. New Directions for Institutional Research, 27(3), 45-63. Retrieved from RIS Format UTF-8 database. 
Creswell, J. W. (2007). Qualitative inquiry and research design: Choosing among five approaches. Thousand Oaks, CA: Sage Publications.

Crotty, M. (1998). The foundations of social research: Meaning and perspective in the research process. Thousand Oaks, CA: Sage Publications..

Cundy, L. (2015). Attachment and digital communication. Therapy Today. (26)1.

Davenport, M. Y. (2010). Examining involvement as a critical factor: Perceptions from first generation and non-first generation college students. ProQuest LLC. ProQuest LLC, (ProQuest LLC. 789 East Eisenhower Parkway, P.O. Box 1346, Ann Arbor, MI 48106. Tel: 800-521-0600; Web site: http://www.proquest.com/enUS/products/dissertations/individuals.shtml).

Davidson, C., \& Wilson, K. (2013). Reassessing Tinto's concepts of social and academic integration in student retention. Journal of College Student Retention: Research, Theory and Practice, 15(3), 329-346.

Drozd, B. L. (2008). Comparisons of first-generation and non-first-generation college students on academic and psychosocial measures. ProQuest, UMI Dissertations Publishing).

Fischer, M. J. (2007). Settling into campus life: Differences by race/ethnicity in college involvement and outcomes. Journal of Higher Education, 78(2), 125-161. Retrieved from RIS Format UTF-8 database.

Gibbons, M. M., \& Shoffner, M. F. (2004). Prospective first-generation college students: meeting their needs through social cognitive career theory. Professional School Counseling, 8(1), 91-97. Retrieved from RIS Format UTF-8 database.

Gold, J. (2011). Bowlby's Attachment Theory. In Goldstein, S. \& Naglieri, J. (Eds.), Encyclopedia of Child Behavior and Development. (p. 272). U.S.: Springer. 
Green, K. M. (2007). Understanding college students' and parents' perceptions of cell phone communication in family relationships: A grounded theory approach. (Doctoral dissertation). Retrieved from ProQuest Dissertations Publishing (9780549367420).

Guiffrida, D. A. (2006). Toward a cultural advancement of Tinto's theory. The Review of Higher Education, 29(4), pp. 451-472.

Hand, C., \& Payne, E. M. (2008). First-generation college students: A study of Appalachian student success. Journal of Developmental Education, 32(1), 4.

HERI. (2013). Your first college year survey 2012. Los Angeles, CA: Higher Education Research Institute at UCLA.

Hirsch, D. (2010). The high school to college transition: Minding the gap. New England Journal of Higher Education, 9-9. Retrieved from RIS Format UTF-8 database.

Holmbeck, G. N., \& Wandrei, M. L. (1993). Individual and relational predictors of adjustment in first-year college students. Journal of Counseling Psychology, 40(1), 73.

Horn, L., \& Nuñez, A. (2000). Mapping the road to college first-generation students' math track, planning strategies, and context of support. DIANE Publishing.

Housel, T. H., \& Harvey, V. L. (2011). Introduction: Shall we gather in the classroom? New Directions for Teaching and Learning, 2011(127), 5-10.

Hurtado, S., \& Carter, D. F. (1997). Effects of college transition and perceptions of the campus racial climate on Latino college students' sense of belonging. Sociology of Education, 70(4), 324-345.

Husserl, E (1982). Ideas pertaining to a pure phenomenology and to a phenomenological philosophy (Kersten, F. Trans.) Dordrecht: Klurew. (Original work published 1913). 
Hycner, R. H. (1985). Some guidelines for the phenomenological analysis of interview data. Human Studies, 8(3), 279-303.

Inkelas, K. K., Daver, Z. E., Vogt, K. E., \& Leonard, J. B. (2007). Living-Learning programs and first-generation college students' academic and social transition to college. Research in Higher Education, 48(4), 403-434. doi:10.1007/s11162-006-9031-6.

Inman, E. W., \& Mayes, L. (1999). The importance of being first: Unique characteristics of first generation community college students. Community College Review, 26(4), 3-22. doi:10.1177/009155219902600402.

Ishitani, T. T. (2003). A longitudinal approach to assessing attrition behavior among firstgeneration students: Time-varying effects of pre-college characteristics. Research in Higher Education, 44(4), 433-449.

Komada, N. M. (2002). First-generation college students and resiliency. ProQuest, UMI Dissertations Publishing).

Lehmann, W. (2007). "I just didn't feel like I fit in": The role of habitus in university dropout decisions. Canadian Journal of Higher Education, 37(2), 89-110. Retrieved from RIS Format UTF-8 database.

London, H. B. (1992). Transformations: Cultural challenges faced by first generation students. New Directions for Community Colleges, 1992(80), 5-11.

London, H. B. (1996). How college affects first-generation students. About Campus, 1(5), 9-13, London, H. B. (1989). Breaking away: A study of first-generation college students and their families. American Journal of Education, 97(2), 144-170. doi:10.1086/443919 
Lowery-Hart, R., \& Pacheco, G. (2011). Understanding the first-generation student experience in higher education through a relational dialectic perspective. New Directions for Teaching and Learning, 2011(127), 55-68. doi:10.1002/t1.457

Macy, B. (2000). From rusty wire fences to wrought-iron gates: How the poor succeed in getting to--and through--college. policy perspectives. New York: College Board.

Martinez, J. A., Sher, K. J., Krull, J. L., \& Wood, P. K. (2009). Blue-collar scholars?: Mediators and moderators of university attrition in first-generation college students. Journal of College Student Development, 50(1), 87-103. doi:10.1353/csd.0.0053.

Merleau-Ponty, M. (1962). Phenomenology of perception (Smith, C. Trans.). London: Routledge and Kegan Paul.

Merriam, S. B. (2009). Qualitative research: A guide to design and implementation. John Wiley \& Sons.

Metz, G. W. (2002). Challenges and changes to Tinto's persistence theory. Paper presented at the Annual Meeting of the Mid-Western Educational Research Association (Columbus, OH, October 16-19, 2002).

Miller, R. (2007). The association of family history knowledge and cultural change with persistence among undergraduate low-income, first-generation college students. Research \& Teaching in Developmental Education, 24(1), 29-45.

Moschetti, R., \& Hudley, C. (2008). Measuring social capital among first-generation and nonfirst-generation, working-class, white males. Journal of College Admission, 198, 25.

NCHEMS. (2014). Retention rates - first-time college freshmen returning their second year. Retrieved 02/8, 2014, from 
http://www.higheredinfo.org/dbrowser/index.php?submeasure=223\&year=2010\&level=n $\underline{\text { ation } \& \text { mode }=\text { graph } \& \text { state }=0}$.

Nora, A., Barlow, E., \& Crisp, G. (2005). Student persistence and degree attainment beyond the first year in college. In A. Seidman (Ed.), College student retention: Formula for student success (pp. 129-153). Westport, CT: Greenwood Publishing Group.

Nuñez, A. (2004). Using segmented assimilation theory to enhance conceptualization of college participation. InterActions: UCLA Journal of Education and Information Studies, 1(1).

Nunez, A., \& Cuccaro-Alamin, S. (1998). First-generation students: Undergraduates whose parents never enrolled in postsecondary education. statistical analysis report. postsecondary education descriptive analysis reports. ERIC.

Oliverez, P. M. \& W. G. Tierney. (2005). Show Us the Money: Low-Income Students, Families, and Financial Aid. Center for Higher Education Policy Analysis.

Orbe, M. P. (2004). Negotiating multiple identities within multiple frames: An analysis of firstgeneration college students. Communication Education, 53(2), 131-149. doi:10.1080/03634520410001682401.

Orbe, M. P. (2008). Theorizing multidimensional identity negotiation: Reflections on the lived experiences of first-generation college students. New Directions for Child and Adolescent Development, 2008(120), 81-95. doi:10.1002/cd.217.

Pascarella, E. T., \& Terenzini, P. T. (1983). Predicting voluntary freshman year persistence/withdrawal behavior in a residential university: A path analytic validation of Tinto's model. Journal of Educational Psychology, 75(2), 215. 
Pascarella, E. T., Terenzini, P. T., Pierson, C. T., \& Wolniak, G. C. (2004). First-generation college students: Additional evidence on college experiences and outcomes. The Journal of Higher Education, 75(3), 249-284. doi:10.1353/jhe.2004.0016.

Patton, M. (2015). Qualitative research \& evaluation: Integrating theory and practice. Thousand Oaks, CA: SAGE Publications.

Paulsen, M. B., \& Martin Lohfink, M. (2005). Comparing the determinants of persistence for first-generation and continuing-generation students. Journal of College Student Development, 46(4), 409-428. doi:10.1353/csd.2005.0040.

Pike, G. R., \& Kuh, G. D. (2005). First-and second-generation college students: A comparison of their engagement and intellectual development. Journal of Higher Education, 276-300.

Pollard, K., \& Jacobsen, L. (2014). The Appalachian Region: A data overview from the 20082012 American Community Survey. Retrieved 4/15, 2014, from http://www.arc.gov/research/researchreportdetails.asp?REPORT_ID=109 .

Pratt, P. A., \& Skaggs, C. T. (1989). First generation college students: Are they at greater risk for attrition than their peers? Research in Rural Education, 6(2), 31-34. Retrieved from RIS Format UTF-8 database.

Prawat, R. S. (1999). Dewey, Peirce, and the learning paradox. American Educational Research Journal, 36(1), 47-76.

Prospero, M., \& Vohra-Gupta, S. (2007). First generation college students: Motivation, integration, and academic achievement. Community College Journal of Research and Practice, 31(12), 963-975. 
Psathas, G. (1989). Phenomenology and sociology: Theory and research. Center for Advanced Research in Phenomenology. Washington DC: Center for Advanced Research in Phenolenology and University Press of America.

Ramsey, M. A., Gentzler, A. L., Morey, J. N., Oberhauser, A. M. \& Westerman, D. (2013). College students' use of communication technology with parents: comparisons between two cohorts in 2009 and 2011. Cybertechnology. 16(10), 747-752.

Reason, R. D., Terenzini, P. T., \& Domingo, R. J. (2006). First things first: Developing academic competence in the first year of college*. Research in Higher Education, 47(2), 149-175.

Saenz, V. B. (2007). First in my family: A profile of first-generation college students at four-year institutions since 1971 Higher Education Research Institute.

Somers, P., Woodhouse, S., \& Cofer, J. (2004). Pushing the boulder uphill: The persistence of first-generation college students. NASPA Journal, 41(3), 418-435.

Soria, K. M., \& Stebleton, M. J. (2012). First-generation students' academic engagement and retention. Teaching in Higher Education, 17(6), 673-685.

Spiegelberg, H. (1975). Doing phenomenology: Essays on and in phenomenology.

Stephens, N. M., Fryberg, S. A., Markus, H. R., Johnson, C. S., \& Covarrubias, R. (2012). Unseen disadvantage: How American universities' focus on independence undermines the academic performance of first-generation college students. Journal of Personality and Social Psychology, 102(6), 1178.

Terenzini, P. T., Rendon, L. I., Upcraft, M. L., Millar, S. B., Allison, K. W., Gregg, P. L., et al. (1994). The transition to college: Diverse students, diverse stories. Research in Higher Educaton, 35(1), 57-73. doi:10.1007/BF02496662. 
Terenzini, P. T., Springer, L., Yaeger, P. M., Pascarella, E. T., \& Nora, A. (1996). Firstgeneration college students: Characteristics, experiences, and cognitive development. Research in Higher Education, 37(1), 1-22. doi:10.1007/BF01680039.

Tierney, W. G. (1992). An anthropological analysis of student participation in college. The Journal of Higher Education, 603-618.

Tornatzky, L.G., R. Cutler, \& Lee, J. (2002). College Knowledge: What Latino Parents Need to Know and Why They Don’t Know It. Claremont, CA: Tomas Rivera Policy Institute.

Tinto, V. (1993). Leaving college: Rethinking the causes and cures of student attrition. Chicago: The University of Chicago Press.

Tinto, V. (2005). Taking student success seriously: Rethinking the first year of college. Paper presented at the Ninth Annual Intersession Academic Affairs Forum, California State University, Fullerton, pp. 05-01.

U.S. Census Bureau. (2013). State \& county quickfacts. Retrieved 10/11, 2013, from http://quickfacts.census.gov/qfd/states/54000.html .

Van Gennep, A. (1960). The rites of passage [Les rites de passage] (M. Vizedom, G. L. Caffee Trans.). Chicago: The University of Chicago.

Van Manen, M. (2014). Phenomenology of practice. Walnut Creek, CA: Left Coast Press.

Vargas, J. H. (2004). College knowledge: Addressing information barriers to college. Boston, MA: Education Research Institute.

Warburton, E. C., Bugarin, R., \& Nunez, A. (2001). Bridging the gap: Academic preparation and postsecondary success of first-generation students. Education Statistics Quarterly, 3(3), 73-77.

Ziliak, J. P. (2007). Human capital and the challenge of persistent poverty in Appalachia. Federal 
Reserve Bank of Cleveland Research Department, Cleveland, OH. ISSN 0428-1276. 
Appendix A

Initial Letter of Invitation

November 5, 2014

Hello! I am a new professor here at ABU and I am writing to you because I would like you to be a part of my research project. My project explores the first year of college for firstgeneration students--students who I consider pioneers. Every student is different, everyone has a different experience in college, and I want to hear your story.

\section{Selected participants will receive a $\$ \mathbf{1 0}$ gift for their time and effort.}

It will be easy, about 20-30 minutes, and I'll do all of the work! All we have to do is sit down for a conversation — an interview — and you tell me about your experience of coming to ABU.

Who am I looking for?

- First-generation students (your parents did not go to college)

- First-year freshmen students (you graduated high school last year)

- West Virginia residents (you're from here!)

I need to start very soon, so please act quickly. If you want to be involved, please reply

to:

bushjt@ab.edu

or call 304-457-6457

or text 304-906-1904

I hope to hear from you soon!

Thanks!

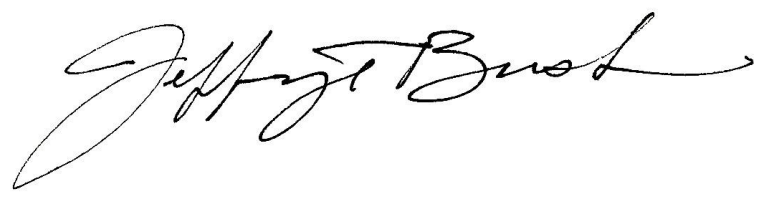

Jeffrey T. Bush

Assistant Professor

School of Teacher Education

Alderson Broaddus University 
Appendix B

Participant Consent Form

\section{Only Minimal Risk \\ Consent Information Form (without HIPAA)}

Study Title: The Process of Transition as Told by First-Year, First-Generation Students

Principal Investigator: Dr. Sam Stack

Co-Investigator: Jeffrey T. Bush

Department: College of Education \& Human Resources, West Virginia University

Protocol Number: 1402213892

\section{Contact Persons}

If you have any questions, concerns, or complaints about this research, you can contact Dr. Sam Stack at 304-293-2071, or Jeff Bush at 304-906-1904. For information regarding your rights as a research subject, to discuss problems, concerns, or suggestions related to the research, to obtain information or offer input about the research, contact Jonathan Young at the Office of Research Integrity and Compliance at (304) 293-7073.

\section{Introduction}

You, , have been asked to participate in this research study, which has been explained to you by Jeffrey Bush. This study is being conducted by Jeffrey Bush of the Department of Curriculum and Instruction in the College of Education and Human Resources at West Virginia University.

\section{Purpose(s) of the Study}

The purpose of this study is to explore the process of transition from home to college for first-generation students at West Virginia University.

\section{Description of Procedures}

This study will involve an interview with the co-investigator, Jeffrey Bush and will take approximately45 minutes to complete. You do not have to answer all the questions. You will have the opportunity to see the interview questions before signing this consent form.

\section{Discomforts}

There are no known or expected risks from participating in this study.

\section{Alternatives}

You do not have to participate in this study-your participation is voluntary.

\section{Benefits}

You may not receive any direct benefit from this study. The knowledge gained from this study may eventually benefit others. 


\section{Financial Considerations}

There are no special fees for participating in this study. You will be paid $\$ 10.00$ for each interview conducted with Jeff Bush, co-investigator.

\section{Confidentiality}

Any information about you that is obtained as a result of your participation in this research will be kept as confidential as legally possible. Audio or video recordings will be kept locked up and will be destroyed as soon as possible after the research is finished. In any publications that result from this research, neither your name nor any information from which you might be identified will be published without your consent.

\section{Voluntary Participation}

Participation in this study is voluntary. You are free to withdraw your consent to participate in this study at any time.

Refusal to participate or withdrawal will not affect your class standing or grades, and will involve no penalty to you. In the event new information becomes available that may affect your willingness to participate in this study, this information will be given to you so that you can make an informed decision about whether or not to continue your participation.

You have been given the opportunity to ask questions about the research, and you have received answers concerning areas you did not understand. Upon signing this form, you will receive a copy.

The participant agrees to be recorded via audio? YES NO Initial

I willingly consent to participate in this research.

\section{Signatures}

Participant Signature

Participant Name (printed)

Date 
Appendix C

Participant Demographic Questionnaire

\section{Hometown information}

Name of hometown

Estimated population of Hometown

\section{High school information}

Private or public

High school GPA

Extracurricular activities?

Courses taken for college credit?

\section{Family information}

Number of people in immediate family

Participant place in birth order

Parent education level

$$
\bullet
$$

$\bullet$

Sibling post-high school decisions

• 


\section{Appendix D}

\section{Interview Question Guide}

1. Why did you decide to go to college? What were you were thinking?

a. What did your family think about the idea of you going to college?

b. And your friends, what did they think about the idea of you going to college?

2. Tell me about the day you received your acceptance letter?

a. What was that like for you?

b. How did you tell your family? How'd they react?

3. Do you remember how you were feeling as the first day came closer? Tell me about that.

4. And your first day on campus, what was that like? What went on?

5. Is college the way you expected it to be?

a. YES: How so?

b. NO: Why not?

6. What surprises you about college?

7. If you could change anything about college, what would you change?

8. What is most difficult about being in college?

9. Have you talked with your family about being in college?

a. YES:

i. What have you told them about?

ii. What's that conversation like?

b. NO: why not?

10. How about your friends at home? Do you talk them about college?

a. YES: what do you tell them? How do they react? 
b. NO: what do you talk about?

11. Do you have much free time?

a. NO: why not? What's going on?

b. YES: nice! What do you like to do with free time?

12. How do you feel about returning next semester?

13. Anything you want to tell me about being the first in your family to go to college? 


\section{Appendix E}

\section{Guiding Questions Rationale}

1. Why did you decide to go to college? What were you were thinking? Question 1 seeks to understand the initial thoughts of going away to school. It presumes that the notion of going away and attending college is a departure from norms of family and possibly high school friends. Beyond the student's ideas and feelings, follow-up questions seek to understand the reactions of family and friends. It is possible that this point marks a beginning in the transition process of attending college for the student.

2. Tell me about the day you received your acceptance letter? Question 2 pertains to an important point in the college transition process-when the notion of going to college becomes realistic. The full weight of 'this is really happening!' places the student in a position of making an important decision as to whether to accept.

3. Do you remember how you were feeling as the first day came closer? Tell me about that. Question 3 addresses the time between acceptance and leaving to attend college. It seeks to understand the student's thoughts and feelings as the beginning of college came closer.

4. And your first day on campus, what was that like? What went on? Question 4 addresses the third milestone in the transition process: relocating from home community to college community. Often, students arrive with family or friends, go through the moving process, and spend their first night on their own. This question presumes that this is an important and memorable part of the transition process. 
5. Is college the way you expected it to be? Question 5 addresses presumptions and expectations the student may have had about college. It assumes that firstgeneration students lack first-hand accounts of college from family, and possibly friends, and therefore may enter college with unrealistic expectations. This question seeks to understand how expectations of college were met or not met, and what this means for the student.

6. What surprises you about college? Question 6 appears similar to question \#5, however, it does not presume a pre-established expectation of college and it asks the student to reflect on his/her life in college rather than the college life in general. This question presumes that the student is perceptive of any changes in his/her life due to attending college.

7. If you could change anything about college, what would you change? Question 7 asks the student to reflect critically about his/her college experience. The term 'college' in the question is intentionally ambiguous, and invites the participant to discuss aspects of college that are most relevant to him/her. The nature and direction of the response may lead to an understanding of the types of conditions or situations are problematic for first-generation students.

8. What is most difficult about being in college? Question 8 is a follow-up question to 7. It intends to identify specific difficulties the student may be having with college transition.

9. How about your friends at home? Do you talk them about college? Questions 9 and 10 pertain to communications the student has with family and friends about their college experience. It seeks to understand the nature of the conversations and 
the content of those conversations. The response to these questions may reveal insight to the relationship dynamics of the student to family and friends concerning college.

10. Do you have much free time? Question 11 refers to student engagement. It seeks to understand the amount and direction of energy the student places, whether towards social and academic demands of school or towards family and friends at home.

11. How do you feel about returning next semester? Question 12 is perhaps the most direct and important guiding question; it addresses student commitment and persistence. This question cuts to the heart of the matter, and seeks to know if the student is comfortable enough to continue, or if there are persistent difficulties. A response of not wanting to return will be followed-up with a request to explain.

12. Anything you want to tell me about being the first in your family to go to college? Question 13 is an open invitation for the student participant to share any thoughts or feelings about being first-generation and what that means to him/her. 


\section{Appendix F}

Tinto's (1993) Longitudinal Model of Student Departure

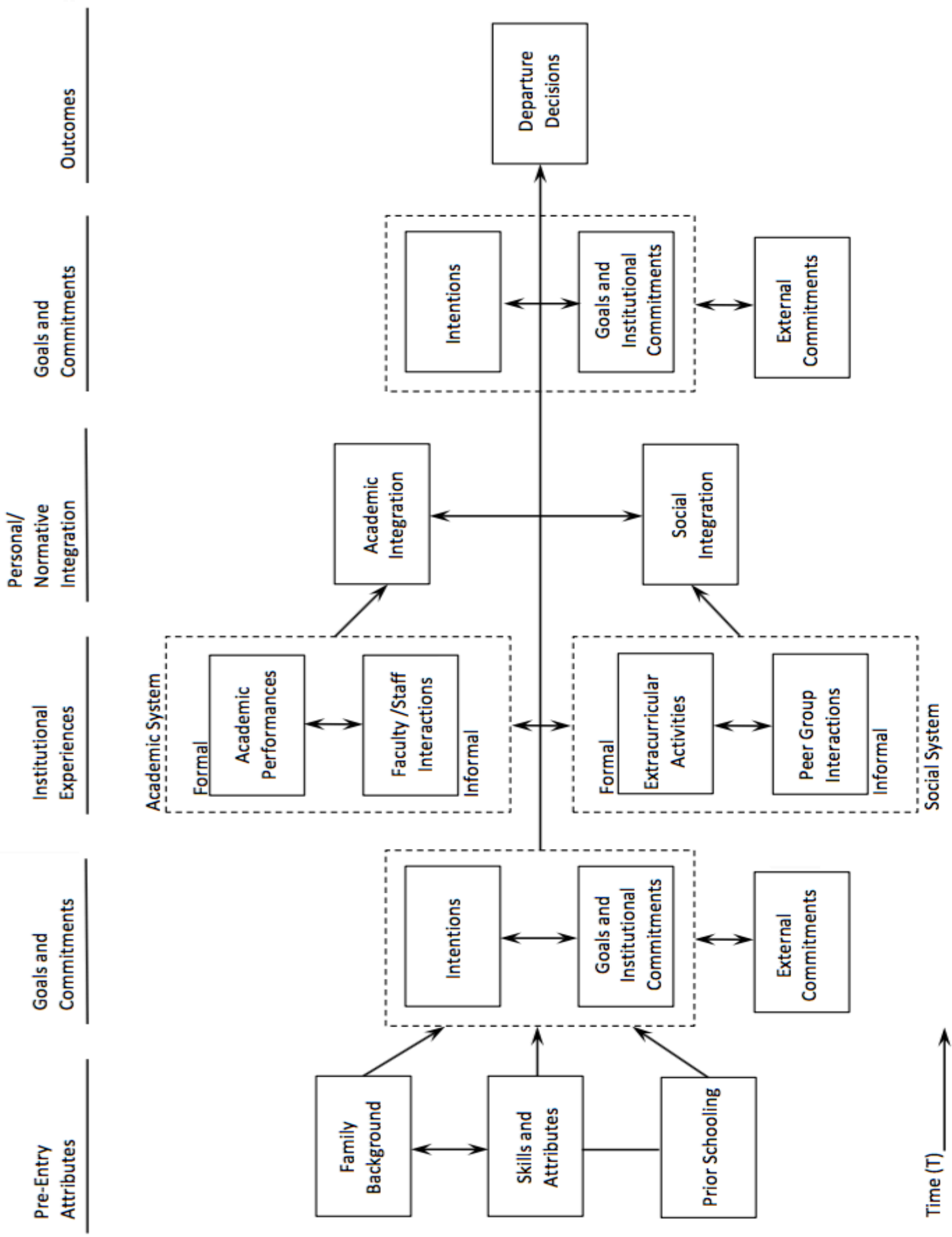




\section{Appendix G}

First-Generation Transition Theme: Separation

\begin{tabular}{|c|c|}
\hline \multirow{4}{*}{$\begin{array}{l}\text { Indirect } \\
\text { Separation } \\
\text { Difficulties }\end{array}$} & $\begin{array}{l}\text { She was just kinda upset that I'm leaving, because I'm the one that--I keep the } \\
\text { girls in line so they don't back-sass her too much or anything (Jesse). }\end{array}$ \\
\hline & $\begin{array}{l}\text { I think it's harder on him sometimes, than it is me, because he's used to me } \\
\text { being home, having someone there, having someone to talk to and now he } \\
\text { doesn't. He just has work and sleep (Shane). }\end{array}$ \\
\hline & $\begin{array}{l}\text { I know she's not financially stable, and she's paying my tuition instead of paying } \\
\text { the bills (Kathleen) }\end{array}$ \\
\hline & $\begin{array}{l}\text { My dad's side of the family, they were all excited, but my mom, she was upset. } \\
\text { So that kind of tore me down a little bit (Krystal). }\end{array}$ \\
\hline \multirow{3}{*}{$\begin{array}{l}\text { Direct } \\
\text { Separation } \\
\text { Difficulties }\end{array}$} & $\begin{array}{l}\text { The most difficult thing? It's still really difficult being away from home } \\
\text { (Kathleen). }\end{array}$ \\
\hline & $\begin{array}{l}\text { the hardest part is just being away from home, so far, I can't just visit any time I } \\
\text { want (Sandy). }\end{array}$ \\
\hline & $\begin{array}{l}\text { even just being like } 45 \text { minutes away, it's still hard because I've never been } \\
\text { without [them]. So I like to go home every weekend. I don't think I could have } \\
\text { lived any further away (Krystal). }\end{array}$ \\
\hline \multirow{5}{*}{$\begin{array}{l}\text { Positive } \\
\text { Transition }\end{array}$} & $\begin{array}{l}\text { I'll still be able to go home for school breaks and so it's not like I'm being away } \\
\text { for forever (Michael) }\end{array}$ \\
\hline & $\begin{array}{l}\text { My friends are back home, but I'm always going to see them when I have } \\
\text { breaks. I mean, my friends are always going to be there if they're going to be } \\
\text { real friends (Alex). }\end{array}$ \\
\hline & $\begin{array}{l}\text { I try to go home--well I work at home--so I almost go home every weekend, and } \\
\text { sometimes every other, but I don't stay at home (Braelynn). }\end{array}$ \\
\hline & $\begin{array}{l}\text { I tried to go every other week, but it's got to the point now, I might go weekend } \\
\text { out of the month, it kind of depends on my paycheck and stuff, and if there's a } \\
\text { game or something going on (Kayla). }\end{array}$ \\
\hline & $\begin{array}{l}\text { I was like, "oh man, I'm going to have to leave home, this is a really far drive, } \\
\text { I'm going to be all by myself, I have nobody that I'm going with", and then I got } \\
\text { here and I was here for the first week and I was like, "alright, this is pretty cool" } \\
\text { (Brianna). }\end{array}$ \\
\hline
\end{tabular}




\section{Appendix $\mathrm{H}$}

First-Generation Transition Theme: Social Integration

\begin{tabular}{|c|c|}
\hline \multirow{3}{*}{$\begin{array}{l}\text { Social } \\
\text { Integration } \\
\text { and sports } \\
\text { program }\end{array}$} & $\begin{array}{l}\text { I thought I was going to stick with [teammates] from my high school, but I've met } \\
\text { multiple people that I'm now friends with and it's been pretty good (Alex). }\end{array}$ \\
\hline & $\begin{array}{l}\text { Everybody got along because the first week--we were just football players, so we } \\
\text { all got along, started telling stories, which made it easier (Shane). }\end{array}$ \\
\hline & $\begin{array}{l}\text { I just figured there'd be your different groups, like high school: everybody groups } \\
\text { themselves off with who they're familiar with. So, yeah, it's pretty much what I } \\
\text { expect (Sandy). }\end{array}$ \\
\hline \multirow{3}{*}{$\begin{array}{l}\text { Attending } \\
\text { College } \\
\text { with High } \\
\text { School } \\
\text { Friends }\end{array}$} & $\begin{array}{l}\text { we talked about it and then like a week went by and I made friends in a class and } \\
\text { he [best friend/roommate] made friends in a class, and then it was just like we're } \\
\text { hanging out as a group-type thing (Jesse). }\end{array}$ \\
\hline & $\begin{array}{l}\text { we're familiar so we kind of hang out and just talk over what we do and if an } \\
\text { other one needs help the other ones try to help them, so it's actually been a cool } \\
\text { thing (Jesse). }\end{array}$ \\
\hline & $\begin{array}{l}\text { For a while there, we really didn't have anyone, because we're not--I'm not out } \\
\text { going. She's kind of outgoing, but I'm not, so I don't like to meet new people. I } \\
\text { don't like change at all, so it's hard. Everything's a big adjustment but finally she } \\
\text { [best friend/roommate] drug me out, and we get along with those girls, so we do } \\
\text { stuff together now all the time (Krystal). }\end{array}$ \\
\hline \multirow{3}{*}{$\begin{array}{l}\text { Accepting } \\
\text { Nature of } \\
\text { the } \\
\text { Student } \\
\text { Body }\end{array}$} & $\begin{array}{l}\text { [The college experience is] a lot less drama than high school because everybody } \\
\text { here's a lot more friendlier and everyone wants to get to know everybody unlike } \\
\text { in the high school (Michael). }\end{array}$ \\
\hline & $\begin{array}{l}\text { I didn't think that you could find so much support in a small place because in high } \\
\text { school I'd been so bullied, but there're so many nice people here, it's so different, } \\
\text { so much more relaxing (Kathleen). }\end{array}$ \\
\hline & $\begin{array}{l}\text { Yeah, it's pretty nice, because most people don't really judge you here. You just } \\
\text { do whatever, like in high school, if you wear a certain thing, or something like } \\
\text { that, people judge you but like here, it's just like, there's so many different walks } \\
\text { of life that came here so it's just like everyone accepts everybody, pretty much } \\
\text { (Jesse). }\end{array}$ \\
\hline \multirow{2}{*}{$\begin{array}{l}\text { Positive } \\
\text { Social } \\
\text { Integration }\end{array}$} & $\begin{array}{l}\text { I thought I'd be more--kind of keep to myself, but really, like the whole third floor } \\
\text { of [dorm] over there, it's literally a family. We all sit in the kitchen every night; } \\
\text { we got a little study group and everything. It became a second home really fast, } \\
\text { really. All the people--I wouldn't even call them friends, they're family now. It's a } \\
\text { really nice place; I really like it up here (Kayla). }\end{array}$ \\
\hline & $\begin{array}{l}\text { I was kind of sad because I was going to have to leave everybody, because } \\
\text { everybody was going to a different school and I came here by myself, and } \\
\text { everybody else has friends - at least one person, that went with them to another } \\
\text { college, and I was all by myself, but now I'm here, I'm like, "this is awesome!" } \\
\text { (Brianna). }\end{array}$ \\
\hline
\end{tabular}




\section{Appendix I}

First-Generation Transition Theme: Academic Integration

\begin{tabular}{|c|c|}
\hline \multirow{7}{*}{$\begin{array}{l}\text { No } \\
\text { Intellectual } \\
\text { Difficulty }\end{array}$} & $\begin{array}{l}\text { They [high school teachers] made me feel like college was going to be super } \\
\text { hard I wasn't going to be able to do it and now I'm here and I'm like, "this isn't } \\
\text { much different than what I've done before, it's just a little more in depth } \\
\text { (Braelynn). }\end{array}$ \\
\hline & $\begin{array}{l}\text { It's just boring--it's all too easy. That's my biggest surprise, probably. I expected } \\
\text { it to be a challenge, and I'm really not yet--I'm sure I will be, but just not at this } \\
\text { point (Krystal). }\end{array}$ \\
\hline & I thought it was going to be a lot harder (Kayla). \\
\hline & I was expecting them [classes] to be harder than what they are (Michael). \\
\hline & I expected it to be harder, a lot harder (Brianna). \\
\hline & $\begin{array}{l}\text { I kind of psyched myself out and I was like, "I'm not going to be able to do it, } \\
\text { it's so hard, it's going to be so hard" but really if you just talk to who--whoever- } \\
\text {-if you're having trouble somewhere, somebody can help you somehow } \\
\text { (Sandy). }\end{array}$ \\
\hline & $\begin{array}{l}\text { I thought--I thought it was going to be, you know, I though I wasn't going to do } \\
\text { that good, with football and all that, but, I'm doing alright, so I guess I'm doing } \\
\text { better than I though I was going to do (Alex). }\end{array}$ \\
\hline \multirow{5}{*}{$\begin{array}{l}\text { Time } \\
\text { Management }\end{array}$} & $\begin{array}{l}\text { It's not a problem for me to get my work in, it's a problem, like sometimes so } \\
\text { many things are due at the same time (Brianna). }\end{array}$ \\
\hline & $\begin{array}{l}\text { you don't have somebody sitting there, telling you that you have to do your } \\
\text { work (Jesse). }\end{array}$ \\
\hline & $\begin{array}{l}\text { I wasn't ready for someone not to be on my back all the time, telling me, 'you } \\
\text { need to do your homework, you need to do this, you need to get this done' } \\
\text { (Krystal) }\end{array}$ \\
\hline & $\begin{array}{l}\text { I don't have very much time management because I'm like, 'oh I have time, I } \\
\text { don't have to do it right now' and I really do need to do it! (Braelynn). }\end{array}$ \\
\hline & $\begin{array}{l}\text { At first it was difficult because I always had these people to keep reminding me } \\
\text { of everything but now I'm being better about it because--pretty much my entire } \\
\text { side of like my dorm room has like sticky notes everywhere reminding me } \\
\text { about [laughing] everything, its like this homework for this class, this meeting, } \\
\text { and all of this stuff going on (Michael). }\end{array}$ \\
\hline \multirow{4}{*}{$\begin{array}{l}\text { Lack of } \\
\text { Preparation }\end{array}$} & I was one of those kids in high school that never had to study (Kayla). \\
\hline & I could probably pass high school without cracking a book (Sandy) \\
\hline & $\begin{array}{l}\text { I got to sit down and actually have to study. I can't just walk through class, } \\
\text { write a paper in fifteen minutes and it be good enough to get a B and pass it on } \\
\text { (Alex). }\end{array}$ \\
\hline & $\begin{array}{l}\text { I feel where I came from is such a small community I don't feel like I have as } \\
\text { many tools as a lot of the other people (Braelynn) }\end{array}$ \\
\hline
\end{tabular}




\section{Appendix J}

First-Generation Transition Theme: College Scale and Size

I like small colleges ... I know people that went to big colleges and they don't like it because it's always loud and partying all the time (Shane).

Everybody in my class was, 'woo, [state college], [large state university], but I need someplace smaller and quieter (Kayla)

I wanted to go to a small college, I didn't want to go to a huge college ... I don't want to be a number, I want to be a person in the room (Shane)

I've been up to [large state university] multiple times. I couldn't go there . . . but I like this-I like the small, you know (Alex).

I really like it here, just because it was mainly like back home- there was mountains, small town (Sandy).

I'm used the small atmosphere. I wasn't ready to go into something as big as [large state university], because I was accepted there ... especially going from a town of - there's not even a stoplight in my town! So going by myself somewhere that's like thirty-plus students-I couldn't even think about it! (Krystal).

\section{Appendix K}

First-Generation Transition Theme: Personal Transformation

\begin{tabular}{|c|c|}
\hline \multirow{5}{*}{$\begin{array}{l}\text { Greater } \\
\text { Maturity }\end{array}$} & \\
\hline & $\begin{array}{l}\text { it's pretty awesome, you know, you're taking that step and making that decision for } \\
\text { yourself (Kathleen). }\end{array}$ \\
\hline & $\begin{array}{l}\text { I'm kinda independent now, I don't really have any rules to follow, so I make my } \\
\text { own schedule (Krystal). }\end{array}$ \\
\hline & $\begin{array}{l}\text { [attending college is] helping me just become more mature and more as an adult } \\
\text { (Michael). }\end{array}$ \\
\hline & I knew I was growing up. It's just a big change (Alex). \\
\hline \multirow{4}{*}{$\begin{array}{l}\text { Break } \\
\text { from } \\
\text { Former } \\
\text { Self }\end{array}$} & $\begin{array}{l}\text { I can definitely tell that I've changed. If I was just to go back home-when I do go } \\
\text { back home, it's just gonna be like, "Hmm, this is different" (Brianna). }\end{array}$ \\
\hline & Sometimes I go back home and it's kind of like, "what is this place?" (Kayla) \\
\hline & $\begin{array}{l}\text { Sometimes we talk about college stuff, but not that much because they've never } \\
\text { been, so they don't know what it's really like, but they ask me, sometimes, and I'll } \\
\text { just answer the questions they ask (Alex). }\end{array}$ \\
\hline & $\begin{array}{l}\text { It's just a giant difference you have adjust to. You go home every summer, and you } \\
\text { get back in your routine of being at home, then you come back here. It's just a } \\
\text { constant thing of getting used to it (Krystal). }\end{array}$ \\
\hline $\begin{array}{l}\text { No } \\
\text { Perceived } \\
\text { Change }\end{array}$ & $\begin{array}{l}\text { here I'm gone, we don't really skip a } \\
\text { as changed (Jesse) }\end{array}$ \\
\hline
\end{tabular}




\section{Appendix L}

First-Generation Transition Theme: Communication Technology

I don't really call home-I text my mom a lot (Brianna).

she [mother] calls me about every night, and my friends call me three or four times a week to see how I'm doing (Alex).

I don't really talk on the phone too much, but we'll text and Facetime every now and then, and see how things are going (Jesse).

About once a week me and a few friends will get on Skype and have a group chat, [and] talk to everybody (Michael).

All I did was lay in bed and talk to my girlfriend on the phone--either it was texting or Snapchat (Shane).

\section{Appendix M}

First-Generation Transition Theme: Being First-Generation

\begin{tabular}{|c|c|}
\hline \multirow{4}{*}{$\begin{array}{l}\text { Breaking } \\
\text { Traditional } \\
\text { Cycles }\end{array}$} & $\begin{array}{l}\text { I saw a lot of my family members ending up jobless - not a lot of money-and I } \\
\text { wanted to have more out of life than always having to ask other people for } \\
\text { things, and I wanted a stable foundation (Kathleen). }\end{array}$ \\
\hline & $\begin{array}{l}\text { I just want be able to go do something if I want to go do it, and I don't ever want } \\
\text { to have to struggle, I want to be able to be financially independent, on my own } \\
\text { (Braelynn). }\end{array}$ \\
\hline & Once I made it, they were proud (Jesse). \\
\hline & $\begin{array}{l}\text { [There is] the tradition of your family tradition and then going against it--doing } \\
\text { something completely different (Shane). }\end{array}$ \\
\hline \multirow{4}{*}{$\begin{array}{l}\text { Role } \\
\text { Model }\end{array}$} & You're a role model (Brianna). \\
\hline & in example for my brothers (Alex). \\
\hline & $\begin{array}{l}\text { It was something completely different, something nobody else in my family ever } \\
\text { experienced it, so it was kind of like, 'Okay, I'm the test subject now, what's it } \\
\text { gonna be like?' My experiences are gonna reflect on everybody else (Kayla). }\end{array}$ \\
\hline & $\begin{array}{l}\text { Being the first person in my family to go to college means a lot. With me going } \\
\text { to college, I'm hoping that one day when I get married and have kids, that they } \\
\text { will also be inspired to go to college and chase after their dreams (Michael). }\end{array}$ \\
\hline \multirow{3}{*}{$\begin{array}{l}\text { Lack of } \\
\text { Family } \\
\text { Knowledge }\end{array}$} & $\begin{array}{l}\text { [I wish there was] some type of way me or my mom finding about the } \\
\text { scholarships they offered in school because I had no clue about any of that, like } \\
\text { nothing, and my mom didn't either (Alex). }\end{array}$ \\
\hline & $\begin{array}{l}\text { I didn't really have anyone to tell me that it was going to be okay 'cause nobody } \\
\text { had been through it (Krystal). }\end{array}$ \\
\hline & $\begin{array}{l}\text { I just feel like it's a lot harder just because, you don't have anything to go off of. } \\
\text { You don't have parents to tell you, how hard it's gong to be, just because they } \\
\text { don't know (Sandy). }\end{array}$ \\
\hline
\end{tabular}

